Check for updates

Cite this: Mater. Horiz., 2019, 6,470

Received 28th October 2018, Accepted 11th December 2018

DOI: $10.1039 / \mathrm{c} 8 \mathrm{mh} 01365 a$

rsc.li/materials-horizons

\section{Advances in designs and mechanisms of semiconducting metal oxide nanostructures for high-precision gas sensors operated at room temperature}

\author{
Zhijie Li, (D) ${ }^{a}$ Hao Li, ${ }^{a}$ Zhonglin Wu, ${ }^{a}$ Mingkui Wang, (D) ${ }^{b}$ Jingting Luo, ${ }^{c}$ \\ Hamdi Torun, (D) ${ }^{d}$ PingAn Hu, (D) ${ }^{e}$ Chang Yang, (D) ${ }^{f}$ Marius Grundmann, (D) \\ Xiaoteng Liu ${ }^{d}$ and YongQing Fu (D)*da
}

\begin{abstract}
High-precision gas sensors operated at room temperature are attractive for various real-time gas monitoring applications, with advantages including low energy consumption, cost effectiveness and device miniaturization/flexibility. Studies on sensing materials, which play a key role in good gas sensing performance, are currently focused extensively on semiconducting metal oxide nanostructures (SMONs) used in the conventional resistance type gas sensors. This topical review highlights the designs and mechanisms of different SMONs with various patterns (e.g. nanoparticles, nanowires, nanosheets, nanorods, nanotubes, nanofilms, etc.) for gas sensors to detect various hazardous gases at room temperature. The key topics include (1) single phase SMONs including both $\mathrm{n}$-type and $\mathrm{p}$-type ones; (2) noble metal nanoparticle and metal ion modified SMONs; (3) composite oxides of SMONs; (4) composites of SMONs with carbon nanomaterials. Enhancement of the sensing performance of SMONs at room temperature can also be realized using a photo-activation effect such as ultraviolet light. SMON based mechanically flexible and wearable room temperature gas sensors are also discussed. Various mechanisms have been discussed for the enhanced sensing performance, which include redox reactions, heterojunction generation, formation of metal sulfides and the spillover effect. Finally, major challenges and prospects for the SMON based room temperature gas sensors are highlighted.
\end{abstract}

\section{Introduction}

Various types of hazardous gases, such as $\mathrm{H}_{2} \mathrm{~S}, \mathrm{CO}, \mathrm{NO}_{2}, \mathrm{NH}_{3}$, $\mathrm{H}_{2}, \mathrm{CH}_{4}$, toluene, acetone, ethanol, methanol and benzene, are routinely and daily released from industrial and agriculture processes, or emitted as vehicle exhaust emissions. Some of them, such as $\mathrm{H}_{2}$ and $\mathrm{CH}_{4}$, are explosive when exposed to air, whereas the others, such as $\mathrm{NO}_{2}$ and toluene, are harmful for human health and the environment, when their concentrations are above a critical threshold, sometimes as low as at parts-per-million

${ }^{a}$ School of Physics, University of Electronic Science and Technology of China, Chengdu, 610054, P. R. China

${ }^{b}$ Wuhan National Laboratory for Optoelectronics, Huazhong University of Science and Technology, Luoyu Road 1037, Wuhan 430074, P. R. China

${ }^{c}$ Shenzhen Key Laboratory of Advanced Thin Films and Applications, College of Physics and Energy, Shenzhen University, 518060 Shenzhen, China

${ }^{d}$ Faculty of Engineering and Environment, Northumbria University, Newcastle Upon Tyne, NE1 8ST, UK. E-mail: richard.fu@northumbria.ac.uk

${ }^{e}$ Key Laboratory of Micro-systems and Micro-structures Manufacturing of Ministry of Education, Harbin Institute of Technology, Harbin 150080, P. R. China

${ }^{f}$ Felix-Bloch-Institut für Festkörperphysik, Universität Leipzig, Linnéstr. 5, 04103 Leipzig, Germany (ppm) levels. Therefore, development of high-precision gas sensors with high sensitivity, fast response, good selectivity, low limit of detection (LOD), as well as in situ and real-time monitoring capabilities is paramount. ${ }^{1,2}$ For this purpose, various types of gas sensors have been developed, mainly including resistive, ${ }^{3-5}$ optical, $^{6-9}$ ultrasonic and acoustic wave, ${ }^{10-12}$ thermoelectric $^{13,14}$ and electrochemical ${ }^{15-17}$ ones.

Among these gas sensors, the resistive gas sensor is one of the most popular types, and is simple and easy to fabricate using cost effective processes. The transduction mechanism of resistive gas sensors is based on the change in resistance of a sensing layer upon adsorption and reaction with the target gas molecules. The sensing layer usually determines the sensitivity and selectivity. Therefore, the sensing materials and the structures of the sensing layer are highly critical to their sensing performance. The sensing materials used in these resistive gas sensors are mainly semiconducting metal oxide nanostructures (SMONs), ${ }^{18-21}$ carbon materials ${ }^{22-26}$ and organic semiconductors. ${ }^{27-30}$ Compared to the carbon materials and organic semiconductors, SMONs generally have higher sensitivity, faster response/recovery speed, better reversibility and stability, and they are cost-effective with simple 
fabrication processes. ${ }^{18-20}$ SMONs have large specific surface areas with numerous active sites, which facilitate fast adsorption and reaction of target gases, thus enhancing their sensing performance. They have been used to detect various hazardous gases for different applications as shown in Fig. 1. These SMON sensing materials mainly include $\mathrm{ZnO},{ }^{31,32} \mathrm{CuO},{ }^{33-36} \mathrm{SnO}_{2},{ }^{37-39}$ $\mathrm{TiO}_{2},{ }^{40,41} \mathrm{Fe}_{2} \mathrm{O}_{3},{ }^{42,43} \mathrm{In}_{2} \mathrm{O}_{3},{ }^{44-47} \mathrm{Co}_{3} \mathrm{O}_{4}{ }^{48-50}$ and $\mathrm{WO}_{3}{ }^{18,51}$ For further improvement of sensing performance, they have been modified using noble metals, ${ }^{52-55}$ metal ions, ${ }^{56-60}$ and carbon materials. ${ }^{61-64}$ Composites of multi-phase SMONs ${ }^{65-67}$ have also been frequently reported.

SMON-based sensors are usually heated to a higher temperature (between $100{ }^{\circ} \mathrm{C}$ to $400{ }^{\circ} \mathrm{C}$ ) for performance enhancement at the expense of structural complications. ${ }^{42-47}$ Operation at elevated temperature levels significantly increases the energy consumption, overall device size and cost of gas sensors. Heating up to a high temperature could lead to changes in the microstructure of the sensing nanomaterials, which can result in degradation of sensing performance. In addition, hightemperature sensing has its practical limitations. Particularly, heating is very dangerous for the detection of flammable and explosive gases, with a risk of explosion. Therefore, sensors operated at room temperature (RT) are desirable for minimizing energy consumption and cost, increasing security and stability, realizing device miniaturization and suitability for handheld operations. ${ }^{68,69}$ For these reasons, RT gas sensors based on the SMONs have received extensive attention in recent years. Different configurations of SMONs employing nanostructures have been demonstrated with desirable performance enhancements, ${ }^{70}$ regarding sensitivity, response/recovery time, selectivity, reversibility, reproducibility and long-term stability. Various SMONs have been designed and synthesized, such as nanorods, ${ }^{71-75}$ nanoparticles, ${ }^{76-81}$ nanowires, ${ }^{82-89}$ nanospheres, ${ }^{90}$ nanosheets, ${ }^{91-94}$ nanotubes, ${ }^{95-98}$ and mesoporous nanostructures. ${ }^{99-103}$

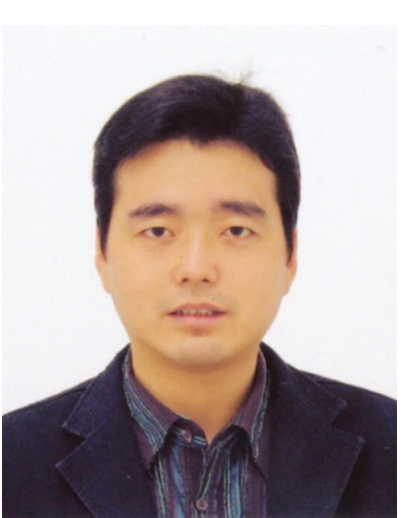

Zhijie Li
Dr Zhijie $L i$ is an associate professor at the University of Electronic Science and Technology of China. He obtained his PhD degree in physical chemistry from the Institute of Coal Chemistry, Chinese Academy of Sciences in 2005. His research work has been focused on nanomaterials, gas sensors, photocatalysis, supercapacitors and surface acoustic wave devices. He has published over 70 SCI-indexed refereed journal papers and his $H$-index is 20.

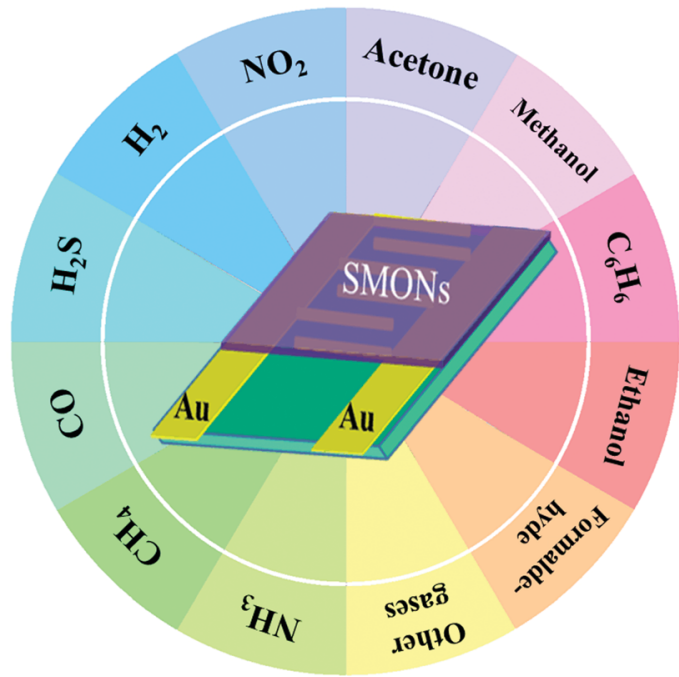

Fig. 1 Schematic diagram of resistance-type gas sensors based on semiconducting metal oxide nanostructures for detection of various hazardous gases.

The literature on SMON-based RT gas sensing is rich and the application area is very critical. New devices have been regularly introduced. Although the merits of the SMON based RT gas sensors have already been demonstrated, currently there are still some key challenges:

(1) The sensing performance of these SMON based gas sensors is limited, when operated at RT. For example, many of these sensors exhibit insufficient sensitivities. ${ }^{104-108}$

(2) The response/recovery times of many RT gas sensors, which are crucial for rapid detection of target dangerous gases to timely trigger an alarm, are generally quite long, sometimes, up to tens of minutes. ${ }^{109-111}$

(3) Poor reversibility has been reported for some of these sensors operated at RT. ${ }^{101}$

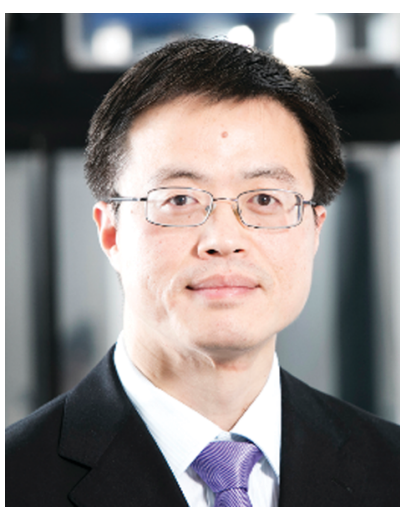

YongQing Fu
Professor Richard YongQing Fu has extensive experience in smart thin film/materials, biomedical microdevices, lab-on-chip, micromechanics, MEMS, nanotechnology, sensors and microfluidics. His research work has been focused on shape memory films, piezoelectric thin films, nanostructured composites, and smart materials and smart microsystems for applications in MEMS, sensing and energy applications. Up to 2018, he has published over 350 science citation index (SCI) journal papers (with an SCI H-index of 43), two books and over 120 conference papers. He is an associate editor/editorial board member for seven international journals, has co-organized 12 international conferences worldwide and co-edited six special issues for journals. 
(4) Poor selectivity is another key limitation for the RT gas sensors. Selectivity of many SMON based RT gas sensors needs to be improved to avoid interference and cross-talks. ${ }^{112}$

The aim of this topical review is to critically evaluate the design and structure of SMON-based gas sensors that may help guide the design of new devices. The performance of these SMON based gas sensors operated at RT could be improved significantly by modifying the SMONs using noble metal nanoparticles, ${ }^{113-116}$ metal ions, ${ }^{117-119}$ composites of multiple $\mathrm{SMONs}^{120-123}$ and carbon nanomaterials. ${ }^{124-126}$ In addition, not only the quantity of chemisorbed oxygen species, ${ }^{127}$ defects ${ }^{128}$ and element compositions ${ }^{129,130}$ on the surface of SMONs, but also the structural properties, i.e., porosity ${ }^{131}$ heterojunction properties ${ }^{132-134}$ and conductivity ${ }^{135,136}$ can affect the RT gas sensing performance. Therefore, understanding the relationship between the sensing properties and structures of SMONs is crucial to design gas sensing materials with good sensing performance operated at RT.

Several review papers have been published on gas sensors based on different SMON sensing materials, including n-type oxide semiconductors such as $\mathrm{ZnO},{ }^{20,137} \mathrm{Fe}_{2} \mathrm{O}_{3},{ }^{138} \mathrm{SnO}_{2},{ }^{39,139,140}$ p-type oxide semiconductors, ${ }^{141}$ metal oxide-based heterojunctions, ${ }^{142}$ noble metal/metal oxide semiconductors ${ }^{143,144}$ and graphene-metal oxide nanohybrids. ${ }^{145}$ However, these review papers discuss the sensing properties of the sensors which are generally operated at higher working temperatures above RT. ${ }^{146-150}$ Others about the RT gas sensors are focused more on certain types of SMONs based on RT sensors, such as nanostructured ZnO based RT gas sensors. ${ }^{151}$ However, there is no comprehensive review which is focused on the recent progress in various SMONs for high-precision gas sensors operated at RT. Therefore, this review will comprehensively summarize and discuss the recent developments of the RT gas sensors based on single phase SMONs, noble metal and metal ion modified SMONs, composites of SMONs with other metal oxides, and composites of SMONs with carbon nanomaterials, as shown in Fig. 2. In addition, we will discuss the effect of UV light stimulation on enhancing the performance of SMON based RT gas sensors, and mechanically flexible RT gas sensors based on SMONs.

\section{Room temperature gas sensors based on single phase semiconducting metal oxide nanostructures}

\subsection{N-type semiconducting metal oxide nanostructures and} gas sensors

$\mathrm{N}$-type SMONs are the most reported sensing materials for RT resistive gas sensors, and they include $\mathrm{ZnO}^{152-156} \mathrm{SnO}_{2},{ }^{157-160}$ $\mathrm{In}_{2} \mathrm{O}_{3},{ }^{161} \mathrm{WO}_{3}{ }^{162} \mathrm{TiO}_{2},{ }^{163-166} \mathrm{Fe}_{2} \mathrm{O}_{3},{ }^{167-169} \mathrm{MoO}_{3},{ }^{170} \mathrm{VO}_{2}{ }^{171}$ and $\mathrm{CeO}_{2} \cdot{ }^{172}$ Various forms of nanostructures including nanoparticles, nanorods, nanowires, nanoflowers, nanosheets, nanofilms, nanotubes, porous structures and hierarchical nanostructures have been employed to detect various types of gases including $\mathrm{H}_{2} \mathrm{~S},{ }^{99,101} \mathrm{NO}_{2},{ }^{157} \mathrm{H}_{2},{ }^{173} \mathrm{NH}_{3},{ }^{174}$ acetone,${ }^{175}$ alcohol, ${ }^{106} \mathrm{HCHO},{ }^{176}$

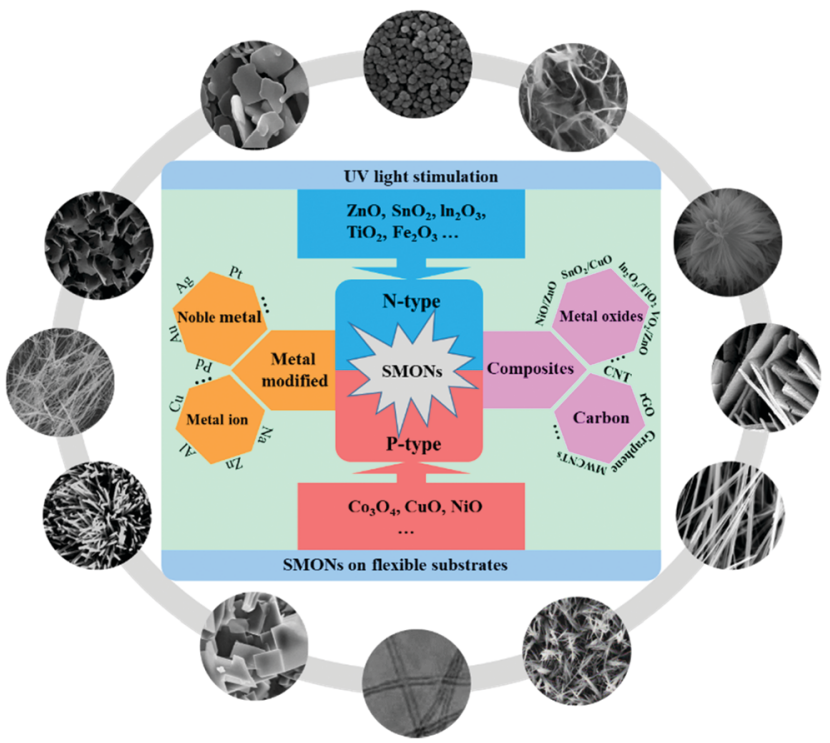

Fig. 2 Schematic diagram of various semiconducting metal oxide nanostructures used for RT gas sensors presented in this review.

liquefied petroleum gas (LPG), etc. Table 1 summarizes some of the reported RT sensors using the n-type SMONs.

2.1.1 Gas sensing mechanisms. The gas sensing mechanism of semiconductor oxide based resistive sensors is mostly based on the changes of resistance after they are exposed to the target gases due to the chemical interactions between target gas molecules and the adsorbed oxygen ions on the surface of SMONs. ${ }^{153,154}$ Conductance of n-type SMONs relies on electron carriers. When the n-type SMONs are surrounded by air, the oxygen molecules are absorbed on their surfaces. The absorbed oxygen molecules extract electrons from the conduction band of the surface layer, which results in the formation of negatively charged chemisorbed oxygen ions including $\mathrm{O}_{2}^{-}, \mathrm{O}^{-}$and $\mathrm{O}^{2-}$ at different operating temperatures. Due to the decrease in the electron density, an electron depletion layer is formed on the surface of SMONs and a potential barrier is generated. ${ }^{42,43}$ Therefore, the conductivity of the SMONs decreases, thus resulting in an increased resistance.

The operation temperature of gas sensors determines the types of chemisorbed oxygen ions. For example, they are mainly $\mathrm{O}_{2}{ }^{-}$when the temperature is below $100{ }^{\circ} \mathrm{C}$. When the working temperature is increased between $100{ }^{\circ} \mathrm{C}$ and $300{ }^{\circ} \mathrm{C}$, the $\mathrm{O}_{2}{ }^{-}$ ions will capture electrons and then transform into $\mathrm{O}^{-}$ions. The $\mathrm{O}^{-}$can be converted into $\mathrm{O}^{2-}$ ions at a higher working temperature above $300{ }^{\circ} \mathrm{C}$. The formation process of oxygen ions can be summarized using the following equations: ${ }^{42,43}$

$$
\begin{gathered}
\mathrm{O}_{2(\text { gas })} \leftrightarrow \mathrm{O}_{2(\text { ads })} \\
\mathrm{O}_{2(\text { ads })}+\mathrm{e}^{-} \leftrightarrow \mathrm{O}_{2}^{-{ }^{-} \text {(ads) }}\left(<100{ }^{\circ} \mathrm{C}\right) \\
\mathrm{O}_{2}{ }^{-}{ }_{\text {(ads })}+\mathrm{e}^{-} \leftrightarrow 2 \mathrm{O}^{-}{ }_{\text {(ads) }}\left(100-300{ }^{\circ} \mathrm{C}\right) \\
\mathrm{O}^{-}{ }_{\text {(ads })}+\mathrm{e}^{-} \leftrightarrow \mathrm{O}^{2-}{ }_{\text {(ads) }}\left(>300{ }^{\circ} \mathrm{C}\right)
\end{gathered}
$$

Therefore, at RT, the oxygen ions on the surface of n-type SMONs are mainly $\mathrm{O}_{2}{ }^{-}$ions. When the sensor is exposed to 
Table 1 Summary of room temperature sensing properties of $n$-type semiconducting metal oxide nanostructures

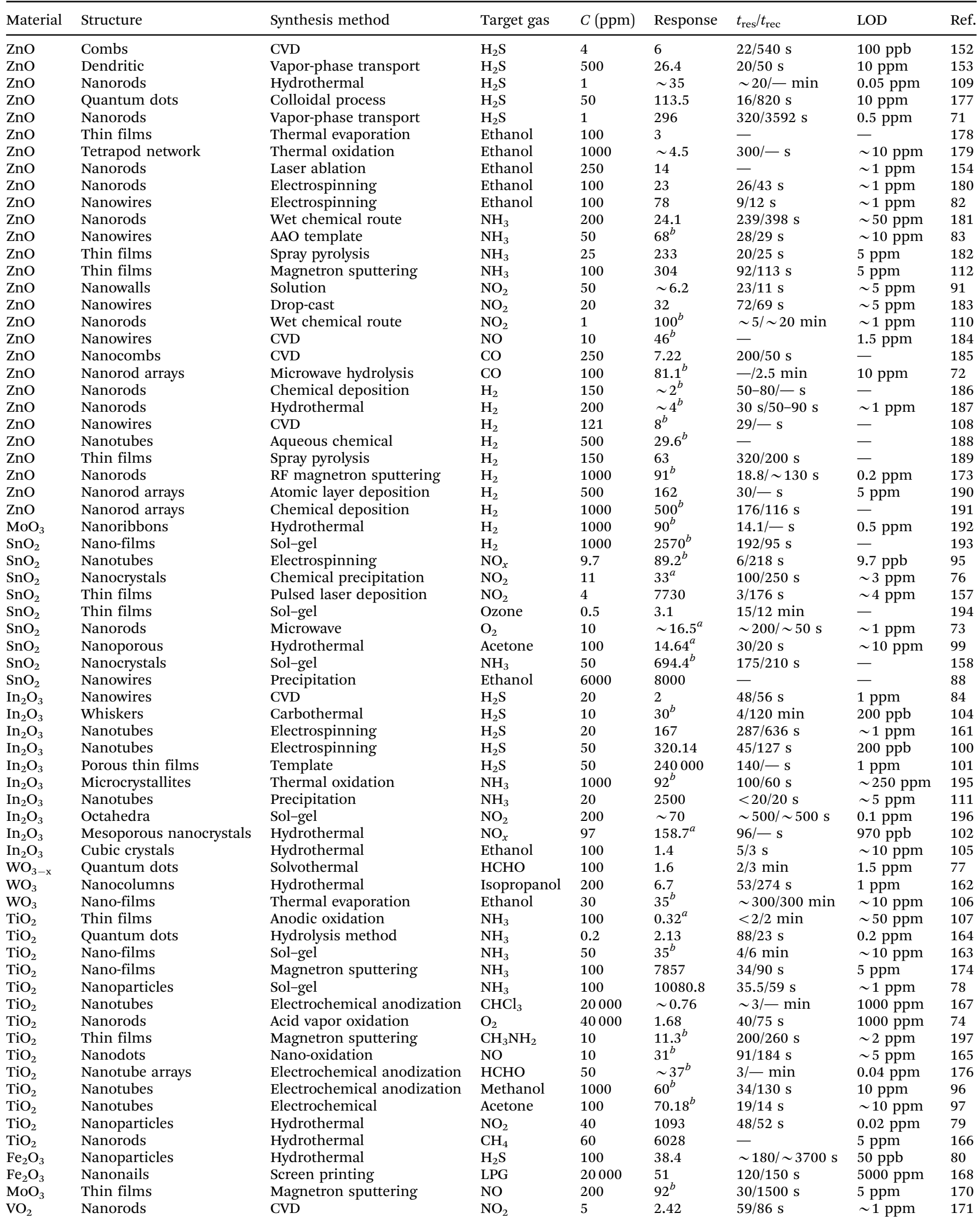


Table 1 (continued)

\begin{tabular}{|c|c|c|c|c|c|c|c|c|}
\hline $\mathrm{V}_{2} \mathrm{O}_{5}$ & Nanoneedles & Vapor deposition & Acetone & 1.7 & 1.025 & $73 /-s$ & $941 \mathrm{ppb}$ & 175 \\
\hline
\end{tabular}

$C=$ concentration; $t_{\text {res }} / t_{\text {rec }}=$ response time/recovery time; LOD = limit of detection; response is defined as $R_{\mathrm{a}} / R_{\mathrm{g}}$ (for reducing gases) or $R_{\mathrm{g}} / R_{\mathrm{a}}$ (for oxidizing gases), $R_{\mathrm{a}}$ : resistance of the sensor exposed to the reference, $R_{\mathrm{g}}$ : resistance of the sensor exposed to the target. ${ }^{a}$ Here the response is defined as $\Delta R / R_{\mathrm{g}}$ (for reducing gases) or $\Delta R / R_{\mathrm{a}}$ (for oxidizing gases), $\Delta R$ : the change in resistance. ${ }^{b}$ Here the response is defined as $\left(\Delta R / R_{\mathrm{g}}\right) \times 100 \%$ (for reducing gases) or $\left(\Delta R / R_{\mathrm{a}}\right) \times 100 \%$ (for oxidizing gases).

the target gases, the gas molecules are absorbed on the surface of SMONs, and then react with these chemisorbed oxygen ions.

If the target gases are reducing gases, such as $\mathrm{H}_{2} \mathrm{~S}, \mathrm{H}_{2}, \mathrm{NH}_{3}$, $\mathrm{HCHO}$, or $\mathrm{C}_{2} \mathrm{H}_{5} \mathrm{OH}$, the chemical reaction releases electrons, which are reinjected back to the electron depletion layer (see Fig. 3, the schematic diagram for $\mathrm{H}_{2} \mathrm{~S}$ gas sensing mechanism). This results in the reduction of the electron depletion layer and reduces the potential barrier energy $(\Delta \phi)$. As a result, the surface resistance of SMONs is decreased. In contrast, if the target gases are oxidizing gases, such as $\mathrm{NO}, \mathrm{NO}_{2}, \mathrm{Cl}_{2}$ and $\mathrm{O}_{3}$, the reaction with the chemisorbed oxygen ions will capture the electrons, which will widen the electron depletion layer, resulting in an increase of the potential barrier energy $(\Delta \phi)$. Accordingly, the surface resistance of the SMONs is increased.

There are generally three definitions for the response values of n-type SMON based gas sensors, which are $R_{\mathrm{a}} / R_{\mathrm{g}},\left(R_{\mathrm{a}}-R_{\mathrm{g}}\right) / R_{\mathrm{g}}$ and $\left(\left(R_{\mathrm{a}}-R_{\mathrm{g}}\right) / R_{\mathrm{g}}\right) \times 100 \%$ for the target reducing gases, respectively (where $R_{\mathrm{g}}$ and $R_{\mathrm{a}}$ are the resistance of sensors in the target gas and air, respectively). However, for the oxidizing gases, $R_{\mathrm{a}}$ and $R_{\mathrm{g}}$ need to be inter-changed in the above three definitions. ${ }^{196}$ The time from the injection of the target gas to the time of reaching $90 \%$ of the final response is defined as the response time, and the time from the extraction of the gas to the time of reaching $10 \%$ of the final response is defined as the recovery time.

Generally, formation of chemisorbed oxygen ions determines the sensing performance. However, the gas sensing mechanism is sometimes attributed to the formation of new compounds as a result of reactions between the target gas and the surface of the SMONs. For example, $\mathrm{H}_{2} \mathrm{~S}$ gas molecules can react with $\mathrm{ZnO}$

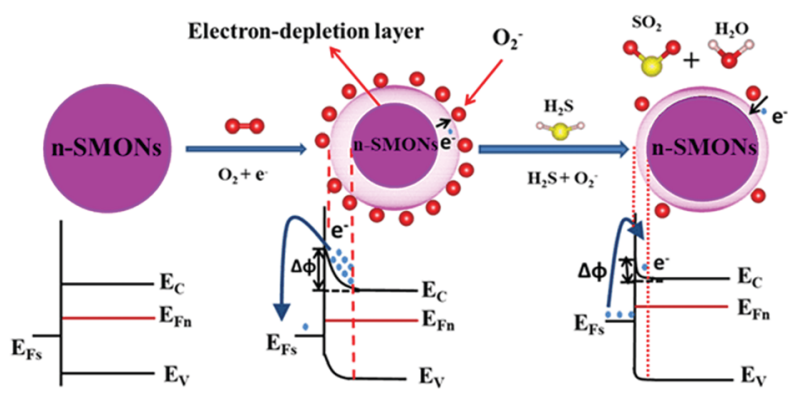

$\mathbf{E}_{\mathbf{C}}$ : bottom of conduction band; $\mathbf{E}_{\mathrm{V}}$ : top of valence band; $\mathbf{E}_{\mathrm{Fn}}$ : bulk Fermi level; $\mathbf{E}_{\mathrm{Fs}}$ : surface Fermi level; $\Delta \varphi$ : potential barrier;

Fig. 3 Schematic diagram of the sensing mechanism of $n$-type semiconducting metal oxide nanostructures for reducing gas of $\mathrm{H}_{2} \mathrm{~S}$. to form ZnS at RT. ${ }^{71,109}$ Formation of such type of conductive metal sulfide significantly decreases the resistance of the SMONbased sensors, which accounts for high sensitivities of n-type SMON-based sensors for $\mathrm{H}_{2} \mathrm{~S}$.

Chemical and electronic sensitization of the SMONs can be realized by adding noble metals on their surface and thus can remarkably enhance their sensing properties. Surface modifications and introduction of defects on the surfaces and interfaces such as introduction of heterojunctions ${ }^{134}$ and vacancies ${ }^{117}$ influence the sensing performance of SMON sensing materials. Addition of carbon nanomaterials on the surface of SMONs can also significantly improve their conductivity and enhance their sensitivities at RT. ${ }^{135}$ In addition, an alkaline center ${ }^{129}$ and hydroxide radicals ${ }^{198}$ on the surfaces of SMONs have also been reported to affect the sensing properties, which will be discussed further.

2.1.2 Room temperature hydrogen sulfide sensors. N-type SMONs based on $\mathrm{ZnO},{ }^{152} \mathrm{In}_{2} \mathrm{O}_{3},{ }^{199} \mathrm{CeO}_{2}{ }^{86}$ and $\mathrm{Fe}_{2} \mathrm{O}_{3}{ }^{80}$ have frequently been reported for $\mathrm{H}_{2} \mathrm{~S}$ gas sensing at RT. Among these, $\mathrm{ZnO}$ and $\operatorname{In}_{2} \mathrm{O}_{3}$ are wide band-gap semiconductors, with band gaps of $3.3 \mathrm{eV}$ and $3.6 \mathrm{eV}$, respectively. They are very effective for $\mathrm{H}_{2} \mathrm{~S}$ sensing because $\mathrm{H}_{2} \mathrm{~S}$ molecules can be easily decomposed and can react with the chemisorbed oxygen species on the surface of these sensing materials due to the small bond energy of $\mathrm{H}-\mathrm{S}-\mathrm{H}$. On the surface of $\mathrm{ZnO}$ or $\mathrm{In}_{2} \mathrm{O}_{3}$, the $\mathrm{H}_{2} \mathrm{~S}$ molecules not only react with the oxide ions of $\mathrm{O}_{2}{ }^{-}$to form $\mathrm{SO}_{2}$ and $\mathrm{H}_{2} \mathrm{O}$, but also react with $\mathrm{ZnO}$ or $\operatorname{In}_{2} \mathrm{O}_{3}$ to form $\mathrm{ZnS}$ or $\operatorname{In}_{2} \mathrm{~S}_{3}$, based on the following reactions: ${ }^{71,101,109}$

$$
\begin{aligned}
& 2 \mathrm{H}_{2} \mathrm{~S}_{(\mathrm{g})}+\mathrm{O}_{2}^{-}{ }_{(\mathrm{ads})} \leftrightarrow 2 \mathrm{H}_{2} \mathrm{O}_{(\mathrm{g})}+2 \mathrm{SO}_{2(\mathrm{~g})}+3 \mathrm{e}^{-} \\
& \mathrm{ZnO}+\mathrm{H}_{2} \mathrm{~S}_{(\mathrm{ads})} \rightarrow \mathrm{ZnS}+\mathrm{H}_{2} \mathrm{O} \\
& \mathrm{In}_{2} \mathrm{O}_{3}+3 \mathrm{H}_{2} \mathrm{~S}_{(\mathrm{ads})} \rightarrow \mathrm{In}_{2} \mathrm{~S}_{3}+3 \mathrm{H}_{2} \mathrm{O}
\end{aligned}
$$

The reactions with the oxide ions increase electron concentrations on the surface of $\mathrm{ZnO}$ or $\operatorname{In}_{2} \mathrm{O}_{3}$, which leads to a significant decrease in resistance. Because $\mathrm{ZnS}$ and $\mathrm{In}_{2} \mathrm{~S}_{3}$ are metallic conductors, the formation of $\mathrm{ZnS}$ or $\mathrm{In}_{2} \mathrm{~S}_{3}$ also decreases the resistance of sensors, thus the responses to the gases are enhanced significantly at RT. Formation of $\mathrm{ZnS}$ or $\operatorname{In}_{2} \mathrm{~S}_{3}$ is an exothermic process and spontaneously occurs at RT, so the sensors based on $\mathrm{ZnO}$ or $\operatorname{In}_{2} \mathrm{O}_{3}$ nanostructures are very suitable to detect $\mathrm{H}_{2} \mathrm{~S}$ at RT. Due to the formation of these metal sulfides, which are not reactive to most of the other gases, such as $\mathrm{NH}_{3}, \mathrm{H}_{2}, \mathrm{NO}_{2}, \mathrm{CO}, \mathrm{CH}_{4}, \mathrm{C}_{2} \mathrm{H}_{5} \mathrm{OH}$, and $\mathrm{HCHO}$, the selectivity of RT sensors made of the nanostructured $\mathrm{ZnO}$ or 
$\mathrm{In}_{2} \mathrm{O}_{3}$ to $\mathrm{H}_{2} \mathrm{~S}$ is excellent. Therefore, the $\mathrm{ZnO}$ and $\mathrm{In}_{2} \mathrm{O}_{3}$ nanostructured gas sensors generally have a high response and excellent selectivity for $\mathrm{H}_{2} \mathrm{~S}$ gas sensing.

The reaction of metal sulfides in the sensing process and the transformation of metal sulfides back to metal oxides in the recovery process are sometimes very slow at RT. Therefore, for the $\mathrm{RT} \mathrm{H}_{2} \mathrm{~S}$ gas sensors, the response time and especially the recovery time are often relatively long, sometimes as long as several hours. ${ }^{71,109}$ Furthermore, the sensors may not fully recover at RT. ${ }^{101}$ The sensor should often be heated to a relatively higher temperature $\left(e . g .200{ }^{\circ} \mathrm{C}\right.$ to $\left.300{ }^{\circ} \mathrm{C}\right)$ in the recovery process for a complete recovery or shortening of the recovery time down to minute-scales. ${ }^{109}$

Hosseinia et al. ${ }^{71}$ prepared vertically aligned $\mathrm{ZnO}$ rods with a diameter of 300-500 $\mathrm{nm}$ and a length of 1-9.5 $\mu \mathrm{m}$ using a vapor phase transport method. The nanorods are grown along the $c$-axis or (0002) planes perpendicularly to the substrate surface as shown in Fig. 4a. The porous network of vertically aligned ZnO rods forms directional channels, which facilitates the mobility of gas molecules. As shown in Fig. 4b, the sensor based on the vertically aligned $\mathrm{ZnO}$ rods shows a much higher response to $\mathrm{H}_{2} \mathrm{~S}$ at $26{ }^{\circ} \mathrm{C}$ than that at $250{ }^{\circ} \mathrm{C}$, and its response value for $\mathrm{H}_{2} \mathrm{~S}$ at RT is almost 600 times larger than those for other gases, such as $\mathrm{CH}_{4}, \mathrm{CO}, \mathrm{H}_{2} \mathrm{~S}$, methanol, ethanol, acetone, $\mathrm{H}_{2}$ and He. However, at $250{ }^{\circ} \mathrm{C}$, it is less than twice the original value. The response and recovery times of this sensor are very long, which are $320 \mathrm{~s}$ and $3592 \mathrm{~s}$ for $1 \mathrm{ppm}_{2} \mathrm{~S}$ as shown in Fig. 4c. ZnO nanorods were also grown using a hydrothermal method with diameters of 70-110 nm and lengths of $0.2-1.3 \mu \mathrm{m}$ and then used for $\mathrm{H}_{2} \mathrm{~S}$ sensing. ${ }^{109}$ These sensors exhibit a high response (about 35 to 1 ppm $\mathrm{H}_{2} \mathrm{~S}$ ) and a very low LOD (50 ppb). However, its response time is longer than $20 \mathrm{~min}$, and the
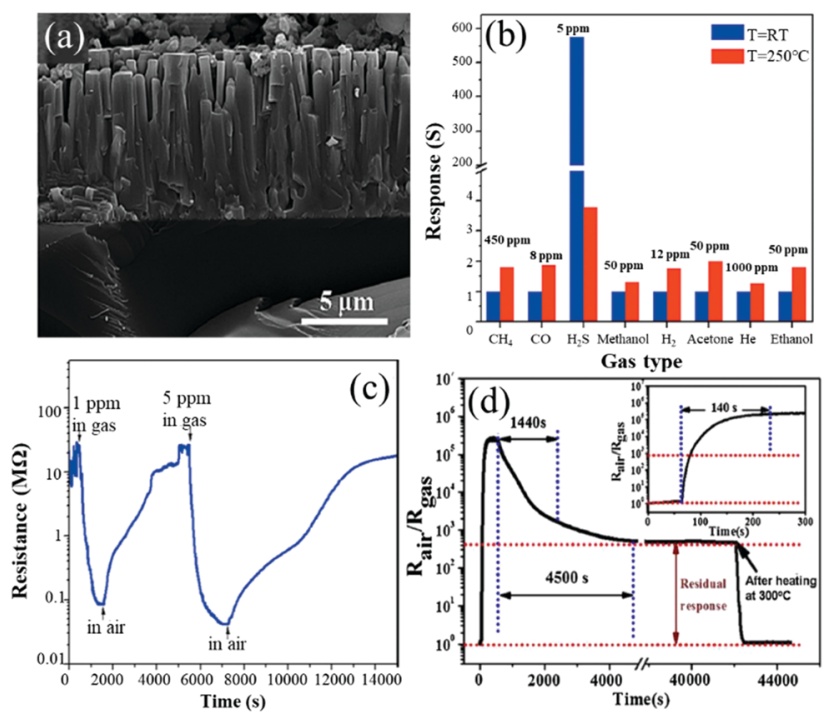

Fig. 4 (a) Cross-section SEM image of vertically aligned ZnO rods; (b) selectivity of the sensor at $25^{\circ} \mathrm{C}$ and $250{ }^{\circ} \mathrm{C}$; (c) response/recovery curves to 1 and 5 ppm $\mathrm{H}_{2} \mathrm{~S}$ at room temperature. ${ }^{71}$ Copyright 2015. Elsevier. (d) The response/ recovery curve at $50 \mathrm{ppm} \mathrm{H}_{2} \mathrm{~S}$ gas at room temperature. ${ }^{101}$ Copyright 2017 , Elsevier. sensor is difficult to recover at RT. Response and recovery rates of $\mathrm{RT} \mathrm{H}_{2} \mathrm{~S}$ gas sensors can be improved using dendritic $\mathrm{ZnO}$ nanostructures prepared using a vapor-phase transport method with $\mathrm{Cu}$ as the catalyst at $930{ }^{\circ} \mathrm{C} .{ }^{153}$ The multilevel branches of $\mathrm{ZnO}$ have well-oriented nanorods with diameters of 60 to $800 \mathrm{~nm}$. The response/recovery times are 20/50 s, which make this sensor the fastest SMON-based $\mathrm{H}_{2} \mathrm{~S}$ sensor at RT reported so far. The sensor exhibits a high response of 26.4 to $500 \mathrm{ppm}$ $\mathrm{H}_{2} \mathrm{~S}$ and good selectivity against various gases including $\mathrm{H}_{2} \mathrm{~S}$, $\mathrm{NH}_{3}, \mathrm{H}_{2}$ and $\mathrm{NO}_{2}$ in dry air at RT. The large degree modulation of the contact energy barriers due to the $\mathrm{H}_{2} \mathrm{~S}$ gas in $\mathrm{ZnO}$ dendrites is the key reason for their excellent sensing performance at RT.

Nanostructured $\operatorname{In}_{2} \mathrm{O}_{3}$ is another widely studied material for $\mathrm{H}_{2} \mathrm{~S}$ sensing. Apart from reactions of $\mathrm{H}_{2} \mathrm{~S}$ gas with oxygen ions on the surface of $\operatorname{In}_{2} \mathrm{O}_{3}$, the formation of $\operatorname{In}_{2} \mathrm{~S}_{3}$ is another key factor for the sensor's high response at RT. Remarkably, the response value of the $\mathrm{In}_{2} \mathrm{O}_{3}$ nanostructure can reach 240000 for 50 ppm of $\mathrm{H}_{2} \mathrm{~S}$ at $\mathrm{RT}^{101}$ as shown in Fig. 4d. The micro/nanostructured porous $\mathrm{In}_{2} \mathrm{O}_{3}$ film was synthesized onto an $\mathrm{Al}_{2} \mathrm{O}_{3}$ ceramic tube using a self-assembly method, ${ }^{101}$ which has an ordered porous structure with a thickness of $200 \mathrm{~nm}$. Although the sensor does not fully recover to its baseline at RT, it can be rapidly and completely recovered at $300{ }^{\circ} \mathrm{C}$. Using a conventional electrospinning process, Duan et al. ${ }^{100}$ prepared $\operatorname{In}_{2} \mathrm{O}_{3}$ thick walled toruloid nanotubes. Owing to their larger surface areas, the nanotubes have more active sites among them, which results in enhanced responses to $\mathrm{H}_{2} \mathrm{~S}$ gas. The sensors based on the $\mathrm{In}_{2} \mathrm{O}_{3}$ nanotubes exhibit high response values of 320.14 to $50 \mathrm{ppm} \mathrm{H}_{2} \mathrm{~S}$ and fast response/recovery times of 45/127 $\mathrm{s}$ at the RT. In addition, good selectivity and a very low LOD with a value of $100 \mathrm{ppb}$ have been demonstrated. ${ }^{100}$ Porous $\operatorname{In}_{2} \mathrm{O}_{3}$ nanotubes with a cubic phase have been prepared using the electrospinning method, ${ }^{161}$ and a high response value of 166.6 to $20 \mathrm{ppm} \mathrm{H}_{2} \mathrm{~S}$ has been demonstrated. However, the response/ recovery times are quite long (287/636 s).

Other n-type SMONs such as $\alpha-\mathrm{Fe}_{2} \mathrm{O}_{3}{ }^{80}$ and $\mathrm{CeO}_{2}{ }^{86}$ have also been reported as good sensing materials for $\mathrm{H}_{2} \mathrm{~S}$ sensing at RT. For example, porous $\alpha-\mathrm{Fe}_{2} \mathrm{O}_{3}$ nanoparticles with a diameter of $34 \mathrm{~nm}$ and pore sizes from $2 \mathrm{~nm}$ to $10 \mathrm{~nm}$ were obtained after annealing a FeOOH nanoparticle precursor. ${ }^{80}$ The sensor based on these porous $\alpha-\mathrm{Fe}_{2} \mathrm{O}_{3}$ nanoparticles exhibits a high sensitivity (38.4 for $100 \mathrm{ppm}_{2} \mathrm{~S}$ ) with a low LOD (50 ppb). In addition, it has good selectivity to $\mathrm{H}_{2} \mathrm{~S}$ against the other gases (e.g., $\mathrm{C}_{2} \mathrm{H}_{5} \mathrm{OH}, \mathrm{CO}, \mathrm{H}_{2}$ and $\mathrm{NH}_{3}$ ) and shows good reproducibility. The response time is fast with a value of $180 \mathrm{~s}$. However, the recovery time is very long with a value of $3750 \mathrm{~s}$ for $100 \mathrm{ppm}$ $\mathrm{H}_{2} \mathrm{~S}$. $\mathrm{CeO}_{2}$ nanowires ${ }^{86}$ were also synthesized using a facile hydrothermal process and they show fast response/recovery times with values of 24/15 $\mathrm{s}$ for $50 \mathrm{ppb} \mathrm{H}_{2} \mathrm{~S}$.

For the $\alpha-\mathrm{Fe}_{2} \mathrm{O}_{3}$ and $\mathrm{CeO}_{2}$ nanostructure-based $\mathrm{H}_{2} \mathrm{~S}$ gas sensors, the main sensing mechanism is the interactions of the $\mathrm{H}_{2} \mathrm{~S}$ molecules with the oxygen ions on their surface. Accordingly, the sensing is much faster than those sensors based on $\mathrm{ZnO}$ and $\mathrm{In}_{2} \mathrm{O}_{3}$, although their response to $\mathrm{H}_{2} \mathrm{~S}$ is much lower. ${ }^{80,86}$

2.1.3 Room temperature nitrogen dioxide sensors. Various SMON based gas sensors have demonstrated excellent sensing 
performance at RT for $\mathrm{NO}_{2}$ gas sensing, using different materials such as $\mathrm{ZnO},{ }^{110,200,201} \mathrm{SnO}_{2},{ }^{76} \mathrm{In}_{2} \mathrm{O}_{3},{ }^{196} \mathrm{WO}_{3}{ }^{202-206} \mathrm{Sb}_{2} \mathrm{O}_{5}{ }^{207}$ $\mathrm{Bi}_{2} \mathrm{O}_{3},{ }^{208}$ etc. The sensing mechanism of SMONs to $\mathrm{NO}_{2}$ is based on the formation of $\mathrm{NO}_{2}{ }^{-}$by capturing electrons and the reaction between $\mathrm{NO}_{2}$ gas molecules and $\mathrm{O}_{2}{ }^{-}$ions on the surface of the SMONs. All these reactions extract electrons from the surface of the SMONs, thus resulting in an increase in the resistance of these sensors, based on the following reactions: ${ }^{209}$

$$
\begin{aligned}
& \mathrm{NO}_{2 \text { (gas) }}+\mathrm{e}^{-} \leftrightarrow \mathrm{NO}_{2}{ }^{-} \text {(ads) } \\
& \mathrm{NO}_{2}{ }^{-}{ }_{\text {(ads })}+\mathrm{O}_{2}{ }^{-}{ }_{\text {(ads })}+2 \mathrm{e}^{-} \leftrightarrow \mathrm{NO}_{(\text {gas })}+2 \mathrm{O}^{2-}{ }_{\text {(ads) }}
\end{aligned}
$$

One of the outstanding features of SMON-based $\mathrm{RT} \mathrm{NO}_{2}$ gas sensors is their fast response speeds due to the strong oxidation of $\mathrm{NO}_{2}$ molecules. Kodu et al. ${ }^{157}$ reported $\mathrm{NO}_{2}$ sensors based on granular $\mathrm{SnO}_{2}$ thin films with a thickness of $\sim 90 \mathrm{~nm}$ deposited using a pulsed laser deposition method. The sensor exhibits not only a remarkably high response value of 7730 to $4 \mathrm{ppm}$ $\mathrm{NO}_{2}$, but also a very fast response time of $3 \mathrm{~s}$ at RT. Wei et al. ${ }^{76}$ prepared $\mathrm{SnO}_{2}$ nanocrystals by annealing $\mathrm{Sn}(\mathrm{OH})_{4}$ precursor powders at $550{ }^{\circ} \mathrm{C}$ in both vacuum and ambient air environments, respectively. The vacuum-annealed $\mathrm{SnO}_{2}$ and air-annealed $\mathrm{SnO}_{2}$ nanocrystals have different particle diameters of $7.2 \mathrm{~nm}$ and $10.3 \mathrm{~nm}$ as shown in Fig. 5a. The response value of the vacuum-annealed $\mathrm{SnO}_{2}$ sensor at $\mathrm{RT}$ is $\sim 2.4$ to $5 \mathrm{ppm}$ of $\mathrm{NO}_{2}$, which is higher than that of air-annealed $\mathrm{SnO}_{2}(\sim 0.35)$. This is mainly because the increased oxygen vacancies on the surface of the vacuum-annealed $\mathrm{SnO}_{2}$ are much more than those on the air-annealed $\mathrm{SnO}_{2}$ nanocrystals, which can be identified by X-ray photoelectron spectroscopy (XPS) analysis as shown in Fig. $5 \mathrm{~b}$ and $\mathrm{c}$.

Yu et al. ${ }^{91}$ prepared $\mathrm{ZnO}$ nanowalls with uniformly distributed and cross-linked nanowalls of $\sim 20 \mathrm{~nm}$ using a solution method. The cross-linked nanowalls have a porous structure with pore sizes from $200 \mathrm{~nm}$ to $500 \mathrm{~nm}$. The sensor exhibits a high response value (6.4) and fast response/recovery times (23/11 s) towards $50 \mathrm{ppm} \mathrm{NO}_{2}$ at RT with good repeatability. Based on the analysis from fluorescence emission spectrum, it was identified that the key factors for effective $\mathrm{NO}_{2}$ sensing are (1) the presence of oxygen vacancies in the $\mathrm{ZnO}$ nanowall nanostructures, and (2) a delicate balance between oxygen vacancy defects and porosity.

$\mathrm{TiO}_{2}$ and $\mathrm{In}_{2} \mathrm{O}_{3}$ are two other frequently reported nanomaterials for $\mathrm{NO}_{2}$ sensing. Tshabalala et al. ${ }^{79}$ prepared $\mathrm{TiO}_{2}$ nanoparticles with an average particle size of $6.5 \mathrm{~nm}$ using a hydrothermal method. The fluffy and porous $\mathrm{TiO}_{2}$ layer has a pore volume of $0.4170 \mathrm{~cm}^{3} \mathrm{~g}^{-1}$ and a large surface area of $80.3 \mathrm{~m}^{2} \mathrm{~g}^{-1} .^{79}$ The porous nanostructures, high concentration of oxygen vacancies and the interstitial defect states on the surface are crucial for the efficient adsorption and desorption of $\mathrm{NO}_{2}$ gas molecules. Therefore, the sensor made of these nanostructures exhibits a high response (1093 to $40 \mathrm{ppm} \mathrm{NO}_{2}$ ), fast response/recovery times of 48/52 s and a low LOD of $0.02 \mathrm{ppm}$ at RT. However, the selectivity of this sensor is poor with its relatively high responses to many other gases such as $\mathrm{H}_{2}, \mathrm{NH}_{3}$ and $\mathrm{CH}_{4} \cdot \mathrm{In}_{2} \mathrm{O}_{3}$ octahedra have also been prepared using the sol-gel technique for $\mathrm{NO}_{2}$ sensing, ${ }^{102}$ and the sensor using these $\mathrm{In}_{2} \mathrm{O}_{3}$ octahedra has a response value of 63 to $200 \mathrm{ppm}$ $\mathrm{NO}_{2}$ at RT, with good selectivity to $\mathrm{NO}_{2}$ against $\mathrm{CO}, \mathrm{H}_{2}$ and $\mathrm{NH}_{3}$.

2.1.4 Room temperature ammonia sensors. The sensing mechanism of SMON-based ammonia gas sensors operated at RT is also based on the reactions between $\mathrm{NH}_{3}$ gas molecules and adsorbed $\mathrm{O}_{2}{ }^{-}$ions on the surfaces of the SMONs as shown in the following reactions: $:^{92,183}$

$$
\begin{gathered}
\mathrm{NH}_{3 \text { (gas) }} \rightarrow \mathrm{NH}_{3(\text { ads })} \\
4 \mathrm{NH}_{3(\text { ads })}+3 \mathrm{O}_{2}^{-} \rightarrow 2 \mathrm{~N}_{2}+6 \mathrm{H}_{2} \mathrm{O}+3 \mathrm{e}^{-}
\end{gathered}
$$

The majority of the single phase n-type SMONs without modifications by other elements can be used for $\mathrm{NH}_{3}$ gas sensors, including $\mathrm{ZnO},{ }^{210-212} \mathrm{In}_{2} \mathrm{O}_{3},{ }^{111} \mathrm{SnO}_{2},{ }^{213} \mathrm{SnS}_{2},{ }^{214} \mathrm{MoO}_{3},{ }^{215} \mathrm{WO}_{3}{ }^{216}$ and $\mathrm{TiO}_{2}{ }^{217}$ They have good RT performance for $\mathrm{NH}_{3}$ sensing with high responses and fast response/recovery. Among these, the sensors based on $\mathrm{In}_{2} \mathrm{O}_{3}$ and $\mathrm{TiO}_{2}$ exhibit ultra-high responses and response/recovery times. For example, a RT sensor based on $\mathrm{TiO}_{2}$ nanoparticles has an ultra-high response of 10080.8 to $100 \mathrm{ppm}$ of $\mathrm{NH}_{3}$ and fast response/recovery times of $35.5 / 59 \mathrm{~s}^{78}$

Du et al. ${ }^{111}$ reported a $\mathrm{RT} \mathrm{NH} \mathrm{N}_{3}$ gas sensor using porous $\mathrm{In}_{2} \mathrm{O}_{3}$ nanotubes. This gas sensor exhibits an ultra-high response
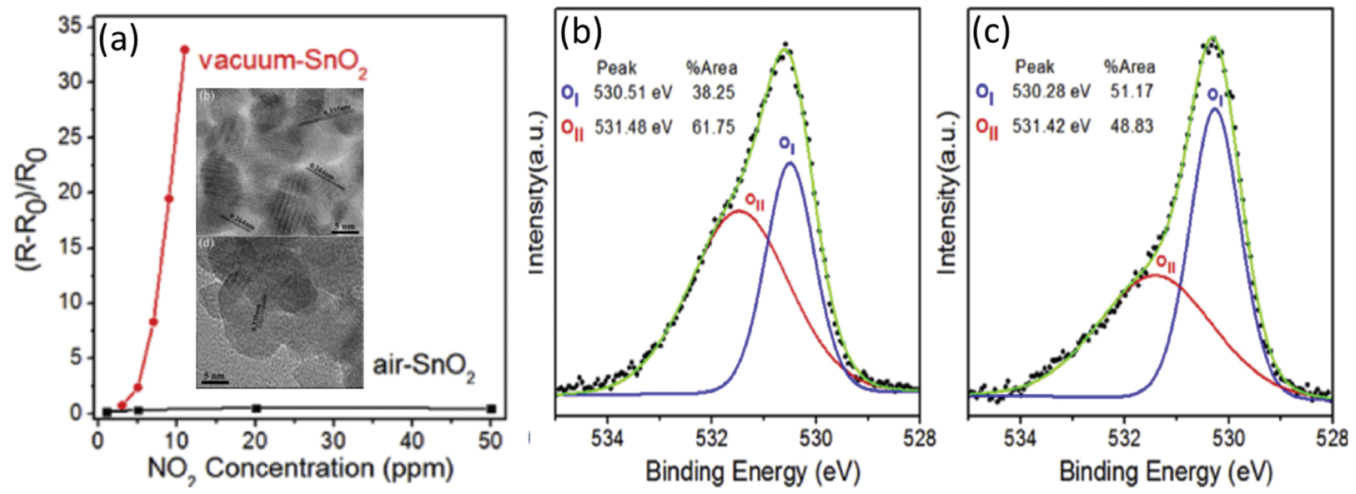

Fig. 5 (a) Response of vacuum-annealed $\mathrm{SnO}_{2}$ compared to air-annealed $\mathrm{SnO}_{2}$ nanocrystals to different concentrations of $\mathrm{NO}_{2}$ at room temperature; the inset shows the TEM images of two types of nanocrystals; (b) and (c) deconvolution of the $O$ 1s peaks of X-ray photoelectron spectra (XPS) for vacuum $-\mathrm{SnO}_{2}$ and air $-\mathrm{SnO}_{2}$ (the peaks with red color belong to adsorbed $\mathrm{O}$ ions). ${ }^{76}$ Copyright 2016, Elsevier. 
value of 2500 and good reproducibility with response and recovery times less than $20 \mathrm{~s}$, both of which are better than those of the sensors made of $\operatorname{In}_{2} \mathrm{O}_{3}$ nanowires or nanoparticles. The performance enhancement is attributed to the porous structure and ultra-high surface-to-volume ratio of the porous $\operatorname{In}_{2} \mathrm{O}_{3}$ nanotubes, which can adsorb more oxygen molecules. Another gas sensor made of $\mathrm{TiO}_{2}$ films prepared using a reactive magnetron sputter method also exhibits an excellent response with a value of 7857 to $100 \mathrm{ppm}$ of $\mathrm{NH}_{3}$, fast response/recovery times of 34/90 s and a low LOD of $\sim 5$ ppm. ${ }^{174}$ Kumar et al. ${ }^{83}$ used an anodic aluminum oxide template route to prepare highly ordered $\mathrm{ZnO}$ nanowire arrays as the sensing layer for detection of $\mathrm{NH}_{3}$. The diameters of these nanowires are in the range of 60 to $70 \mathrm{~nm}$ and their length is about $11 \mu \mathrm{m}$ as shown in Fig. 6a. At RT, the sensor exhibits $68 \%$ of response value (defined as $\left.\left(\Delta R / R_{\mathrm{g}}\right) \times 100 \%\right)$ to $50 \mathrm{ppm} \mathrm{NH}_{3}$ and fast response/recovery times (28/29 s) (see Fig. 6b). ${ }^{83}$ Another $\mathrm{NH}_{3}$ sensor made of nanostructured $\mathrm{ZnO}$ thin films ${ }^{112}$ synthesized using a magnetron sputtering technique shows a high response with a value of 304 to $100 \mathrm{ppm} \mathrm{NH}_{3}$ with response/recovery times of 92/113 s.

Mani et al. ${ }^{182}$ reported a sensor made of a nanostructured ZnO thin film (shown in Fig. 6c) using a spray pyrolysis technique. As shown in Fig. 6d, the sensor using this thin film exhibits a high response with a value of 233 to $25 \mathrm{ppm}$ of $\mathrm{NH}_{3}$ at $\mathrm{RT}$, and fast response and recovery times of 20/25 s. It has good selectivity to ammonia gas against other VOC gases (i.e. ethanol, methanol, benzyl alcohol, 2-propanol and acetone). Moreover, the sensor is insensitive to relative humidity. However, the sensor becomes saturated when the concentration of $\mathrm{NH}_{3}$ is above $20 \mathrm{ppm}$, indicating that the LOD is about from $5 \mathrm{ppm}$ to 25 ppm. In brief, high responses, fast response/recovery, and superior LOD have been achieved for the n-type SMON-based RT $\mathrm{NH}_{3}$ gas sensors.
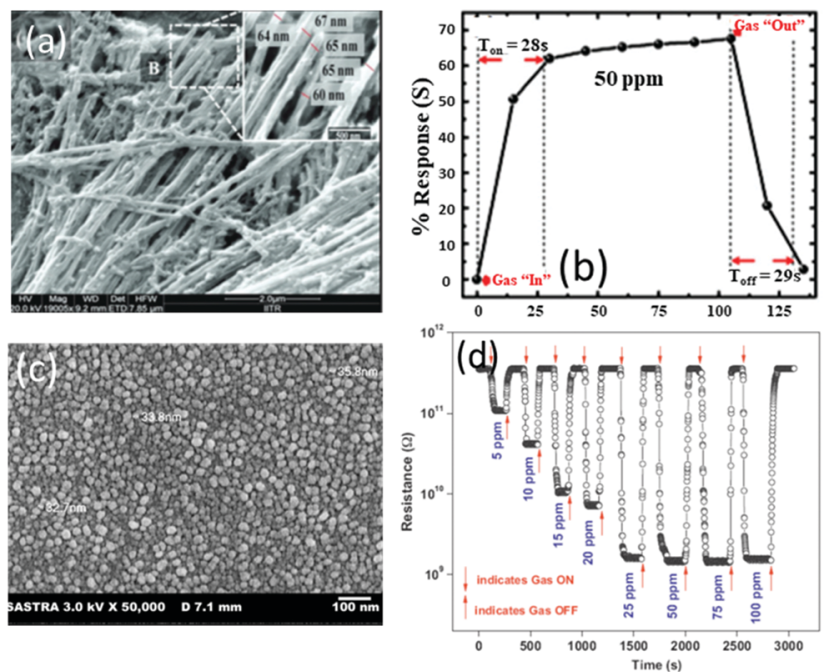

Fig. 6 (a) SEM images of the ZnO nanowire array; (b) response/recovery curves of the $\mathrm{ZnO}$ nanowire array for $50 \mathrm{ppm} \mathrm{NH}{ }^{83}$ Copyright 2014, Royal Society of Chemistry. (c) SEM image of nanostructured $\mathrm{ZnO}$ thin films on glass substrates; (d) response/recovery curves of the nanostructured $\mathrm{ZnO}$ thin film-based sensor for $\mathrm{NH}_{3}{ }^{182}$ Copyright 2013, Elsevier.
2.1.5 Room temperature ethanol sensors. Most n-type SMONs made of $\mathrm{ZnO},{ }^{218-220} \mathrm{Fe}_{2} \mathrm{O}_{3},{ }^{221} \mathrm{SnO}_{2},{ }^{222} \mathrm{In}_{2} \mathrm{O}_{3},{ }^{105} \mathrm{TeO}_{2}{ }^{85}$ and $\mathrm{WO}_{3}{ }^{106}$ can be used for ethanol sensing. The sensing mechanism of n-type SMON-based ethanol gas sensors is based on the interaction of ethanol gas molecules with chemisorbed $\mathrm{O}_{2}{ }^{-}$ions on the surfaces of the SMONs. The ethanol molecules react with the adsorbed oxygen ions to form $\mathrm{CO}_{2}$ and $\mathrm{H}_{2} \mathrm{O}$. Subsequently, electrons are released thus resulting in an increase in electron density and a decrease in potential barrier energy. These can be expressed using the following reactions: ${ }^{180}$

$$
\begin{gathered}
\mathrm{CH}_{3} \mathrm{CH}_{2} \mathrm{OH}_{(\text {gas })} \rightarrow \mathrm{CH}_{3} \mathrm{CH}_{2} \mathrm{OH}_{(\text {ads })} \\
\mathrm{C}_{2} \mathrm{H}_{5} \mathrm{OH}+3 \mathrm{O}_{2}{ }_{\text {(ads) }}^{-} \rightarrow 2 \mathrm{CO}_{2}+3 \mathrm{H}_{2} \mathrm{O}+3 \mathrm{e}^{-}
\end{gathered}
$$

The RT ethanol gas sensors based on the n-type SMONs usually exhibit rapid response and recovery. For example, a sensor based on $\mathrm{In}_{2} \mathrm{O}_{3}$ cubic crystals ${ }^{105}$ prepared using a hydrothermal method exhibits very fast response/recovery $(3 / 5 \mathrm{~s})$. However, the response is poor with a value of only 1.4 to $100 \mathrm{ppm}$ ethanol vapors. Fast response/recovery times together with high responses have been reported for a sensor made of $\mathrm{ZnO}$ nanowires. ${ }^{82,180}$ Shankar et al. ${ }^{82}$ reported an ethanol sensor made of $\mathrm{ZnO}$ nanowires (see Fig. 7a) prepared using electrospinning. Self-assembled $\mathrm{ZnO}$ nanowires with two different molecular weights of poly(vinyl alcohol) (PVA), e.g., 14000 and $140000 \mathrm{~g} \mathrm{~mol}^{-1}$, were prepared using an electrospinning technique, and then heat-treated to transform them into $\mathrm{ZnO}$ nanospheres and nanowires at a temperature of $600{ }^{\circ} \mathrm{C}$. These nanostructures have good selectivity to ethanol compared to other VOCs including ethanol, methanol, acetaldehyde, and acetone when operated at RT. The nanowire based sensors have a higher ethanol response (78 to $100 \mathrm{ppm}$ ) than those based on the nanoparticles (about 48 to $100 \mathrm{ppm}$ ). ${ }^{76}$ The nanowire-based ones also show fast response/recovery times of 9/12 s. Furthermore, the nanowire-based sensor has excellent repeatability.

Fig. 7b shows a schematic diagram of the ethanol sensing mechanism for the ZnO-based sensor. ${ }^{82}$ The chemisorption of oxygen molecules on the sensor surface results in the formation of a space charge region on the surface of $\mathrm{ZnO}$, which can act as a barrier for electron transport in the $\mathrm{ZnO}$ sensing layer. ${ }^{82}$ Due to the formation of double-spaced charge layers from the intergranular contacts of nanoparticles, the potential barrier energy is increased, which results in the broadening of the percolation path and hinders the electron transport. This further influences the adsorptiondesorption rate and the sensing properties towards ethanol. However, the intergranular contact resistance will be reduced in the ZnO nanowires, which decreases the potential barrier energy, thus enhancing the sensing performance.

Similarly, $\mathrm{TiO}_{2}$ nanotubes ${ }^{96}$ prepared using an electrochemical anodization method and $\mathrm{TeO}_{2}$ nanowires ${ }^{85}$ prepared using thermal evaporation also show good responses to ethanol. ${ }^{8596}$ However, the selectivity is poor as they are also sensitive to methanol and propanol.

2.1.6 Room temperature hydrogen sensors. Hydrogen gas is one of the extremely flammable and explosive gases. Therefore, detection of traces of hydrogen gas using RT gas sensors is 

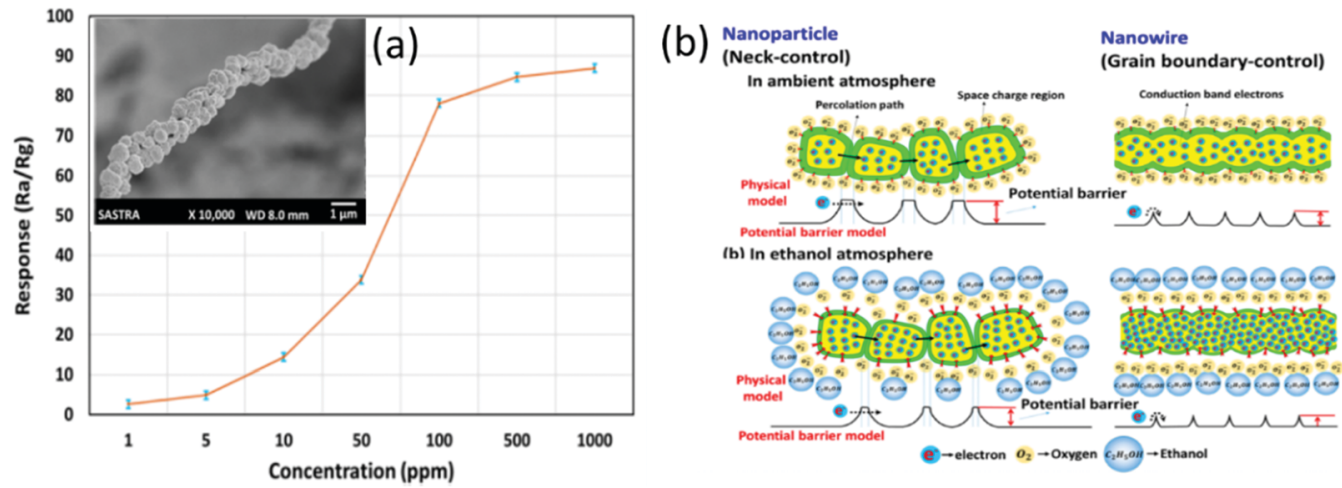

Fig. 7 (a) Responses of the $\mathrm{ZnO}$ nanowire sensor to different concentrations of ethanol at room temperature; the inset shows the SEM image of ZnO nanowires; (b) the schematic diagram of the ethanol sensing mechanism. ${ }^{82}$ Copyright 2017, American Chemical Society.

critical to avoid the dangers of explosion. For this application, the sensors must be fast, highly sensitive and selective. In particular, the fast response is paramount for a timely detection of a possible hydrogen leakage. As summarized in Table 1, the SMONs made of $\mathrm{ZnO},{ }^{188,189} \mathrm{MoO}_{3}{ }^{192}$ and $\mathrm{SnO}_{2}{ }^{193}$ have been demonstrated for hydrogen sensing at RT using various nanostructures including nanofilms, ${ }^{189}$ nanowires, ${ }^{108}$ nanotubes ${ }^{188}$ and nanorods. ${ }^{190,191}$ The sensing mechanism is based on the reaction of $\mathrm{H}_{2}$ molecules with chemisorbed $\mathrm{O}_{2}{ }^{-}$ions on the surface of the SMONs, as shown in the following chemical equation: ${ }^{189}$

$$
2 \mathrm{H}_{2}+\mathrm{O}_{2}^{-} \text {(ads) } \rightarrow 2 \mathrm{H}_{2} \mathrm{O}+\mathrm{e}^{-}
$$

From the literature, sensors made from $\mathrm{ZnO}$ films ${ }^{189}$ and ZnO nanorods ${ }^{191}$ show high responses to $\mathrm{H}_{2}$, but long response/ recovery times (see Fig. 8).
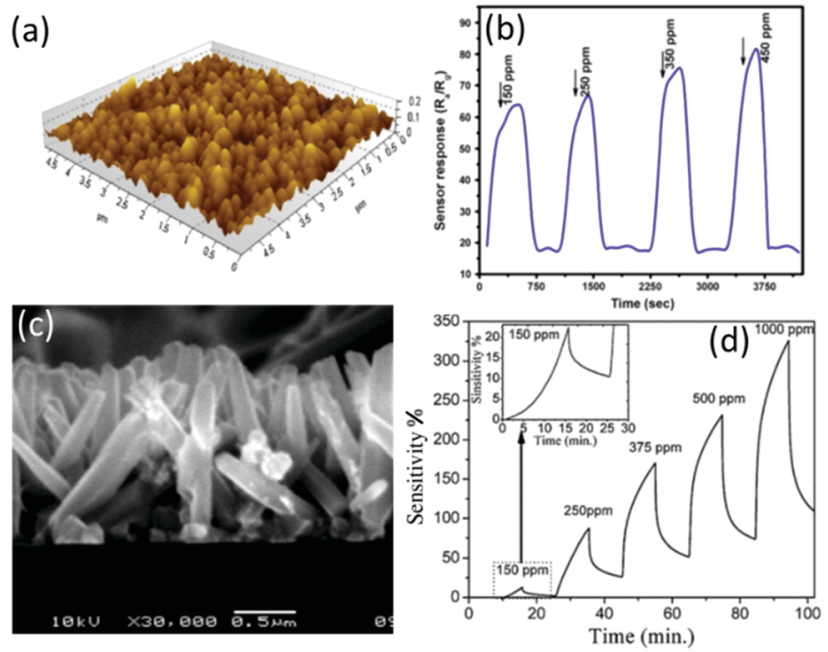

Fig. 8 (a) AFM image of the $\mathrm{ZnO}$ films and (b) response/recovery curves of a $\mathrm{ZnO}$ film-based gas sensor to different concentrations of $\mathrm{H}_{2}{ }^{189}$ Copyright 2014, Springer Nature. (c) Cross section SEM image of the $\mathrm{ZnO}$ nanorods and (d) response/recovery curves of a $\mathrm{ZnO}$ nanorodbased gas sensor to different concentrations of $\mathrm{H}_{2}{ }^{191}$ Copyright 2013 , Elsevier.
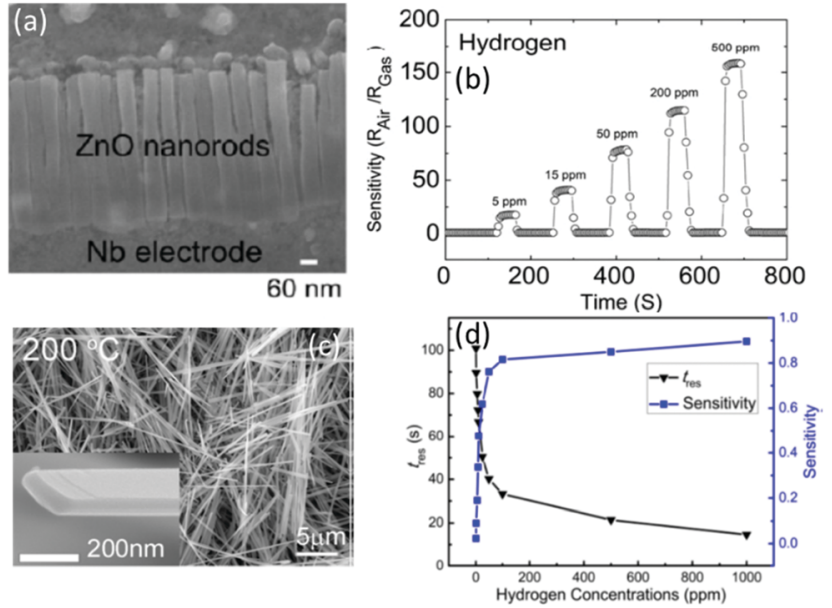

Fig. 9 (a) TEM image of vertical ZnO nanorods; (b) response/recovery curves of a vertical $\mathrm{ZnO}$ nanorod-based gas sensor versus different concentrations of $\mathrm{H}_{2}{ }^{190}$ Copyright 2012, Elsevier. (c) SEM images of $\alpha-\mathrm{MoO}_{3}$ nanoribbons; (d) response values and times of an $\alpha-\mathrm{MoO}_{3}$ nanoribbon-based gas sensor versus different concentrations of $\mathrm{H}_{2}{ }^{192}$ Copyright 2015, American Chemical Society.

Using anodized aluminum oxides as nano-templates, Lim et al. ${ }^{190}$ synthesized vertical $\mathrm{ZnO}$ nanorods (see Fig. 9a) using atomic layer deposition, and a highly sensitive and fast response/ recovery $\mathrm{H}_{2}$ gas sensor was fabricated using these vertical $\mathrm{ZnO}$ nanorods. A response value of 162 for $500 \mathrm{ppm}_{2}$ and a response time of $30 \mathrm{~s}$ were demonstrated (see Fig. $9 \mathrm{~b}$ ). ${ }^{190} \mathrm{~A}$ faster response $\mathrm{H}_{2}$ gas sensor was also reported using [001]-oriented $\alpha-\mathrm{MoO}_{3}$ nanoribbons (see Fig. 9c) ${ }^{192}$ with a response time of $14.1 \mathrm{~s}$ for $1000 \mathrm{ppm}$ of $\mathrm{H}_{2}$ and a low LOD of $500 \mathrm{ppb}$ (see Fig. 9d). ${ }^{192}$ It has good reproducibility and high selectivity against ethanol, $\mathrm{CO}$ and acetone.

In brief, RT gas sensors based on n-type SMONs can detect most of the hazardous gases, with advantages such as easy preparation, low cost, simple post-treatment and good stability of structure. Various morphologies of nanostructures for n-type SMONs have been synthesized and used in gas sensors operated at the RT. These sensors have been widely used to detect various gases and some good sensing properties have been achieved. 
However, it should be addressed that for most of these n-type SMON-based RT gas sensors, their sensitivity at RT is much lower than that at a higher working temperatures. Their responses and recovery times are quite long, and sometimes these sensors cannot be fully recovered at RT. In addition, at RT, the sensing performance is seriously affected by various environmental factors, such as humidity and external light source. To enhance their sensing properties at RT, modification of these n-type SMONs should be adopted, which will be discussed in Section 3 .

\subsection{P-type semiconducting metal oxide nanostructures and gas sensors}

Up to now, the major p-type SMONs used in RT gas sensing have been $\mathrm{CuO},{ }^{223-225} \mathrm{Co}_{3} \mathrm{O}_{4}{ }^{92,103}$ and $\mathrm{NiO},{ }^{94,226}$ and the main target gases include $\mathrm{NH}_{3},{ }^{98,103} \mathrm{H}_{2} \mathrm{~S}^{224,225}$ and $\mathrm{NO}_{2},{ }^{226}$ as listed in Table 2. Apart from the sensing mechanism which is based on the reaction of target gases with the oxygen ions on the surface of SMONs, the formation of metal sulfides is another key reason for $\mathrm{H}_{2} \mathrm{~S}$ sensing, especially for $\mathrm{CuO}$ nanostructures. ${ }^{93,225}$

2.2.1 Gas sensing mechanisms. Generally, the sensing mechanism of p-type SMONs is based on the changes of surface resistance as a result of the changes in the concentrations of hole carriers due to their redox reaction with the target gases. When exposed to air at RT, the oxygen ions of $\mathrm{O}_{2}{ }^{-}$are formed from the adsorbed oxygen molecules on the surface of p-type semiconductors and they capture electrons from the conduction band of the SMONs. The density of hole carriers is increased, thus resulting in a decrease in the surface layer's Fermi level.
Due to an accumulated hole layer formed on the surface of p-type SMONs, the conductivity will be increased and the resistance of the sensors is decreased. This is opposite to the sensing mechanism for the n-type SMON sensors discussed in the last section.

The sensing mechanism of the p-type SMONs to the reducing gas of $\mathrm{NH}_{3}$ is schematically shown in Fig. 10. When the reducing gas molecules (such as $\mathrm{NH}_{3}$ ) are adsorbed on the surface of SMONs, the reaction between the $\mathrm{NH}_{3}$ and $\mathrm{O}_{2}{ }^{-}$ions will release electrons, which will combine with the holes, resulting in an increase in the Fermi level and reduction of the hole accumulation layer. Consequently, the conductivity of the SMON layer is decreased. However, for the oxidizing gases, more free electrons are captured from the surface of the p-type SMONs. For example, the $\mathrm{NO}_{2}$ molecules adsorbed on the sensor surface can capture electrons from the p-type SMONs to form $\mathrm{NO}_{2}{ }^{-}$as listed in the reaction eqn (8). This significantly increases the concentrations of hole carriers, thus resulting in the increase in conductivity of the p-type SMON-based gas sensors. In summary, the resistance of p-type SMON based sensors will be increased in the presence of the reducing gases, whereas their resistance will be decreased in the presence of the oxidizing gases.

2.2.2 Room temperature hydrogen sulfide sensors. At present, the dominant p-type SMON for $\mathrm{RT}_{2} \mathrm{~S}$ gas sensors is $\mathrm{CuO}$, which exhibits excellent sensing performance when operated at RT, especially with high sensitivity and fast response and recovery. Different from the sensing mechanisms discussed above which are based on the reactions between the target gases with the

Table 2 Summary of room temperature sensing properties of $p$-type semiconducting metal oxide nanostructures

\begin{tabular}{|c|c|c|c|c|c|c|c|c|}
\hline Material & Structure & Synthesis method & Target gas & $C(\mathrm{ppm})$ & Response & $t_{\mathrm{res}} / t_{\mathrm{rec}}$ & LOD & Ref. \\
\hline $\mathrm{CuO}$ & Nanosheets & Hydrothermal & $\mathrm{H}_{2} \mathrm{~S}$ & 0.01 & 1.25 & $234 / 76 \mathrm{~s}$ & $10 \mathrm{ppb}$ & 93 \\
\hline $\mathrm{CuO}$ & Flowers & Hydrothermal & $\mathrm{H}_{2} \mathrm{~S}$ & 1 & 2.1 & $240 / 1341 \mathrm{~s}$ & $0.1 \mathrm{ppm}$ & 225 \\
\hline $\mathrm{CuO}$ & Nanofibers & Electrospinning & $\mathrm{H}_{2} \mathrm{~S}$ & 100 & 2.23 & $4.3 /-\mathrm{s}$ & $1 \mathrm{ppm}$ & 227 \\
\hline $\mathrm{CuO}$ & Tubes & Biotemplate & $\mathrm{H}_{2} \mathrm{~S}$ & 5 & $\sim 41$ & $29 / 41 \mathrm{~s}$ & $2 \mathrm{ppb}$ & 98 \\
\hline $\mathrm{CuO}$ & Thin films & Thermal evaporation & $\mathrm{H}_{2} \mathrm{~S}$ & 5 & $\sim 250^{b}$ & $60 / 90 \mathrm{~s}$ & $100 \mathrm{ppb}$ & 224 \\
\hline $\mathrm{CuO}$ & Nanorectangles & Hydrothermal & $\mathrm{NH}_{3}$ & 5 & $\sim 0.25^{a}$ & $90 / 120 \mathrm{~s}$ & 5 ppm & 223 \\
\hline $\mathrm{CuO}$ & Nanoparticles & Sol-gel-combustion & $\mathrm{NH}_{3}$ & 100 & $0.99^{a}$ & $30 /-\mathrm{s}$ & - & 228 \\
\hline $\mathrm{CuO}$ & Nanoparticles & Sol-gel-combustion & $\mathrm{NH}_{3}$ & 100 & $9.83^{a}$ & $\sim 150 / \sim 500 \mathrm{~s}$ & - & 81 \\
\hline $\mathrm{CuO}$ & Microspheres & Reflux method & $\mathrm{NO}_{x}$ & 97 & $64.93^{b}$ & $5.33 /-\mathrm{s}$ & $0.97 \mathrm{ppm}$ & 90 \\
\hline $\mathrm{Cu}_{x} \mathrm{O}$ & Virus-like & Chemical solution & $\mathrm{NO}_{2}$ & 4 & 28.1 & $22 / 42 \mathrm{~s}$ & $1 \mathrm{ppm}$ & 229 \\
\hline $\mathrm{CuO}$ & Nanoplatelets & Sonochemical method & $\mathrm{NO}_{2}$ & 40 & 53737 & - & - & 230 \\
\hline $\mathrm{CuO}$ & Nanowires & Thermal oxidation & Ethanol & 100 & 202 & $0.19 / 0.19 \mathrm{~s}$ & $\sim 10 \mathrm{ppm}$ & 36 \\
\hline $\mathrm{CuO}$ & Nanoribbons & Wet chemical & Ethanol & 100 & $210^{b}$ & $8 / 25 \mathrm{~s}$ & 20 ppm & 231 \\
\hline $\mathrm{NiO}$ & Nanosheets & Microwave synthesis & $\mathrm{NO}_{2}$ & 10 & 0.56 & - & - & 232 \\
\hline $\mathrm{NiO}$ & Nanosheets & Hydrothermal & $\mathrm{NO}_{2}$ & 60 & $3.05^{a}$ & $\sim 200 / \sim 300 \mathrm{~s}$ & $\sim 5 \mathrm{ppm}$ & 94 \\
\hline $\mathrm{NiO}$ & Nanosheets & Hydrothermal & $\mathrm{NO}_{2}$ & 60 & $1.8^{a}$ & $\sim 250 / \sim 250 \mathrm{~s}$ & $\sim 7 \mathrm{ppm}$ & 226 \\
\hline $\mathrm{NiO}$ & Dendritic-like & Electrolytic & $\mathrm{NH}_{3}$ & 30 & $19^{b}$ & $40 / 1500 \mathrm{~s}$ & - & 233 \\
\hline $\mathrm{Co}_{3} \mathrm{O}_{4}$ & Nanosheets & Hydrothermal & $\mathrm{NH}_{3}$ & 100 & 9.5 & $9 / 134 \mathrm{~s}$ & $0.2 \mathrm{ppm}$ & 92 \\
\hline $\mathrm{Co}_{3} \mathrm{O}_{4}$ & Porous structure & Template & $\mathrm{NH}_{3}$ & 100 & $146^{b}$ & $2 /-\mathrm{s}$ & $0.5 \mathrm{ppm}$ & 103 \\
\hline $\mathrm{Co}_{3} \mathrm{O}_{4}$ & Nanosheets & Hydrothermal & $\mathrm{CO}$ & 50 & - & $15 / 20 \mathrm{~s}$ & - & 234 \\
\hline $\mathrm{Co}_{3} \mathrm{O}_{4}$ & Nanoparticles & Thermal treatment & $\mathrm{NO}_{x}$ & 100 & $52.1^{b}$ & - & $100 \mathrm{ppb}$ & 235 \\
\hline $\mathrm{Cr}_{2} \mathrm{O}_{3}$ & Nanospheres & Hydrothermal & Ethanol & 40 & $9^{a}$ & - & 5 ppm & 236 \\
\hline $\mathrm{Cr}_{2} \mathrm{O}_{3}$ & Mesoporous & Impregnation & Ethanol & 1000 & 13.0 & - & $10 \mathrm{ppm}$ & 237 \\
\hline$\alpha-\mathrm{MnO}_{2}$ & Nanospheres & Self-assembly & $\mathrm{NH}_{3}$ & 20000 & 0.2 & - & - & 238 \\
\hline $\mathrm{MnO}_{2}$ & Nanofibers & Chemical solution & $\mathrm{NH}_{3}$ & 100 & $20^{b}$ & - & $1 \mathrm{ppm}$ & 239 \\
\hline$\beta-\mathrm{MnO}_{2}$ & Thin films & Spray pyrolysis & $\mathrm{CH}_{3} \mathrm{COH}$ & 10 & $89^{b}$ & $60 / 11 \mathrm{~s}$ & $10 \mathrm{ppm}$ & 240 \\
\hline
\end{tabular}

$C=$ concentration; $t_{\text {res }} / t_{\text {rec }}=$ response time/recovery time; LOD $=$ limit of detection; response is defined as $R_{\mathrm{a}} / R_{\mathrm{g}}$ (for reducing gases) or $R_{\mathrm{g}} / R_{\mathrm{a}}$ (for oxidizing gases), $R_{\mathrm{a}}$ : resistance of the sensor exposed to the reference, $R_{\mathrm{g}}$ : resistance of the sensor exposed to the target. ${ }^{a}$ Here the response is defined as $\Delta R / R_{\mathrm{g}}$ (for reducing gases) or $\Delta R / R_{\mathrm{a}}$ (for oxidizing gases), $\Delta R$ : the change in resistance. ${ }^{b}$ Here the response is defined as $\left(\Delta R / R_{\mathrm{g}}\right) \times 100 \%$ (for reducing gases) or $\left(\Delta R / R_{\mathrm{a}}\right) \times 100 \%$ (for oxidizing gases). 


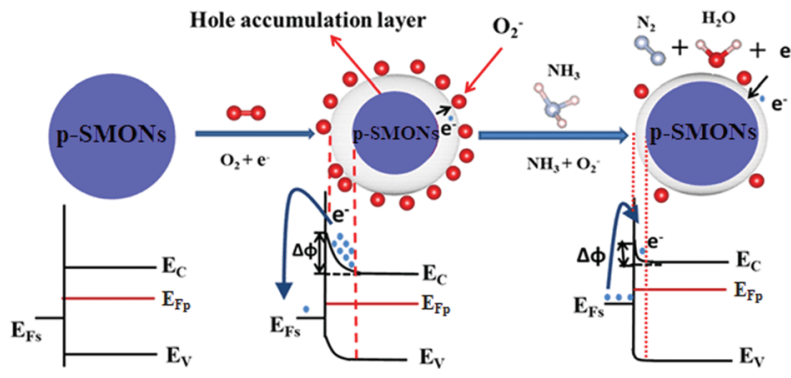

$\mathbf{E}_{\mathbf{C}}$ : bottom of conduction band; $\mathbf{E}_{\mathrm{V}}$ : top of valence band; $\mathbf{E}_{\mathbf{F n}}$ : bulk Fermi level; $\mathbf{E}_{\mathrm{Fs}}$ : surface Fermi level; $\Delta \varphi$ : potential barrier;

Fig. 10 Schematic diagram of the sensing mechanism for $p$-type semiconducting metal oxide nanostructures to reducing gas of $\mathrm{NH}_{3}$.

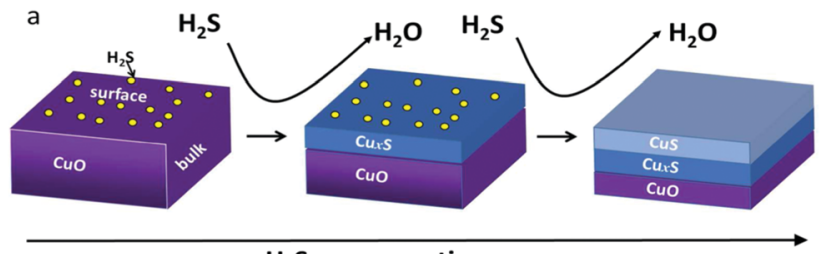

$\mathrm{H}_{2} \mathrm{~S}$ exposure time

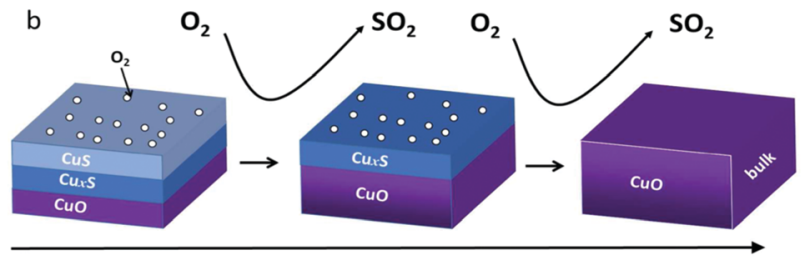

air exposure time

Fig. 11 Schematic diagrams of the sensing mechanism of $\mathrm{CuO}$ : (a) response process in $\mathrm{H}_{2} \mathrm{~S}$ and (b) recovery process in air. ${ }^{93}$ Copyright 2016, American Chemical Society.

oxygen ions, the formation of $\mathrm{CuS}$ is highly responsible for the sensing response to $\mathrm{H}_{2} \mathrm{~S}$ at RT.

Fig. 11 shows schematic diagrams of the sensing mechanism for CuO-based $\mathrm{H}_{2} \mathrm{~S}$ sensors. $\mathrm{H}_{2} \mathrm{~S}$ molecules can react with $\mathrm{CuO}$ to form CuS on the surface at RT, based on the following reactions: ${ }^{93,225}$

$$
\begin{gathered}
\mathrm{H}_{2} \mathrm{~S}_{(\mathrm{g})}+\mathrm{CuO}_{(\mathrm{s})} \rightarrow \mathrm{CuS}_{(\mathrm{s})}+\mathrm{H}_{2} \mathrm{O}_{(\mathrm{g})} \\
\mathrm{CuS}_{(\mathrm{s})}+\mathrm{O}_{2(\mathrm{~g})} \rightarrow \mathrm{CuO}_{(\mathrm{s})}+\mathrm{SO}_{2(\mathrm{~g})}
\end{gathered}
$$

$\mathrm{CuS}$ is a metallic-like conductor. Formation of CuS on the SMON's surface will dramatically decrease the resistance of the sensor. Consequently, although $\mathrm{H}_{2} \mathrm{~S}$ is a reducing gas, the response of the sensors exhibits a decrease in resistance. The $\mathrm{RT}_{2} \mathrm{~S}$ gas sensors are highly selective owing to this unique interaction between $\mathrm{H}_{2} \mathrm{~S}$ and $\mathrm{CuO}$. However, their recovery times are relatively long at RT due to the requirement for the transformation from $\mathrm{CuS}$ to $\mathrm{CuO}$.

This $\mathrm{H}_{2} \mathrm{~S}$ sensing mechanism has been proved from different studies. For example, Li et al. ${ }^{93}$ reported a $\mathrm{H}_{2} \mathrm{~S}$ sensor based on porous $\mathrm{CuO}$ nanosheets with a thickness of about $60 \mathrm{~nm}$ on alumina tubes, prepared using a hydrothermal method. The sensor based on these porous $\mathrm{CuO}$ nanosheets has excellent selectivity to $\mathrm{H}_{2} \mathrm{~S}$. It exhibits high response values to $\mathrm{H}_{2} \mathrm{~S}$, but no apparent responses to $\mathrm{NH}_{3}, \mathrm{CO}, \mathrm{NO}, \mathrm{NO}_{2}, \mathrm{H}_{2}$, and $\mathrm{C}_{2} \mathrm{H}_{5} \mathrm{OH} .{ }^{93}$ The sensor has a superior LOD as low as $10 \mathrm{ppb}$ and good reproducibility at $\mathrm{RT}$. The sensing mechanism based on the transformation from $\mathrm{CuO}$ into $\mathrm{CuS}$ on the surface of nanosheets has been verified using XPS analysis. As seen from the XPS spectra in Fig. 12, after the $\mathrm{CuO}$ is exposed to $\mathrm{H}_{2} \mathrm{~S}$ gas, a new peak of the $\mathrm{Cu} 2 \mathrm{p}_{3 / 2}$ state at $930.8 \mathrm{eV}$ appears which is attributed to CuS, and the $\mathrm{S} 2 \mathrm{p}_{3 / 2}$ and $\mathrm{S} 2 \mathrm{p}_{1 / 2}$ states at 162.3 and $163.4 \mathrm{eV}$ can be identified. Similarly, nanostructures of hierarchical flower-like $\mathrm{CuO}$ nanostructures ${ }^{225}$ have been prepared, and the sensors made of these nanostructured $\mathrm{CuO}$ exhibit high sensitivity, good reproducibility and high sensing selectivity to $\mathrm{H}_{2} \mathrm{~S}$ at RT. Zhang et $a l^{98}$ prepared tube-like $\mathrm{CuO}$ nanostructures using pomelo flesh as a bio-template. The unique tube-like $\mathrm{CuO}$ nanostructures enhance the diffusion of $\mathrm{H}_{2} \mathrm{~S}$ molecules and promote the rapid formation of CuS. The $\mathrm{H}_{2} \mathrm{~S}$ sensor based on the tube-like $\mathrm{CuO}$ nanostructures has good selectivity to $\mathrm{H}_{2} \mathrm{~S}$, compared to gases such as gasoline, formaldehyde, $\mathrm{CH}_{4}, \mathrm{H}_{2}$, acetone, $\mathrm{CO}$, toluene, and ethanol. The response/recovery times are lower than $60 \mathrm{~s}$ for the $\mathrm{H}_{2} \mathrm{~S}$ in a wide range of $10 \mathrm{ppb}-10 \mathrm{ppm}$. In addition, the sensor demonstrates a stable detection performance at RT over 3 months.

2.2.3 Room temperature ammonia sensors. The $\mathrm{CuO}$ nanostructures are also suitable for $\mathrm{NH}_{3}$ sensing at RT. Sakthivel et $a l^{223}$ fabricated a flexible $\mathrm{NH}_{3}$ sensor on a polyethylene terephthalate substrate using $\mathrm{CuO}$ nano-rectangles, which were synthesized using a surfactant-free hydrothermal method. The flexible RT sensor made of the $\mathrm{CuO}$ nano-rectangles is effective
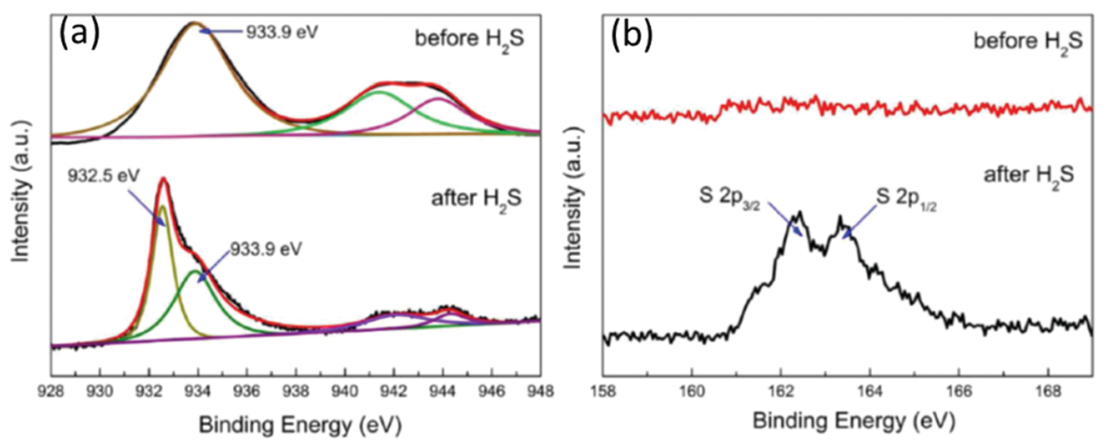

Fig. 12 (a) $\mathrm{Cu} 2 \mathrm{p}_{3 / 2}$ and (b) S 2p XPS spectra of porous $\mathrm{CuO}$ nanosheets before and after exposure to $\mathrm{H}_{2} \mathrm{~S} .{ }^{93}$ Copyright 2016 , American $\mathrm{Chemical}$ Society. 

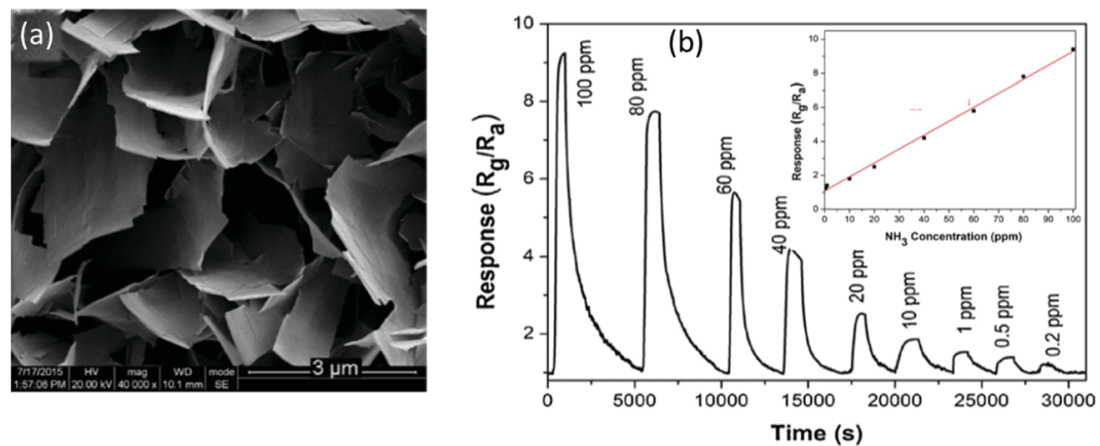

Fig. 13 (a) $\mathrm{SEM}$ image of network $\mathrm{CO}_{3} \mathrm{O}_{4}$ nano-sheet arrays; (b) response/recovery curves of the network $\mathrm{CO}_{3} \mathrm{O}_{4}$ nano-sheet array based sensor to different concentrations of $\mathrm{H}_{2} \mathrm{~S}$ at room temperature (the inset shows the response value). ${ }^{92}$ Copyright 2016, Elsevier.

for sensing ammonia even under different bending conditions as it exhibits identical response and response/recovery times. Furthermore, this flexible $\mathrm{NH}_{3}$ sensor exhibits both good stability and reproducibility in a three-month testing period. ${ }^{223}$

$\mathrm{Co}_{3} \mathrm{O}_{4}$ nanostructures ${ }^{92}$ have also been found to be effective for $\mathrm{NH}_{3}$ detection with fast response speeds at RT. Fig. 13a shows an image of a $\mathrm{Co}_{3} \mathrm{O}_{4}$ nano-sheet array network deposited on an alumina tube prepared using a hydrothermal method. The average sheet thickness of the $\mathrm{Co}_{3} \mathrm{O}_{4}$ nano-sheet is $39.5 \mathrm{~nm}$. $\mathrm{NH}_{3}$ molecules react with the surface chemisorbed $\mathrm{O}_{2}{ }^{-}$ions and form $\mathrm{N}_{2}$ and $\mathrm{H}_{2} \mathrm{O}$. As shown in Fig. 13b, the response time for the gas sensor is as short as $9 \mathrm{~s}$ for $0.2 \mathrm{ppm} \mathrm{NH}_{3}$ at RT. The sensor responds linearly to the concentrations of $\mathrm{NH}_{3}$ within a range between 1-100 ppm. It also exhibits good performance in terms of reproducibility, stability and selectivity to $\mathrm{NH}_{3}$ (compared to $\mathrm{H}_{2}, \mathrm{CO}, \mathrm{H}_{2} \mathrm{~S}$ and $\mathrm{C}_{2} \mathrm{H}_{5} \mathrm{OH}$ ). $3 \mathrm{D}$ hierarchical porous $\mathrm{Co}_{3} \mathrm{O}_{4}$ nanostructures ${ }^{103}$ were synthesized by Wu et al. using polystyrene spheres as the template. The average particle size is $20 \mathrm{~nm}$ and the specific surface area is $58.75 \mathrm{~m}^{2} \mathrm{~g}^{-1}$. The structures have macro-size pores, mesopores and plenty of irregular structural defects. The sensor made of these porous $\mathrm{Co}_{3} \mathrm{O}_{4}$ nanostructures exhibits a sensitivity of $146 \%$ (defined as $\left(\Delta R / R_{\mathrm{g}}\right) \times 100 \%$ ) to $100 \mathrm{ppm} \mathrm{NH}_{3}$, and has a fast response time of $2 \mathrm{~s}$. However, the recovery time is very long, e.g., longer than $1000 \mathrm{~s}^{103}$

Apart from $\mathrm{CuO}$ and $\mathrm{Co}_{3} \mathrm{O}_{4}$ nanostructures, $\mathrm{NiO}^{233,238}$ and $\mathrm{MnO}_{2}{ }^{239}$ were also used to make $\mathrm{RT} \mathrm{NH}_{3}$ gas sensors, although the response was found to be very slow. Applying special nanostructures can improve the responses of the sensors. For example, the hierarchical hollow nanospheres of $\alpha-\mathrm{MnO}_{2}$ composed of densely aligned nanowires were reported to exhibit an improved $\mathrm{NH}_{3}$ gas sensing sensitivity, and faster response and recovery compared with the standard $\alpha-\mathrm{MnO}_{2}$ nanowires. ${ }^{238}$ Doping with metal ions such as $\mathrm{Al}$ doped $\mathrm{NiO}$ was also reported as an effective route for improving the sensitivity and responses of the sensor operated at RT. ${ }^{233}$

2.2.4 Room temperature nitrogen dioxide sensors. P-type nanostructures have also been reported as good $\mathrm{RT} \mathrm{NO}_{2}$ sensing materials. When they are exposed to the oxidizing gases, such as $\mathrm{NO}_{x}$, the $\mathrm{NO}_{x}$ molecules are absorbed on the surface and form $\mathrm{NO}_{x}{ }^{-}$and holes, and the reactions of $\mathrm{NO}_{x}$ with the chemisorbed oxygen ions also increase the concentration of holes on the surface, which can be revealed from the reaction eqn (17)-(19). ${ }^{235}$ These reactions will widen the width of the accumulated hole layer on the surface of p-type SMONs, and cause the increase in conductivity of the sensors.

$$
\begin{aligned}
& \mathrm{NO}_{x(\text { gas })} \leftrightarrow \mathrm{NO}_{x}{ }^{-}{ }^{\text {ads })}+\mathrm{h}^{+} \\
& \mathrm{NO}_{\text {(gas) }}+\mathrm{O}_{2}{ }^{-} \text {(ads) } \leftrightarrow \mathrm{NO}_{2}{ }^{-}{ }_{\text {(ads) }}+\mathrm{O}^{-}{ }_{\text {(ads) }}+\mathrm{h}^{+} \\
& \mathrm{NO}_{2(\mathrm{ads})}+\mathrm{O}_{2}{ }^{-} \text {(ads) } \leftrightarrow \mathrm{NO}_{3}{ }^{-}{ }^{(a d s)}+2 \mathrm{O}^{-}{ }_{(\mathrm{ads})}+\mathrm{h}^{+}
\end{aligned}
$$

Self-assembled mesoporous $\mathrm{Cu}_{x} \mathrm{O}$ virus-like microspheres ${ }^{229}$ exhibited a high response of 28.4 and response/recovery times of $22 / 42 \mathrm{~s}$ to $4 \mathrm{ppm} \mathrm{NO}_{2}$ gas measured at RT. The good sensing performance of this special microstructure is attributed to the formation of hierarchical 3D nanostructures, micropores and large surface area for effective gas diffusion, the abundant surface oxygen vacancies and the heterojunctions at the interfaces between $\mathrm{CuO}$ and $\mathrm{Cu}_{2} \mathrm{O}$. The $\mathrm{RT} \mathrm{NO}_{2}$ gas sensors were also made using unique chain $\mathrm{Co}_{3} \mathrm{O}_{4}$ structures ${ }^{235}$ and self-assembled polycrystalline hexagonal NiO nanosheets. ${ }^{226}$ Because of the reduced grain boundaries, which minimizes the carriers' scattering at the interfaces during the chemisorption of $\mathrm{NO}_{2}$, these special $\mathrm{Co}_{3} \mathrm{O}_{4}$ nanostructures showed much better responses to $\mathrm{NO}_{2}$ than those made of the $\mathrm{Co}_{3} \mathrm{O}_{4}$ and $\mathrm{NiO}$ nanoparticles.

Apart from detecting $\mathrm{H}_{2} \mathrm{~S}, \mathrm{NH}_{3}$ and $\mathrm{NO}_{2}$, the RT sensors based on the p-type SMONs have also been used for detecting other types of gases. For example, a sensor made of $\mathrm{MnO}_{2}$ shows good sensing performance for acetaldehyde vapor, ${ }^{240}$ and at ambient temperature, $\beta-\mathrm{MnO}_{2}$ thin films were reported to have good sensing responses and fast response/recovery. The sensitivity was found to be $89 \%$ for sensing $10 \mathrm{ppm}$ acetaldehyde vapor, and the response and recovery times were found to be of $60 \mathrm{~s}$ and $11 \mathrm{~s}$, respectively. This sensor also showed good selectivity to acetaldehyde gas, compared with the other reducing gases such as acetone, benzene, diethylamine, ethanol, dimethylamine, 2-propanol, monomethylamine and ammonia. ${ }^{240}$ Sensors made of $\mathrm{Co}_{3} \mathrm{O}_{4}$ nanosheets were also reported to have very fast response and recovery of $15 / 20 \mathrm{~s}$ to $50 \mathrm{ppm} \mathrm{CO}$ and $\mathrm{CH}_{4} \cdot{ }^{234}$

The p-type $\mathrm{Cr}_{2} \mathrm{O}_{3}$ based gas sensor is normally operated at higher temperatures above $100{ }^{\circ} \mathrm{C}$, and there are few reports about the $\mathrm{Cr}_{2} \mathrm{O}_{3}$ based RT gas sensors. However, 3D cubic 
mesoporous $\mathrm{Cr}_{2} \mathrm{O}_{3}$ nanostructures were recently prepared and the sensor made of this nanostructure exhibits an enhanced sensitivity for detecting ethanol vapor at room temperature, which is much better than those of the dense $\mathrm{Cr}_{2} \mathrm{O}_{3}$ film. ${ }^{237}$ The response of the 3D cubic mesoporous $\mathrm{Cr}_{2} \mathrm{O}_{3}$ sensor is 13.0 to $1000 \mathrm{ppm}$ ethanol, whereas it is only 2.0 for the dense $\mathrm{Cr}_{2} \mathrm{O}_{3}$ film.

Although there are some reports on using the p-type SMONs in gas sensors operated at high temperature, these are much fewer compared to those on using n-type SMONs. The sensitivity of p-type SMON sensors is generally not as high as that of the n-type SMON sensors. Modification of the p-type SMONs using noble metal nanoparticles or metal ions is an effective route to further enhance the sensing performance, which will be discussed in Section 3.

\section{Room temperature gas sensors based on modified and composite semiconducting metal oxide nanostructures}

\subsection{Metal modified semiconducting metal oxide and gas sensors}

3.1.1 Gas sensors based on noble metal modified semiconducting metal oxide nanostructures. Due to their chemical sensitization and electronic sensitization, noble metals have been widely applied for surface modifications of SMONs, which has become one of the effective routes to improve their sensing performance, especially for the sensors operated at RT. ${ }^{241}$ This can be seen from the comparison of room temperature sensing properties between the pristine and noble metal modified SMONs as listed in Table 3. So far, the noble metals used to modify the SMON based gas sensors are mainly $\mathrm{Au},{ }^{242-246} \mathrm{Ag}^{247,248}$ $\mathrm{Pt}^{249,250}$ and $\mathrm{Pd}^{251-254}$ Nanoparticles of the noble metals are usually decorated onto surfaces of SMONs using the wet-chemical method, ${ }^{116}$ thermal vaporization, ${ }^{253}$ sputtering method ${ }^{255}$ and electrospinning technology. ${ }^{256}$ Many of these sensors have the commonly reported spill-over effect, ${ }^{241}$ which means that the active centers on the surface of the solid catalyst produce oxygen active species by adsorbing oxygen molecules. Due to this effect, more oxygen ions are formed on the surface of the SMONs. Being excellent active catalysts, noble metal nanoparticles can facilitate the adsorption of oxygen molecules and enhance the formation of oxygen ions by chemical reduction, which then spill onto the surface of the SMONs, thus increasing the concentration of oxygen ions. The target molecules can also be directly adsorbed onto these noble metal nanoparticles, and then they migrate onto the surface of the SMONs to react with the oxygen ions. These spill-over effects significantly enhance the sensing performance. In addition, these noble metal nanoparticles can also accelerate the transfer of electrons onto the surfaces of the SMONs. Therefore, both the chemical sensitization and electronic sensitization enhance the sensitivity and speed of the SMON-based sensors.
At RT, some gases such as $\mathrm{CO}$ and $\mathrm{H}_{2}$ are very difficult to detect using the sensors made of pristine SMONs. However, this problem might be solved by modifying the surface of these SMONs using noble metal nanoparticles. For example, Arunkumar et $a$ l. $^{113}$ prepared $\mathrm{ZnO}$ nanostar features using a hydrothermal route and then decorated these nanostars using Au nanoparticles with an average size of $\sim 5-6 \mathrm{~nm}$ as shown in Fig. 14a. The $\mathrm{ZnO}$ nanostars decorated with $3 \mathrm{wt} \%$ gold nanoparticles can enhance the response ( $\sim 15$ for $50 \mathrm{ppm} \mathrm{CO})$ and achieve very fast response/ recovery times $(\sim 8 / 15 \mathrm{~s})$ at $35{ }^{\circ} \mathrm{C} .{ }^{113}$ The selectivity of the sensor for Co sensing is excellent against the other interfering gases including methanol, ethanol, acetone and hydrogen. Fig. 14b shows the energy band diagrams of $\mathrm{ZnO}$ and $\mathrm{Au} / \mathrm{ZnO}$ nanostars before and after CO exposure. Due to the spillover effect, a nanoscale depletion region is formed at the interface between $\mathrm{Au}$ nanoparticles and $\mathrm{ZnO}$ as a result of strong electronic interactions, thus altering the height of the Schottky barrier. Therefore, the enhanced performance of the sensor operated at RT is attributed to the spillover effect. ${ }^{113}$

Choi et al. ${ }^{114}$ grew a network of $\mathrm{ZnO}$ nanowires using a vapor-liquid-solid method and then these nanowires were functionalized with Pd nanodots using a $\gamma$-ray radiolysis method, and the sensor made of these decorated nanowires shows an improvement of the sensing performance. This improvement is attributed to the electronic and chemical sensitizations from the Pd nanodots. ${ }^{114}$ Wang et al. ${ }^{115}$ reported a highly sensitive RT CO sensor based on $\mathrm{Pt} / \mathrm{SnO}_{2}$ porous nanostructures. The porous $\mathrm{SnO}_{2}$ nanostructures were synthesized using a solvothermal method, and Pt nanoparticles were then decorated onto the $\mathrm{SnO}_{2}$ using hexachloro-platinic acid. The sensor exhibits a good response with a value of 64.5 to $100 \mathrm{ppm} \mathrm{CO}$ at RT. It also shows good selectivity, compared to the other gases including $\mathrm{CO}, \mathrm{H}_{2}$, $\mathrm{N}\left(\mathrm{CH}_{3}\right)_{3}, \mathrm{NH}_{3}$ and $\mathrm{CH}_{4}$. Similarly, a RT $\mathrm{CO}$ gas sensor made of $\mathrm{Au} / \mathrm{In}_{2} \mathrm{O}_{3}$ composite nano-rods was fabricated, and showed a high response and fast response/recovery times (30/30 s to 100 ppm CO). ${ }^{244}$

Modification of SMONs by noble metals can not only enhance the sensitivity, but also significantly improve the selectivity and response/recovery speed. For example, a ZnO nanowire-based sensor modified with Pd nanoparticles exhibits both ultra-high sensitivity and very fast response and recovery. ${ }^{252,265}$ A Pd-modified ZnO nanowire-based RT nanosensor was prepared using electrochemical deposition by Lupan et al., ${ }^{252}$ and it exhibits very fast response/recovery times of 6.4/7.4 $\mathrm{s}$ and a super-high response value of 13100 to $100 \mathrm{ppm}_{2}$ as shown in Fig. 15a and b. This $\mathrm{H}_{2}$ sensor shows very good selectivity against the other gases such as $\mathrm{CO}, \mathrm{CH}_{4}$, ethanol and acetone. The sensor can be operated at very low current levels with ultra-low power consumption. ${ }^{252}$

Ultra-sensitive RT hydrogen gas sensors based on noble metal modified $\mathrm{SnO}_{2}$ have also been reported. For example, the sensor based on $\mathrm{Pt} / \mathrm{SnO}_{2}$ nanoparticles exhibits a super-high response (e.g., 10500 to $1000 \mathrm{ppm} \mathrm{H}_{2}$ ) at RT. ${ }^{249}$ Lee et al. ${ }^{253}$ reported a RT hydrogen sensor made of $\mathrm{Pd} / \mathrm{SnO}_{2}$ nanowires (as shown in Fig. 15c) prepared using a thermal evaporation method, and the sensor shows an ultra-high sensitivity of about $120000 \%$ (defined as $\left(\Delta R / R_{\mathrm{g}}\right) \times 100 \%$ ) to $10000 \mathrm{ppm}_{2}$ and a 
Table 3 Comparison of room temperature sensing properties of the noble metal modified semiconducting metal oxide nanostructures

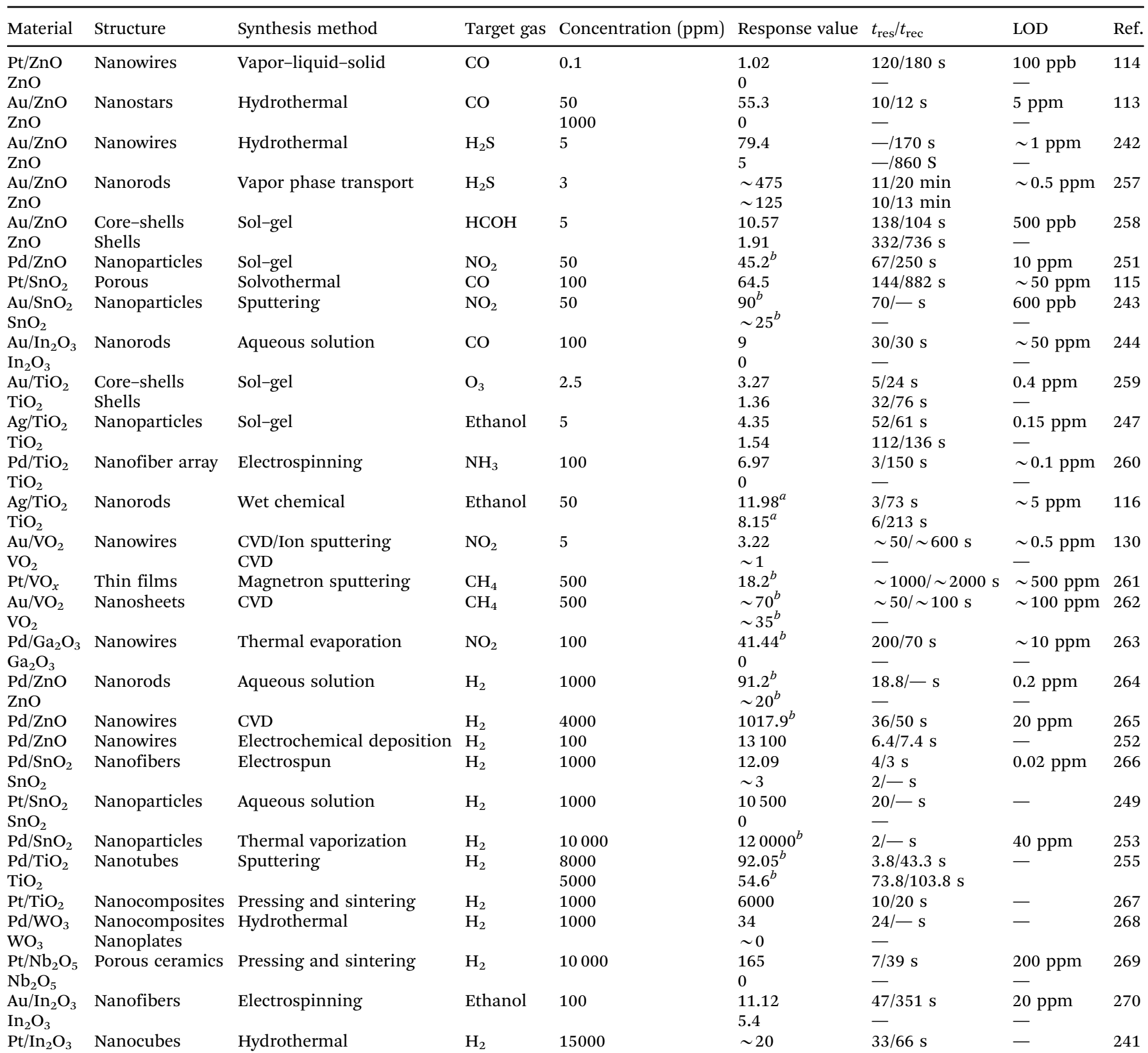

$C=$ concentration; $t_{\text {res }} / t_{\text {rec }}=$ response time/recovery time; LOD $=$ limit of detection; response is defined as $R_{\mathrm{a}} / R_{\mathrm{g}}$ (for reducing gases) or $R_{\mathrm{g}} / R_{\mathrm{a}}$ (for oxidizing gases), $R_{\mathrm{a}}$ : resistance of the sensor exposed to the reference, $R_{\mathrm{g}}$ : resistance of the sensor exposed to the target. ${ }^{a}$ Here the response is defined as $\Delta R / R_{\mathrm{g}}$ (for reducing gases) or $\Delta R / R_{\mathrm{a}}$ (for oxidizing gases), $\Delta R$ : the change in resistance. ${ }^{b}$ Here the response is defined as $\left(\Delta R / R_{\mathrm{g}}\right) \times 100 \%$ (for reducing gases) or $\left(\Delta R / R_{\mathrm{a}}\right) \times 100 \%$ (for oxidizing gases).

fast response time of $2 \mathrm{~s}$ as shown in Fig. 15d. The $\mathrm{Pd} / \mathrm{SnO}_{2}$ nanofibers $^{266}$ were also synthesized using an electrospinning method, and the sensor made of these nanofibers exhibits super-fast response/recovery times to $\mathrm{H}_{2}\left(4 / 3 \mathrm{~s}\right.$ to $\left.1000 \mathrm{ppm} \mathrm{H}_{2}\right)$ and an ultralow LOD of $20 \mathrm{ppb}$. The response of a sensor made of $\mathrm{Pt} / \mathrm{TiO}_{2}$ nanocomposites to $1000 \mathrm{ppm} \mathrm{H}_{2}$ in $\mathrm{N}_{2}$ was also reported as high as 6000 at RT, with short response/recovery times of only 10/20 s. ${ }^{267}$

Apart from the chemical sensitization and electronic sensitization, there are other mechanisms to enhance the sensing performance of the SMONs: for example, the formation of nano-scale Schottky type junctions between Au nanoparticles and $\mathrm{ZnO}$ nanorods and $\mathrm{Au}$ sulfidation with high concentrations of $\mathrm{H}_{2} \mathrm{~S}^{257}$ Hosseini et al. ${ }^{257}$ prepared $\mathrm{ZnO}$ nanorods using a vapor phase transport method, and found that $\mathrm{H}_{2} \mathrm{~S}$ sensing performance has been significantly enhanced at RT after the modification of the surface of $\mathrm{ZnO}$ nanorods with $\mathrm{Au}$ nanoparticles (see Fig. 16a). As shown in Fig. 16b and c, both high response (1270 to 6 ppm of $\mathrm{H}_{2} \mathrm{~S}$ ) and good $\mathrm{H}_{2} \mathrm{~S}$ selectivity of the $\mathrm{Au} / \mathrm{ZnO}$ nanorods have been achieved, which are much better than those of the pristine $\mathrm{ZnO}$ nanorods. 
(a)
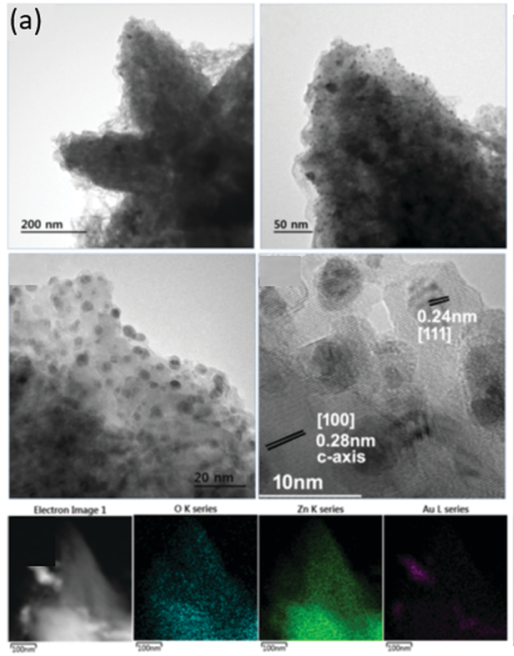

(b)

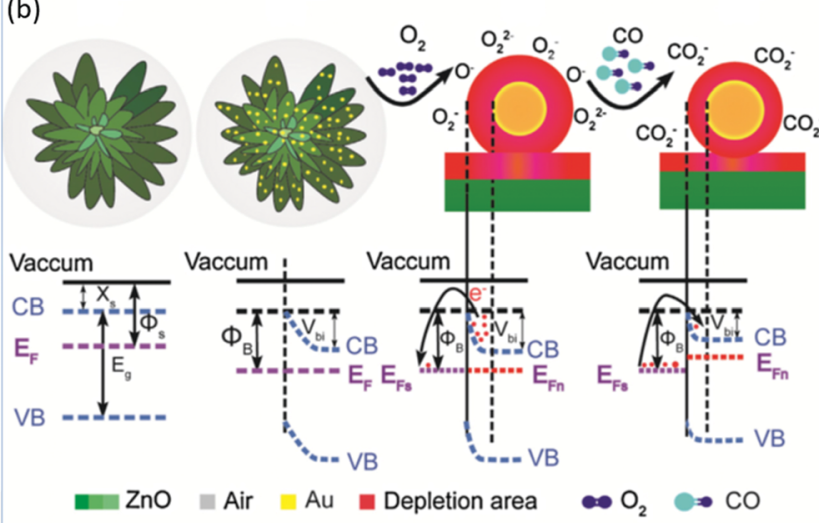

CB: Conduct band; VB: Valance band; $E_{F}$ : Fermi level; $E_{F n}$ : bulk Fermi level; $E_{\mathrm{Fs}}$ : surface Fermi level; $X_{\mathrm{s}}$ : electron affinity; $\Phi_{\mathrm{B}}$ : the energy to across the barrier; $V_{b i}$ : internal field; $\Phi_{s}$ : work function.

Fig. 14 (a) TEM images and element mapping of Au/ZnO nanostars; (b) energy band diagrams of ZnO and Au/ZnO nanostars before and after CO exposure. ${ }^{113}$ Copyright 2017, Elsevier.
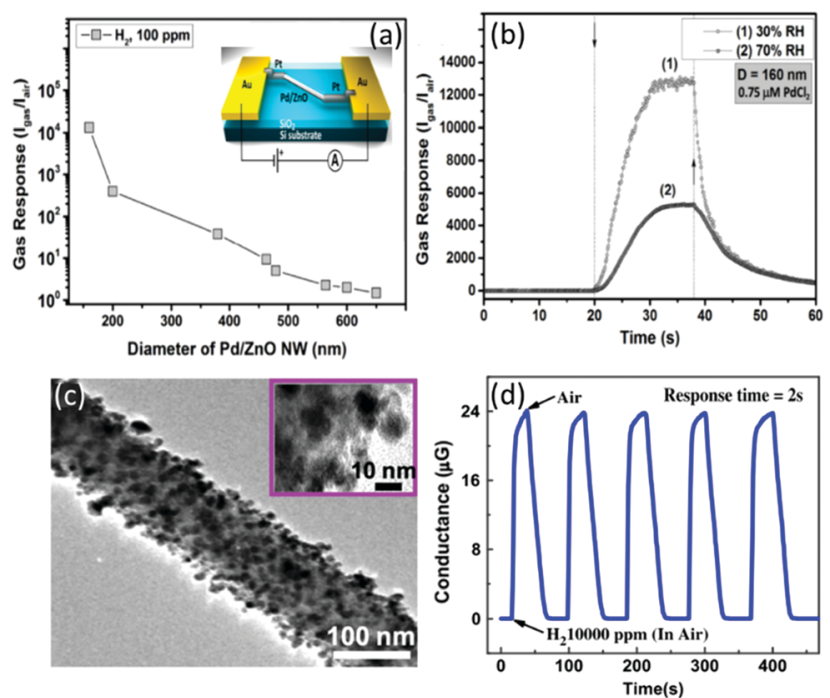

Fig. 15 (a) Responses of nanosensors based on single $\mathrm{Pd} / \mathrm{ZnO}$ nanowires with different diameters to $100 \mathrm{ppm}$ of $\mathrm{H}_{2}$ at $\mathrm{RT}$ and $30 \% \mathrm{RH}$ (the inset shows the schematic of the nanosensor device structure); (b) response of the $\mathrm{Pd} / \mathrm{ZnO}$ nanowire based sensor to $100 \mathrm{ppm}$ of $\mathrm{H}_{2}$ at $30 \%$ and $70 \% \mathrm{RH}$ at RT. ${ }^{252}$ Copyright 2018, Elsevier. (c) TEM image of 30 at $\% \mathrm{Pd} / \mathrm{SnO}_{2}$ nanofiber; (d) the response/recovery curves of the 30 at\% $\mathrm{Pd} / \mathrm{SnO}_{2}$ nanofiber based sensor for $\mathrm{H}_{2}$ gas. ${ }^{253}$ Copyright 2010, Elsevier.

In summary, due to the combined effects of chemical sensitization and electronic sensitization, noble metal nanoparticles and other nanostructures are suitable to be used to modify the SMONs in order to improve the sensing performance of the RT gas sensors. One significant improvement is the shortening of the response and recovery times, along with the enhanced response values and selectivity.

3.1.2 Gas sensors based on conventional metal ion doped semiconducting metal oxide nanostructures. Doping of metal ions in SMONs can increase the number of active sites and defects on the surface of SMON nanocrystals, and thus enhance the amount of oxygen species and increase the adsorbed gas molecules on the sensor's surface. Therefore, the gas sensing performance of the SMONs can be effectively improved by doping of metal ions including $\mathrm{Al}^{3+},{ }^{117,271} \mathrm{Cu}^{2+},{ }^{272,273} \mathrm{Zn}^{2+},{ }^{274}$ $\mathrm{Ni}^{2+},{ }^{275,276} \mathrm{Co}^{3+277,278} \mathrm{Fe}^{3+},{ }^{279} \mathrm{Mg}^{2+280}$ and $\mathrm{Sb}^{5+} \cdot{ }^{281}$ The recent key sensing applications of RT gas sensors using this method are summarized in Table 4.

The amount of dopant $\mathrm{Al}^{3+}$ ions was found to significantly affect the gas sensing properties of $\mathrm{NiO}$ nanosheets. ${ }^{117} \mathrm{Al}^{3+}$ doped NiO nanosheets have introduced many new oxygen vacancies due to aliovalent ion doping. Superoxide complexes such as $\mathrm{Ni}^{2+}-\mathrm{O}_{2}{ }^{-}$are easily formed on the surface of the $\mathrm{NiO}$ due to the existence of oxygen vacancies. As they are very active, they can significantly increase the sensitivity of the $\mathrm{NiO}$ nanosheets. Compared with those of the pure NiO nanosheets, the response of the $\mathrm{Al}$ doped $\mathrm{NiO}$ nanosheet based sensor to $\mathrm{NO}_{2}$ was enhanced up to 35 times at RT. Doping with metal ions including $\mathrm{Sb}, \mathrm{Cd}$, and Ce has also been proved to enhance the sensing properties of the $\mathrm{WO}_{3}$ nanoparticles to $\mathrm{NO}_{2}$ gas at RT. ${ }^{209}$ Among these, Sb-doped $\mathrm{WO}_{3}$ nanoparticles exhibit a 6.8 times higher response and much better selectivity than those of the undoped $\mathrm{WO}_{3}$ (as shown in Fig. 17). The enhancement mechanisms have been identified to be the increase in the number of oxygen vacancies on the surface of metal doped $\mathrm{WO}_{3}$ based on the analysis results from photoluminescence, Raman spectroscopy and XPS. ${ }^{209}$

The responses and recovery speeds of the sensor can be significantly improved by doping of metal ions into the SMONs, which is important for practical applications of the RT gas sensors. For example, a Zn-doped NiO dendritic nanostructure ${ }^{119}$ exhibits faster responses (5-8 times) and faster recovery (30-50 times) rates than those of the pure NiO dendritic crystals. A sensor based on $\mathrm{Mg}$-doped $\mathrm{ZnO}$ thin films on glass substrates deposited through a spray pyrolysis process $^{283}$ shows a much higher response (796 towards $100 \mathrm{ppm}$ of $\mathrm{NH}_{3}$ ) and faster response/recovery speeds (34/28 s) than those of the pure $\mathrm{ZnO}$ film measured at RT. 

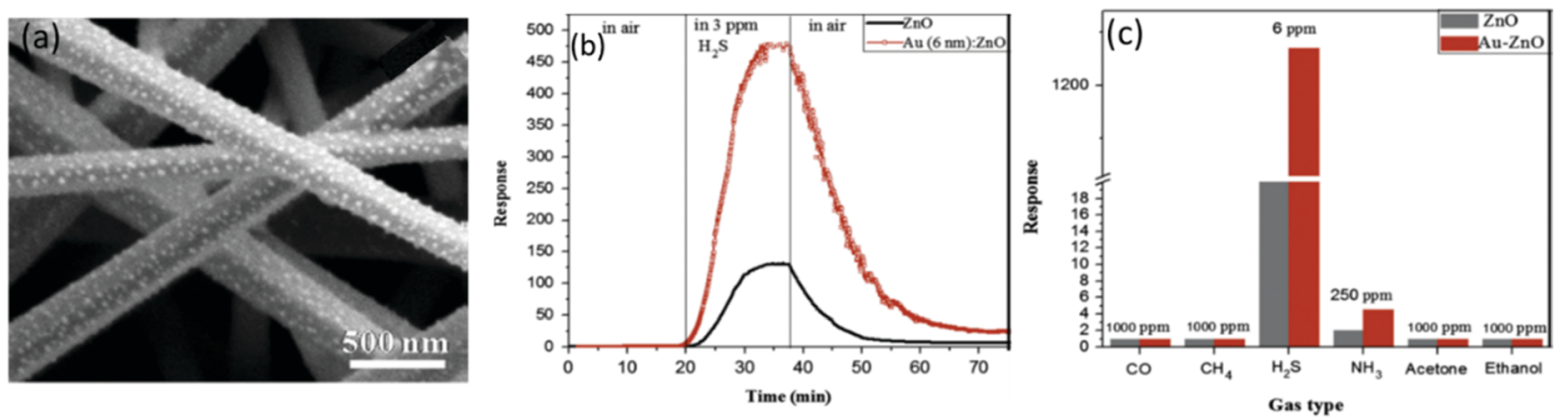

Fig. 16 (a) SEM image of Au/ZnO nanorods; (b) response/recovery curves of the Au/ZnO nanorod-based sensor and pristine ZnO nanorod-based sensor to $3 \mathrm{ppm} \mathrm{H}_{2} \mathrm{~S}$ at room temperature; (c) responses of the Au/ZnO nanorod-based sensor and pure $\mathrm{ZnO}$ nanorod-based sensor to different gases. ${ }^{257}$ Copyright 2015, Elsevier.

Table 4 Summary of room temperature sensors made of metal ion doped semiconducting metal oxide nanostructures and their sensing properties

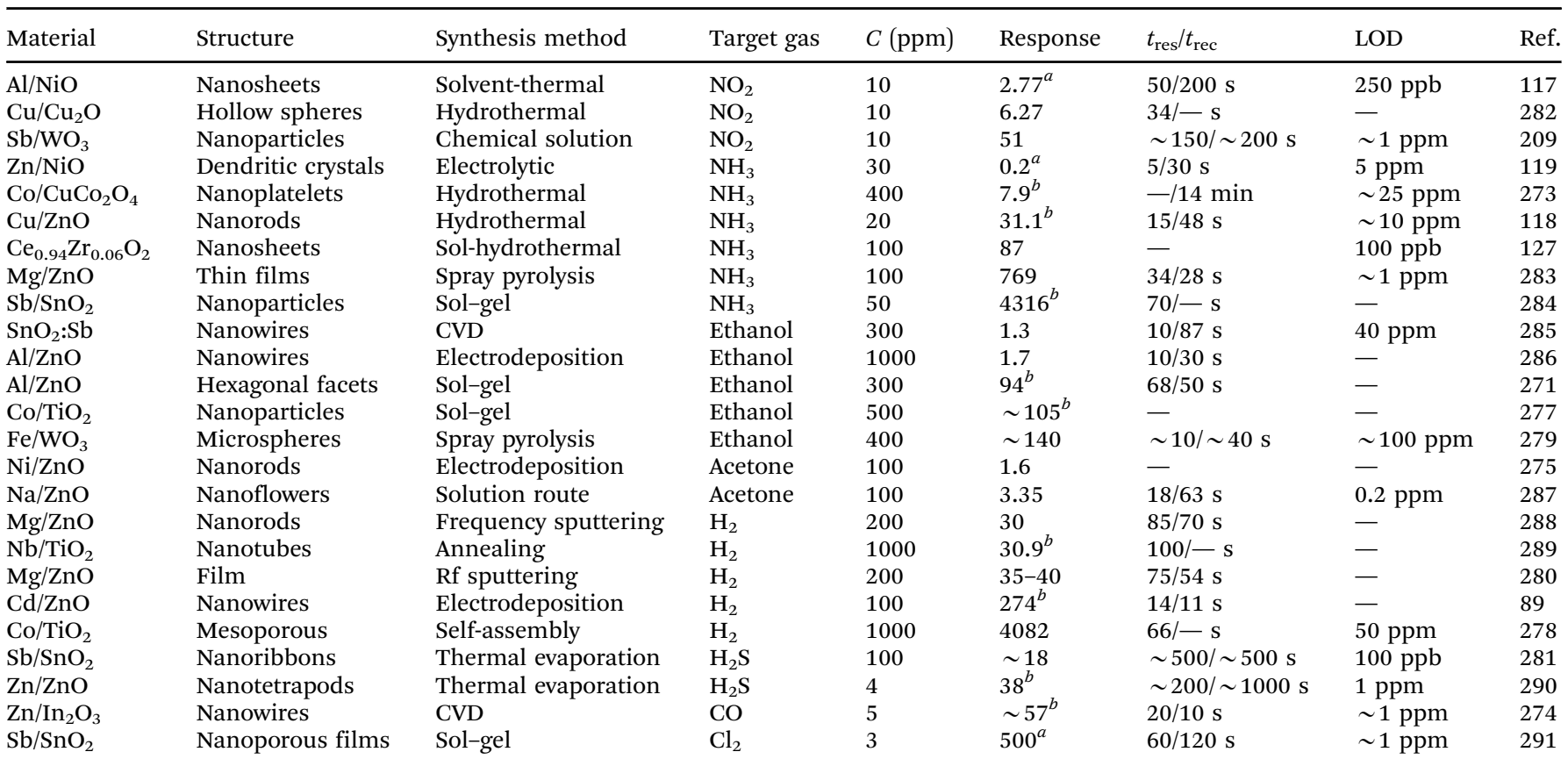

$C=$ concentration; $t_{\text {res }} / t_{\text {rec }}=$ response time/recovery time; LOD $=$ limit of detection; response is defined as $R_{\mathrm{a}} / R_{\mathrm{g}}$ (for reducing gases) or $R_{\mathrm{g}} / R_{\mathrm{a}}$ (for oxidizing gases), $R_{\mathrm{a}}$ : resistance of the sensor exposed to the reference, $R_{\mathrm{g}}$ : resistance of the sensor exposed to the target. ${ }^{a}$ Here the response is defined as $\Delta R / R_{\mathrm{g}}$ (for reducing gases) or $\Delta R / R_{\mathrm{a}}$ (for oxidizing gases), $\Delta R$ : the change in resistance. ${ }^{b}$ Here the response is defined as $\left(\Delta R / R_{\mathrm{g}}\right) \times 100 \%$ (for reducing gases) or $\left(\Delta R / R_{\mathrm{a}}\right) \times 100 \%$ (for oxidizing gases).

The sensor based on $\mathrm{Sb}$ doped $\mathrm{SnO}_{2}$ nanowires prepared using a chemical vapor deposition (CVD) method ${ }^{285}$ shows a typical p-type behavior, and a fast response time of about $10 \mathrm{~s}$ to 300 ppm ethanol at RT.

Adsorption of water vapor on the SMON surfaces is sometimes enhanced by metal ion doping, which seems a bad news for a gas sensor. However, for $\mathrm{RT} \mathrm{NH}_{3}$ gas sensors, this is especially beneficial as the $\mathrm{NH}_{3}$ molecules react with the absorbed $\mathrm{H}_{2} \mathrm{O}$ to form the $\mathrm{NH}_{4}^{+}$and $\mathrm{OH}^{-}$as is schematically shown in Fig. 18a. The electrolytic conductivity of $\mathrm{NH}_{4}^{+}$and $\mathrm{OH}^{-}$can significantly improve the sensitivity of sensors at RT. ${ }^{127,198}$ Porous $\mathrm{Ce}_{0.94} \mathrm{Zr}_{0.06} \mathrm{O}_{2}$ nano-sheets (see Fig. 18b) with an average thickness of $8 \mathrm{~nm}$ were prepared using a sol-hydrothermal process. ${ }^{127}$ Doping of $\mathrm{Zr}^{4+}$ ions into the $\mathrm{CeO}_{2}$ nanosheets enlarges the specific surface areas $\left(185.4 \mathrm{~m}^{2} \mathrm{~g}^{-1}\right)$ and increases the pore volumes $\left(0.51 \mathrm{~cm}^{3} \mathrm{~g}^{-1}\right)$. These modifications result in a much higher sensitivity (e.g. 87 to $100 \mathrm{ppm} \mathrm{NH}_{3}$ ) at RT (see Fig. 18c), better selectivity and a very low LOD of $100 \mathrm{ppb}$.

The $\mathrm{H}_{2}$ sensors made of metal ion doped SMONs were reported to exhibit high responses, although their response/recovery times were also reported to be longer than those made of the noble ion modified SMON-based RT $\mathrm{H}_{2}$ gas sensors. ${ }^{278,280,288,289}$ For example, Co-doped $\mathrm{TiO}_{2}$ sensors exhibit an ultra-high response with a value of 4082 to $1000 \mathrm{ppm} \mathrm{H}_{2}$ gas, although the response time is $66 \mathrm{~s}$, which is quite slow for detection of highly explosive $\mathrm{H}_{2} \cdot{ }^{278}$

In summary, compared to those sensors made of noble metal nanoparticle modified SMONs, the improved effects of gas sensors made of the metal ion modified SMONs are not as significant. 

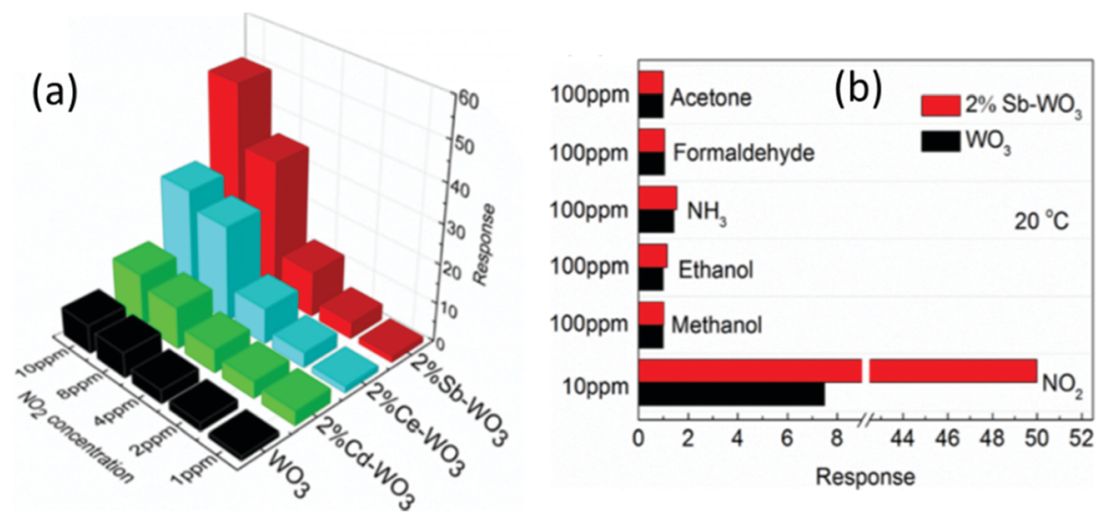

Fig. 17 (a) Responses of sensors made of $2 \%-\mathrm{Sb}-\mathrm{WO}_{3}, 2 \%-\mathrm{Ce}-\mathrm{WO}_{3}$ and $2 \%-\mathrm{Cd}-\mathrm{WO}_{3}$ to different concentrations of $\mathrm{NO}_{2}$; (b) responses of sensors made of $2 \%-\mathrm{Sb}-\mathrm{WO}_{3}$ to different gases. ${ }^{209}$ Copyright 2017, American Chemical Society.
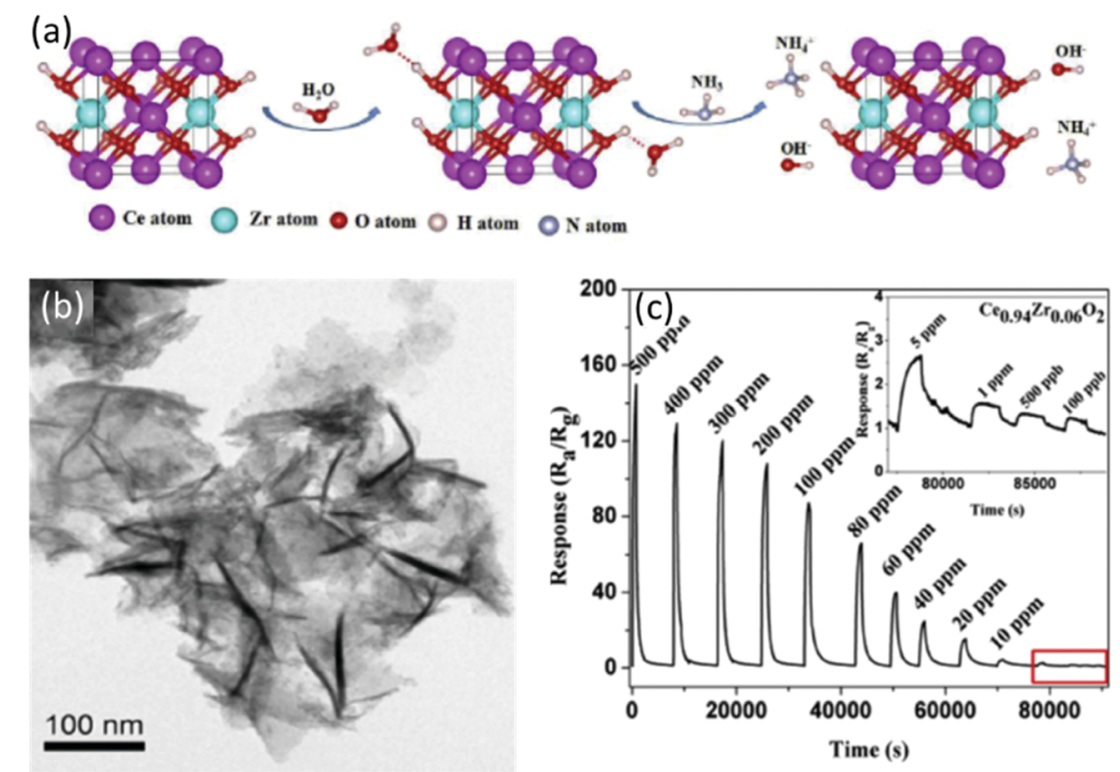

Fig. 18 (a) Schematic diagrams of the $\mathrm{NH}_{3}$ reaction mechanism on the surface of $\mathrm{Ce}_{0.94} \mathrm{Zr}_{0.06} \mathrm{O}_{2}$ nano-sheets; (b) $\mathrm{TEM}_{\text {image of porous } \mathrm{Ce}}$.94 $\mathrm{Zr} \mathrm{r}_{0.06} \mathrm{O}_{2}$ nano-sheets; (c) response/recovery curves of the porous $\mathrm{Ce}_{0.94} \mathrm{Zr}_{0.06} \mathrm{O}_{2}$ nanosheet based sensor to $\mathrm{NH}_{3}{ }^{127}$ Copyright 2018, Elsevier.

However, the SMONs can be modified simultaneously by both metal ions and noble metal nanoparticles, which will combine the advantages of both metal ions and noble metal nanoparticles.

\subsection{Composites of semiconducting metal oxide nanostructures and gas sensors}

3.2.1 Mechanism for enhanced sensing performance. The RT gas sensing performance of the SMONs operated at RT can be improved by integrating them with other metal oxides or carbon nanomaterials. For example, heterojunctions can be formed at the interfaces of different metal oxides or at the interfaces between SMONs and carbon nanomaterials, as schematically illustrated in Fig. 19. At the p-n heterojunctions between p-type and n-type SMONs, the electrons at the conduction band states of n-type SMONs will transfer to the lower energy valence band states of p-type SMONs across the interface. Thus, a depletion layer will form at the $\mathrm{p}-\mathrm{n}$ heterojunction due to recombination of electrons and holes.
For the $n-n$ heterojunction, the electrons will be transported at the interfaces between different materials due to the differences in their conduction band states. As a result, a depletion layer forms at the surface of n-type SMONs with higher-energy conduction band states due to the loss of electrons. At the same time, an accumulation layer forms at the surface of n-type SMONs with lower-energy conduction band states due to the accumulation of electrons.

For the $\mathrm{p}-\mathrm{p}$ heterojunction, the major charge carriers are holes. Due to the differences of valence band energies of different SMONs, the charge carriers are transported from one p-type SMON (which has a higher energy valence band state) to the other p-type SMON (which has a lower-energy valence band state). Therefore, a hole depletion region is formed at the surface of the first SMONs (with higher energy valence band state) and a hole accumulation region is formed at the surface of the second SMONs (with a lower energy valance band state) as shown in Fig. 19. 


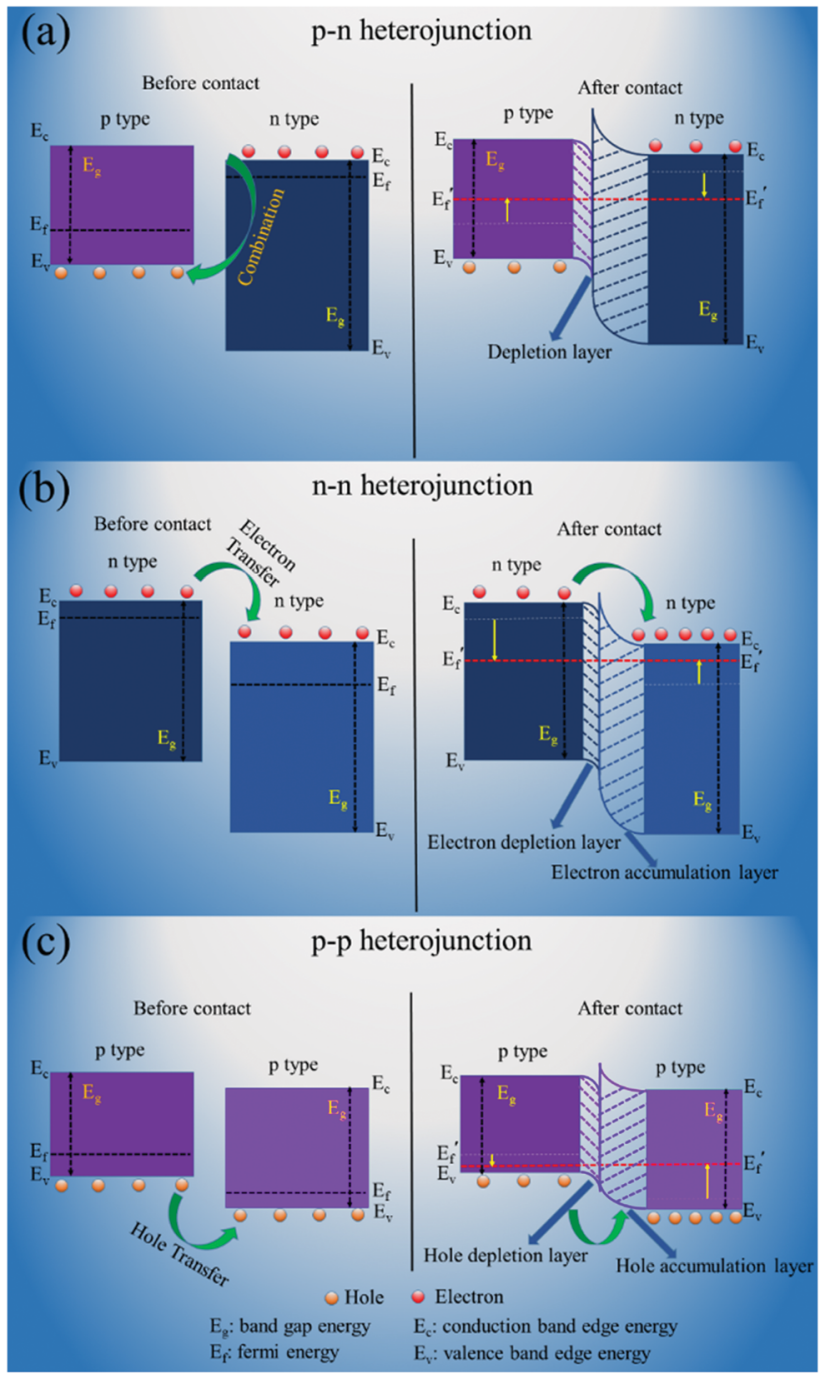

Fig. 19 Schematic illustrations of the energy band structures at heterojunction interfaces of different types of heterojunctions: (a) $p-n$ junction, (b) $n-n$ junction and (c) $p-p$ junction.

These formed heterojunctions can effectively accelerate the transport of electrons. On the other hand, these heterojunctions can also enhance oxygen adsorption, therefore, abundant oxygen vacancies are formed on the surfaces of the SMON composites, which can provide new active sites for sensing reactions. In addition, the composites of SMONs often contain numerous mesopores, which are beneficial to the adsorption and desorption of gas molecules. All of these effects will improve the sensitivity and response rates of the RT gas sensors made of composites of the SMONs.

3.2.2 Gas sensors based on composites of semiconducting metal oxide nanostructures and other metal oxides. Composite oxides of the SMONs have been proposed to combine two or more semiconducting metal oxides together to enhance the gas sensing performance at RT. The examples of composites include n-type SMONs with n-type SMONs (e.g. $\mathrm{Fe}_{2} \mathrm{O}_{3} / \mathrm{ZnO}{ }^{292}$ $\left.\mathrm{ZnO} / \mathrm{SnO}_{2}{ }^{293} \mathrm{In}_{2} \mathrm{O}_{3} / \mathrm{SnO}_{2}{ }^{134,294}\right)$, p-type SMONs with n-type SMONs (e.g. NiO-ZnO, ${ }^{120} \mathrm{CuO} / \mathrm{TiO}_{2},{ }^{121} \mathrm{In}_{2} \mathrm{O}_{3} / \mathrm{CuO},{ }^{122} \mathrm{NiO} / \mathrm{WO}_{3}{ }^{295}$ ) and p-type SMONs with p-type SMONs (e.g. $\mathrm{Cu}_{2} \mathrm{O} / \mathrm{Co}_{3} \mathrm{O}_{4}{ }^{296}$ and $\mathrm{NiO} /$ $\left.\mathrm{CuO}^{131}\right)$. In addition, composites formed by integrating the SMONS with non-semiconductor metal oxide (e.g. $\mathrm{K}_{2} \mathrm{O} / \mathrm{In}_{2} \mathrm{O}_{3}{ }^{129}$ and $\mathrm{CaO} / \mathrm{SnO}_{2}{ }^{297}$ ) have also been reported.

Table 5 summarizes the recently reported RT gas sensors made of composite oxides of the SMONs and/or other metal oxides. For these composite oxides, a number of oxygen vacancies are formed on both the surfaces and interfaces, which provides many active sites for the gas sensing reactions. Plenty of defects will also be formed at the interfaces of nanostructures in different metal oxide nanoparticles. In addition, the heterojunctions are usually formed at the interfaces of different metal oxides, which can effectively accelerate the electron transfer between different particles, thus accelerating the response speed of the sensor. Besides, the composite oxides often contain lots of mesoporous structures due to the accumulation of nanoparticles, which are beneficial to the adsorption and desorption of gas molecules. These factors can improve the sensing performance of the sensor made of these composite oxides, especially for the sensitivity and response speed. Most sensors made of the composite oxides exhibit very fast response times at RT. For example, the gas sensor based on the nanocomposite of $\mathrm{CuO} / \mathrm{TiO}_{2}{ }^{121}$ shows a very fast response time of $2 \mathrm{~s}$ at $\mathrm{RT}$, and the sensor based on plate-like $\mathrm{NiO} / \mathrm{WO}_{3}$ nanocomposites ${ }^{295}$ exhibits excellent sensitivity and ultrafast response/recovery times $(2.5 / 1.1 \mathrm{~s})$ to $\mathrm{NO}_{2}$ at RT.

The composite of mesoporous $\operatorname{In}_{2} \mathrm{O}_{3} / \mathrm{CuO}$ multijunction nanofibers ${ }^{122}$ was prepared using an electrospinning method by Zhou et al. The composite is composed of the $\operatorname{In}_{2} \mathrm{O}_{3}$ nanoparticles and $\mathrm{CuO}$ nanoparticles (with a molar ratio of $\mathrm{Cu}$ : In of $100: 5)$. The TEM images shown in Fig. 20a and b indicate that the composite has many mesoporous structures with diameters from 1.9 to $22.9 \mathrm{~nm}$ and large specific surface areas $\left(48.7 \mathrm{~m}^{2} \mathrm{~g}^{-1}\right)$. The $\mathrm{In}_{2} \mathrm{O}_{3}$ nanoparticles are surrounded by the $\mathrm{CuO}$ nanoparticles to form numerous $\mathrm{p}-\mathrm{p}$ homojunctions and $\mathrm{p}-\mathrm{n}$ heterojunctions. ${ }^{122}$ XPS analysis indicates that the ratio of oxygen defect/vacancy on its surface is as high as $45.4 \%$. Due to the existence of larger specific and mesoporous surface areas and the availability of chemisorbed oxygen and the formation of heterojunctions, the sensor has a much higher response to $\mathrm{NH}_{3}$ than that of a $\mathrm{CuO}$ nanostructured sensor. The response time is also very short with a value lower than $8 \mathrm{~s}$ for $\mathrm{NH}_{3}$ from 0.3 to $100 \mathrm{ppm}$ (see Fig. 20c). The selectivity and LOD are also significantly improved due to the addition of $\operatorname{In}_{2} \mathrm{O}_{3}$.

$\mathrm{Xu}$ et al. ${ }^{134}$ prepared composites of $\mathrm{In}_{2} \mathrm{O}_{3} / \mathrm{SnO}_{2}$ nanorod heterostructures (see Fig. 20d and e) using electrospinning to improve the oxygen deficiency and carrier density of $\mathrm{SnO}_{2}$. The $\mathrm{SnO}_{2}$ nanoparticles are distributed along with the $\operatorname{In}_{2} \mathrm{O}_{3}$ to form numerous heterojunctions and defects at their interfaces. The availability of oxygen vacancies on the surface and at the interface has been verified using XPS. ${ }^{134}$ Compared with pure $\mathrm{SnO}_{2}$ nanorods, $\mathrm{In}_{2} \mathrm{O}_{3} / \mathrm{SnO}_{2}$ nanorods (with the atom ratio of $25: 0.3$ of $\mathrm{Sn}: \mathrm{In}$ ) exhibit 11 times higher response to $\mathrm{NO}_{x}$ with a very faster response time of $4.67 \mathrm{~s}$ and a lower LOD with a value of $0.1 \mathrm{ppm}$ (see Fig. 20f).

$\mathrm{NiO} / \mathrm{CuO}$ nanocomposites with a $\mathrm{NiO}: \mathrm{CuO}$ molar ratio of $1: 1$ have been synthesized using a hydrothermal method, ${ }^{131}$ 
Table 5 Room temperature sensing properties of composites of semiconducting metal oxide nanostructures and other metal oxides

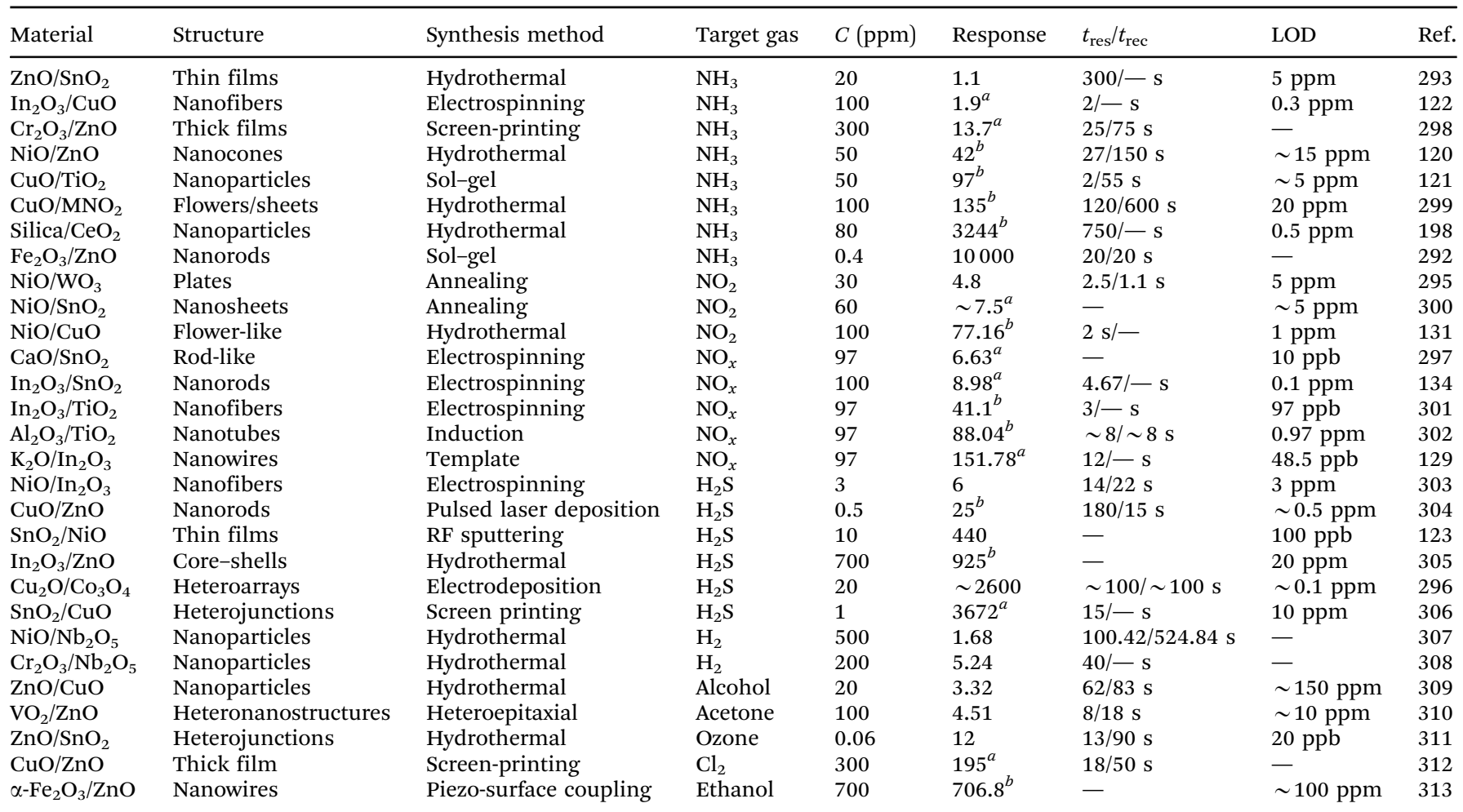

$C=$ concentration; $t_{\text {res }} / t_{\text {rec }}=$ response time/recovery time; LOD $=$ limit of detection; response is defined as $R_{\mathrm{a}} / R_{\mathrm{g}}$ (for reducing gases) or $R_{\mathrm{g}} / R_{\mathrm{a}}$ (for oxidizing gases), $R_{\mathrm{a}}$ : resistance of the sensor exposed to reference, $R_{\mathrm{g}}$ : resistance of the sensor exposed to target. ${ }^{a}$ Here the response is defined as $\Delta R / R_{\mathrm{g}}$ (for reducing gases) or $\Delta R / R_{\mathrm{a}}$ (for oxidizing gases), $\Delta R$ : the change in resistance. ${ }^{b}$ Here the response is defined as $\left(\Delta R / R_{\mathrm{g}}\right) \times 100 \%$ (for reducing gases) or $\left(\Delta R / R_{\mathrm{a}}\right) \times 100 \%$ (for oxidizing gases).

and the nanocomposites are consisted of $\mathrm{CuO}$ nanoparticles and NiO nanoplates with lots of mesoporous structures. The $\mathrm{p}-\mathrm{p}$ heterojunctions formed at the interfaces of $\mathrm{NiO}$ and $\mathrm{CuO}$ accelerate the electron transfers from $\mathrm{NiO}$ to $\mathrm{CuO}$, thus resulting in a faster response. The mesoporous hierarchical nanostructures with much larger surface areas facilitate effective adsorption and desorption of gas molecules on the surface. Thus, the sensor exhibits an ultra-fast response speed ( $2 \mathrm{~s}$ to $100 \mathrm{ppm}$ $\mathrm{NO}_{2}$ ) to $\mathrm{NO}_{2}$ at RT.

Kaur et al. ${ }^{123}$ prepared a $\mathrm{SnO}_{2} / \mathrm{NiO}$ thin film using a sputtering method and then fabricated a $\mathrm{RT}_{2} \mathrm{~S}$ sensor. As shown in Fig. 21a, the sensor exhibits a high response with a value of 440 to $10 \mathrm{ppm} \mathrm{H}_{2} \mathrm{~S}$, which is 9 and 415 times higher than those made of pure $\mathrm{SnO}_{2}$ and $\mathrm{NiO}$ films, respectively. Selectivity has also been improved using the $\mathrm{SnO}_{2} / \mathrm{NiO}$ thin film (see Fig. 21b). The formation of $\mathrm{p}-\mathrm{n}$ heterojunctions using the $\mathrm{p}$-type $\mathrm{NiO}$ and n-type $\mathrm{SnO}_{2}$ semiconductors apparently changes the resistance of the composite film. The enhanced response of the $\mathrm{SnO}_{2}: \mathrm{NiO}$ nanocomposite sensor is mainly due to the modifications of $\mathrm{p}-\mathrm{n}$ junctions resulted from the conversion of $\mathrm{NiO}$ to metallic NiS. However, the recovery time is quite long ( $>20000 \mathrm{~s}$, see Fig. 21c).

Wang et al. ${ }^{198}$ reported a composite oxide sensor using $8 \%$ silica modified $\mathrm{CeO}_{2}$ nanomaterials (see Fig. 21d) synthesized using a sol-hydrothermal route. The addition of silica increases the specific surface areas $\left(83.75 \mathrm{~m}^{2} \mathrm{~g}^{-1}\right)$ and decreases the crystal sizes. Due to the existence of silica, lots of $\mathrm{OH}^{-}$species are formed on the surface of the sensor, which facilitate the adsorption of water, and the water molecules react with $\mathrm{NH}_{3}$ to generate $\mathrm{NH}^{4+}$ and $\mathrm{OH}^{-}$and decrease the electrical resistance of the sensor. As shown in Fig. 21e and $\mathrm{f}$, the $\mathrm{NH}_{3}$ gas sensing performance of the sensor is significantly enhanced as compared to that of pure $\mathrm{CeO}_{2}$ at RT. Its response value reaches $3244 \%$ (defined as $\left(\Delta R / R_{\mathrm{g}}\right) \times 100 \%$ ) for $80 \mathrm{ppm}$ of $\mathrm{NH}_{3}$ gas.

The composites of alkali metal oxide and SMONs have also been reported as an effective way to enhance the sensitivity for sensing acidic gases, such as $\mathrm{NO}_{x} \cdot{ }^{129}$ As shown in the gas sensing mechanism of mesoporous $\mathrm{K}_{2} \mathrm{O}-\mathrm{In}_{2} \mathrm{O}_{3}$ nanowires in Fig. 22 the alkali metal oxides on the surfaces can serve as the alkaline center, which is beneficial to the adsorption and diffusion of acidic gases. Using mesoporous Santa Barbara Amorphous Material-16 (SBA-16) as a template, Rehman et al. ${ }^{129}$ prepared highly crystalline mesoporous $\mathrm{K}_{2} \mathrm{O}-\mathrm{In}_{2} \mathrm{O}_{3}$ nanowires with diameters of $4-8 \mathrm{~nm}$ and pore sizes of 3-5 $\mathrm{nm}$. The composite nanowires possess numerous chemisorbed oxygen and alkaline centers on their surfaces. The gas sensing performance of the mesoporous $\mathrm{K}_{2} \mathrm{O}-\mathrm{In}_{2} \mathrm{O}_{3}$ composite nanowires has been significantly improved with the addition of $\mathrm{K}_{2} \mathrm{O}$. Its response is 151.78 to $97 \mathrm{ppm}$ of $\mathrm{NO}_{x}$, the response time is decreased to $12 \mathrm{~s}$, and the LOD is as low as $48.5 \mathrm{ppb}$ at RT. ${ }^{129}$

Most reported composite SMON sensors exhibit higher response values and faster response time than those of the single phase SMONs. Many active sites can be generated in the 

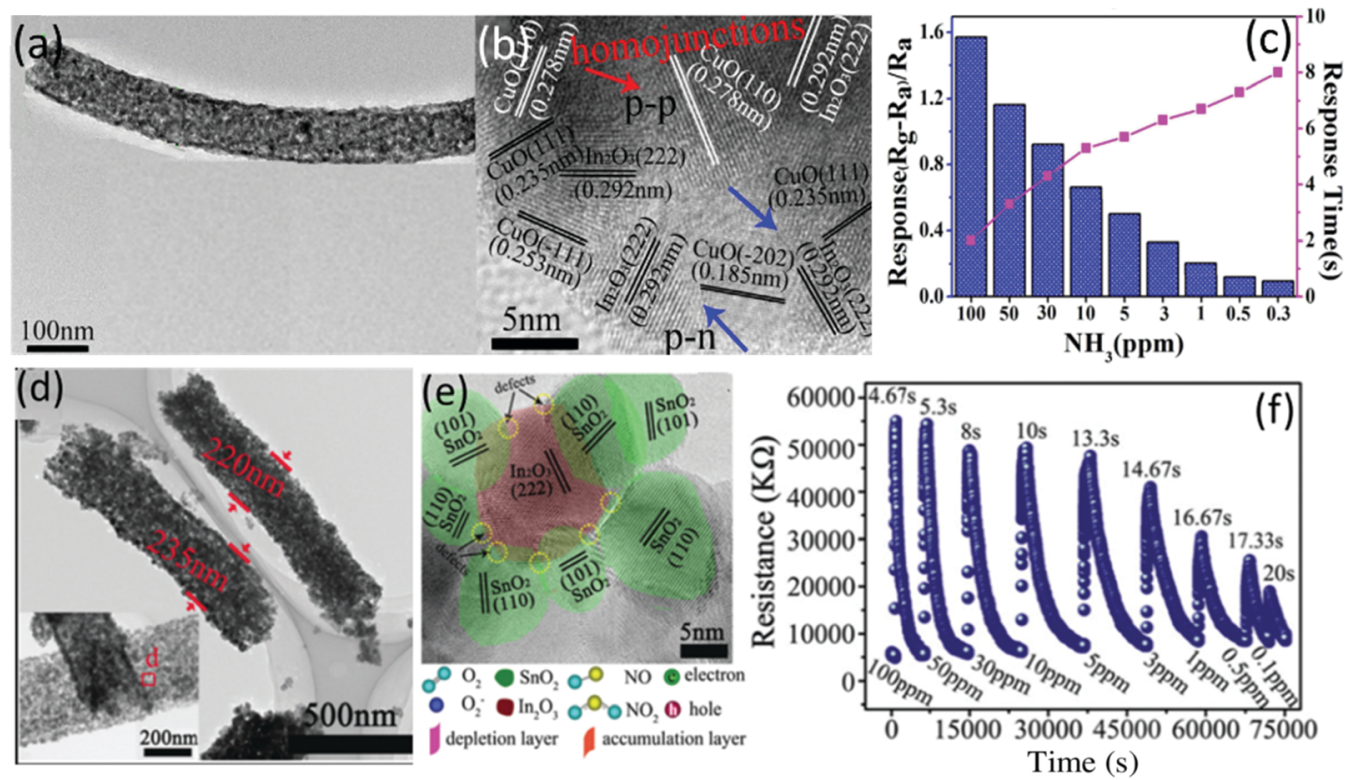

Fig. 20 (a) TEM and (b) HRTEM images of mesoporous $\ln _{2} \mathrm{O}_{3} / \mathrm{CuO}$ composite multijunction nanofibers, (c) response values and times of the sensor to different concentrations of $\mathrm{NH}_{3}{ }^{122}$ Copyright 2018, Elsevier. ( $d$ and e) TEM images of composite of $\mathrm{In}_{2} \mathrm{O}_{3} / \mathrm{SnO}_{2}$ nanorod heterostructures; ( $f$ ) response/ recovery curves of the sensor to different concentrations of $\mathrm{NO}_{x} \cdot{ }^{134}$ Copyright 2015 , Royal Society of Chemistry.
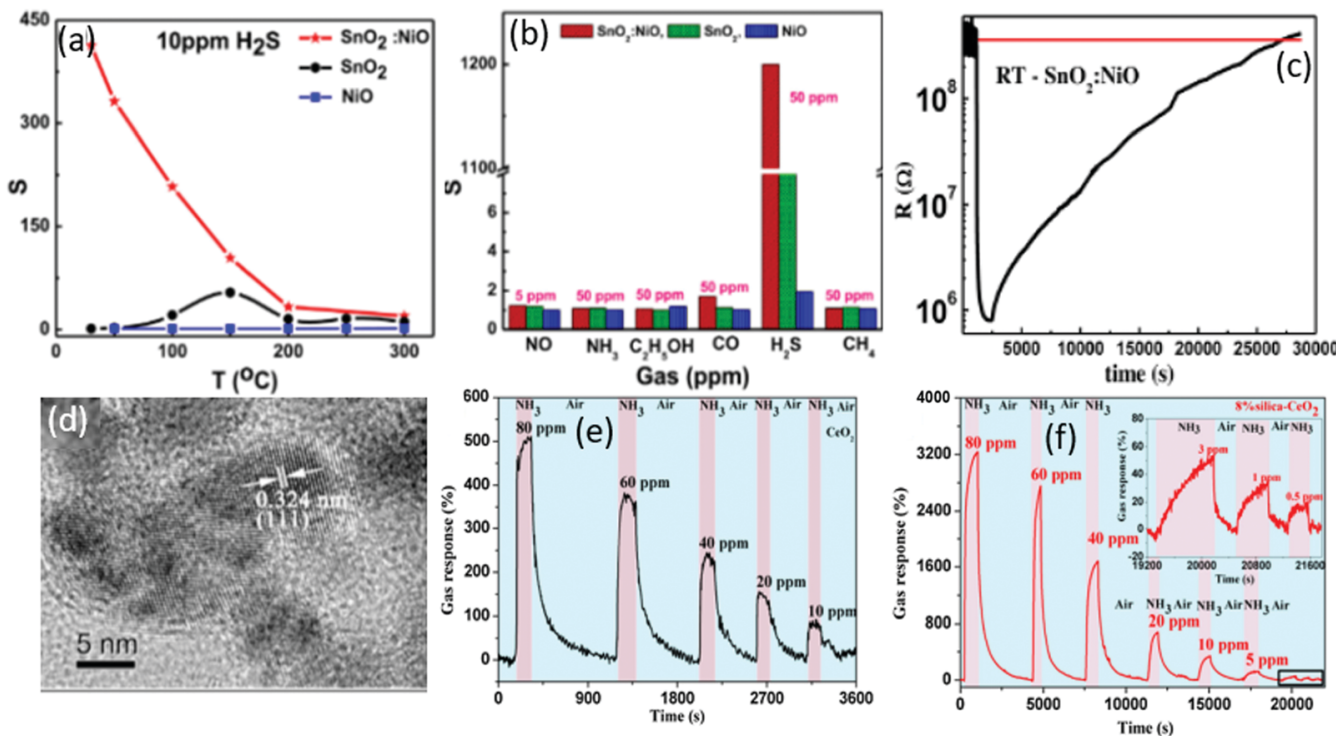

Fig. 21 (a) Response histogram of a $\mathrm{SnO}_{2} / \mathrm{NiO}$ thin film-based room temperature gas sensor to different gases; (b) response values of the $\mathrm{SnO} \mathrm{O}_{2} / \mathrm{NiO}$ thin film-based RT gas sensor to different concentrations of $\mathrm{H}_{2} \mathrm{~S}$; (c) response/recovery curve to 100 ppm $\mathrm{H}_{2} \mathrm{~S}^{123}$ Copyright 2017, Elsevier. (d) TEM image of $8 \%$ silica- $\mathrm{CeO}_{2}$; (e) response/recovery curves of the pure $\mathrm{CeO}_{2}$-based sensor to $\mathrm{NH}_{3}$; (f) response/recovery curves of the $8 \%$ silica-CeO - -based sensor to $\mathrm{NH}_{3}{ }^{198}$ Copyright 2017, Elsevier.

composite SMONs, such as oxygen vacancies, heterojunctions, defects and mesopores, which can effectively enhance the sensing performance. The composite SMON can be further modified by noble metal nanoparticles, which takes advantage of the chemical sensitization and electronic sensitization of noble metal nanoparticles on the composite SMONs.

3.2.3 Gas sensors based on composites of semiconducting metal oxide nanostructures and carbon nanomaterials. Carbon nanomaterials including carbon nanotubes and graphene have been demonstrated as promising sensing materials. ${ }^{314}$ However, the carbon nanomaterial-based gas sensors generally show low sensitivity and slow response/recovery speeds at RT. The synergistic effect by combining SMONs and carbon nanomaterials can improve the sensing performance because (1) conductivity is significantly improved; (2) many active sites (such as oxygen functional groups, vacancies and defects) are formed at the interfaces. Because of the fast carrier transport kinetics, the composites of the SMONs combined with carbon 


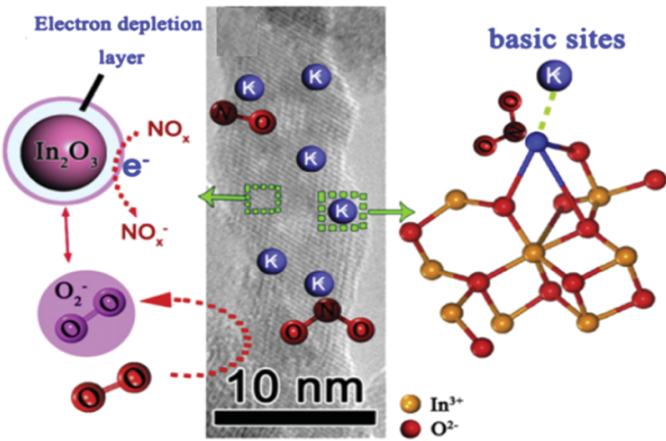

Fig. 22 Gas sensing mechanism to $\mathrm{NO}_{x}$ of mesoporous $\mathrm{K}_{2} \mathrm{O}-\mathrm{In}_{2} \mathrm{O}_{3}$ nanowires. ${ }^{129}$ Copyright 2016, Elsevier.

nanomaterials show enhanced sensitivity and fast response/ recovery at $\mathrm{RT}$.

Table 6 summarizes the RT sensing properties of some composite nanostructures of the SMONs and carbon nanomaterials. Among these carbon materials, the composites of reduced graphene oxide (rGO) and SMONs are the most investigated ones for gas sensor applications. rGO has been used to combine with various types of SMONs for enhancing the gas sensing properties, and these SMONs include $\mathrm{Fe}_{2} \mathrm{O}_{3},{ }^{315} \mathrm{In}_{2} \mathrm{O}_{3},{ }^{316} \mathrm{ZnO},{ }^{317,318} \mathrm{Fe}_{3} \mathrm{O}_{4},{ }^{319} \mathrm{SnO}_{2},{ }^{320-324}$ $\mathrm{WO}_{3}{ }^{325} \mathrm{NiO} / \mathrm{SnO}_{2}{ }^{326}$ and $\mathrm{Pd} / \mathrm{TiO}_{2}{ }^{327}$

The RT $\mathrm{NO}_{2}$ sensor fabricated using $\mathrm{rGO} / \alpha-\mathrm{Fe}_{2} \mathrm{O}_{3}{ }^{126}$ exhibits a response value of 3.86 to $5 \mathrm{ppm} \mathrm{NO}_{2}$, which is better than that of pure rGO, whose response is 1.38. In addition, it has significantly shorter response/recovery times of 32/1432 s, compared with those of the sensors made of pure rGO (2059 s, $40130 \mathrm{~s}$ ). Dong et al. ${ }^{342}$ reported a nanocomposite combining $\alpha-\mathrm{Fe}_{2} \mathrm{O}_{3}$ nanospheres and reduced graphene oxide nanosheets as shown in Fig. 23a. The $\alpha-\mathrm{Fe}_{2} \mathrm{O}_{3}$ nanospheres with a diameter from 40 to $50 \mathrm{~nm}$ were grown on the surface of graphene nanosheets using a hydrothermal method, and the improved sensing performance of the sensor made of this composite was attributed to the synergistic effect of a- $\mathrm{Fe}_{2} \mathrm{O}_{3} / \mathrm{rGO}$ and large specific surface areas. In addition to the interaction of $\mathrm{NO}_{2}$ with $\mathrm{O}_{2}{ }^{-}$on the surface of a- $\mathrm{Fe}_{2} \mathrm{O}_{3}, \mathrm{NO}_{2}$ molecules also capture the electrons from the rGO to form $\mathrm{NO}_{2}{ }^{-}$, thus resulting in an increased hole density, and a decreased resistance of rGO. Therefore, the a- $\mathrm{Fe}_{2} \mathrm{O}_{3} / \mathrm{rGO}$ nanocomposites exhibit a much higher response to $\mathrm{NO}_{2}$ at RT than that of either the pure rGO or a- $\mathrm{Fe}_{2} \mathrm{O}_{3}$ nanospheres. Its LOD for the $\mathrm{NO}_{2}$ gas is as low as 0.18 ppm (see Fig. 23b), and good selectivity has been demonstrated against $\mathrm{CO}, \mathrm{HCHO}, \mathrm{H}_{2} \mathrm{~S}, \mathrm{NH}_{3}$ and $\mathrm{C}_{2} \mathrm{H}_{5} \mathrm{OH}$ (see Fig. 23c).

Besides the good conductivity of carbon materials, the improved interfacial electron transfer is another key factor for improving the SMONs' sensing performance by adding carbon nanomaterials. For example, an $\mathrm{RT} \mathrm{NH}_{3}$ gas sensor was fabricated using $\mathrm{SnO}_{2}$ nanorods/rGO composite nanostructures, ${ }^{347}$ and the sensor shows fast response/recovery with times of 8/13 $\mathrm{s}$ to $200 \mathrm{ppm} \mathrm{NH}_{3}$ at RT. Fig. 23d shows the band gap diagrams of $\mathrm{SnO}_{2}$-nanorods/rGO nanostructures before and after the combination of two nanostructures. The $\mathrm{p}-\mathrm{n}$ heterojunctions are formed at the interface between the rGO and $\mathrm{SnO}_{2}$ as rGO is a p-type semiconductor. The Fermi energy of rGO is higher than that of $\mathrm{SnO}_{2}$, so electrons can be transported to $\mathrm{SnO}_{2}$ from rGO, which can further enhance the adsorption of $\mathrm{NH}_{3}$ molecules to improve the gas sensing performance.

Formation of heterojunction structures was found to contribute to the sensing performance of the $\mathrm{ZnO}$ nanowall/rGO nanocomposite, ${ }^{135}$ in which the $\mathrm{ZnO}$ nanowalls were vertically grown on the rGO thin film using a soft solution process to obtain a heterojunction structure as shown in Fig. 23e. At the interfaces between the rGO and $\mathrm{ZnO}$ nanowalls of the $\mathrm{p}-\mathrm{n}$ heterostructures, the Fermi energy of rGO is higher than that of $\mathrm{ZnO}$. Therefore, the charge transfer from rGO layers to the conduction band of $\mathrm{ZnO}$ enhances the adsorption of $\mathrm{NO}_{2}$ molecules. If compared with the sensor made of pure $\mathrm{ZnO}$ nanowalls, the sensor made of the $\mathrm{ZnO} / \mathrm{rGO}$ heterojunction shows a higher response and shorter response/recovery times to $\mathrm{NO}_{2}$ at RT (see Fig. 23f). ${ }^{135}$

Another key mechanism for the improved gas sensing performance for the SMONs/rGO composite is the increased oxygen vacancy on the SMONs, such as in the $\mathrm{SnO}_{2}-\mathrm{rGO}$ composite. ${ }^{330}$ Due to the $\mathrm{p}-\mathrm{n}$ heterojunction formed at the interfaces between n-type $\mathrm{SnO}_{2}$ and p-type rGO, electrons can easily transfer from the $\mathrm{SnO}_{2}$ into the rGO to form abundant oxygen vacancies on the surface of $\mathrm{SnO}_{2}$. These oxygen vacancies are the electronic charge carriers to increase the conductivity of the composite, and they can adsorb oxygen molecules to form more active sites, which will capture electrons from $\mathrm{SnO}_{2}$ and form the oxygen ions to react with target gas molecules. The oxygen vacancy also facilitates the fast adsorption of the $\mathrm{NO}_{2}$ molecules onto the surface of $\mathrm{SnO}_{2}$. All these factors contribute to the excellent sensing properties of $\mathrm{SnO}_{2} / \mathrm{rGO}$ composite based sensors to $\mathrm{NO}_{2}$ gas at RT.

However, the recovery of these composites of SMONs with carbon materials is very slow, although UV-light illumination can be used to enhance a fast and complete recovery. For example, rGO-CeO $\mathrm{O}_{2}$ hybrids were synthesized by anchoring small $\mathrm{CeO}_{2}$ nanocrystals onto rGO nanosheets using a solvothermal method, and the RT $\mathrm{NO}_{2}$ gas sensor made of this hybrid showed a full recovery time of several hours. ${ }^{371}$ However, the recovery time can be significantly reduced to within $258 \mathrm{~s}$ with the aid of UV-light illumination. This UV light enhancement will be further discussed in Section 3.3.

Fig. 24a shows that an ultra-fast response time for sensing of $\mathrm{H}_{2} \mathrm{~S}$ gas (which is the fastest reported in the literature with a value of 2s to $50 \mathrm{ppm}$ of $\mathrm{H}_{2} \mathrm{~S}$ ) can be achieved using a sensor made of $\mathrm{SnO}_{2}$ quantum wires/rGO nanosheets. ${ }^{4}$ The electronic interactions of $\mathrm{SnO}_{2}$ quantum wires and rGO nanosheets can enhance the electron transport, ${ }^{4}$ and increase the response and recovery speed. In addition, the sensor made of the $\mathrm{SnO}_{2}$ quantum wires/rGO nanosheets shows a response of 33 with an excellent selectivity against other types of gases including $\mathrm{NH}_{3}, \mathrm{SO}_{2}, \mathrm{NO}_{2}$ and ethanol at $\mathrm{RT}$ as shown in Fig. 24b. In this composite material, the ultrathin and one-dimensional microstructure of $\mathrm{SnO}_{2}$ quantum wires is effective in providing large surface areas for gas adsorption and reactions.

The sensors made of composites integrating the rGO with p-type SMONs (such as $\mathrm{CuO}$ and $\mathrm{Co}_{3} \mathrm{O}_{4}$ ) also show enhanced sensing performance. The RT gas sensor based on the $\mathrm{CuO} / \mathrm{rGO}$ 
Table 6 Room temperature sensing properties of composite nanostructures of semiconducting metal oxide nanostructures and carbon nanomaterials

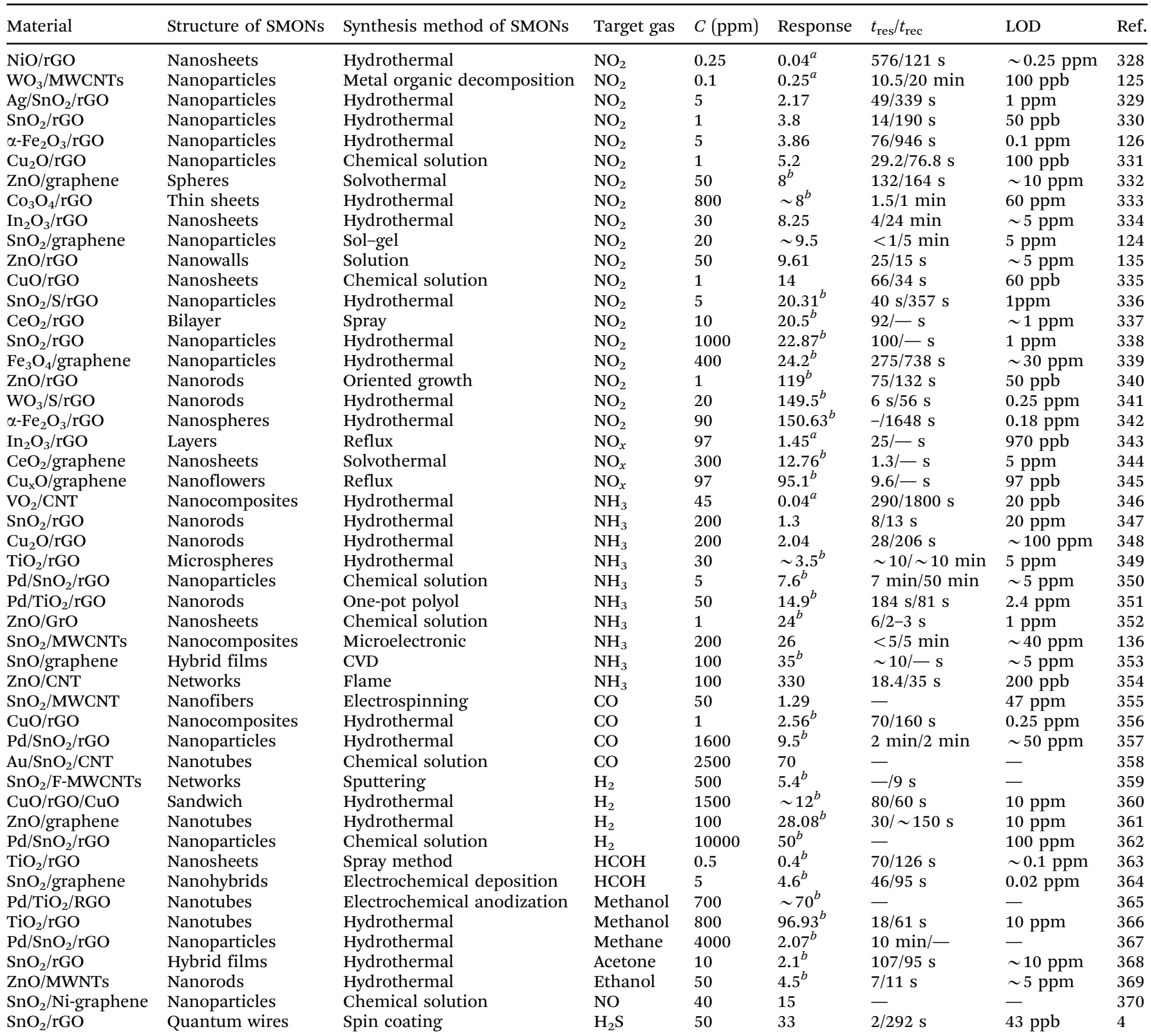

$C=$ concentration; $t_{\text {res }} / t_{\mathrm{rec}}=$ response time/recovery time; LOD $=$ limit of detection; response is defined as $R_{\mathrm{a}} / R_{\mathrm{g}}$ (for reducing gases) or $R_{\mathrm{g}} / R_{\mathrm{a}}$ (for oxidizing gases), $R_{\mathrm{a}}$ : resistance of the sensor exposed to the reference, $R_{\mathrm{g}}$ : resistance of the sensor exposed to the target. ${ }^{a}$ Here the response is defined as $\Delta R / R_{\mathrm{g}}$ (for reducing gases) or $\Delta R / R_{\mathrm{a}}$ (for oxidizing gases), $\Delta R$ : the change in resistance. ${ }^{b}$ Here the response is defined as $\left(\Delta R / R_{\mathrm{g}}\right) \times 100 \%$ (for reducing gases) or $\left(\Delta R / R_{\mathrm{a}}\right) \times 100 \%$ (for oxidizing gases).

nanohybrids can detect a low-concentration of $\mathrm{NO}_{2}$ with a highly sensitive response (14 to $1 \mathrm{ppm} \mathrm{NO}_{2}$ ) and fast response/recovery times (66/34 s), mainly due to the formation of large surface areas and enhanced carrier transfers between the $\mathrm{CuO}$ and $\mathrm{NO}_{2}$ molecules. ${ }^{335}$ Furthermore, Ding et al. reported that the integration of chemically functionalized three-dimensional graphene oxide hydro-gels with metal-organic framework derived $\mathrm{Co}_{3} \mathrm{O}_{4}$ nanostructures achieved ultra-high response, short response time and distinct cross-selectivity. ${ }^{372}$

The composite of SMONs with carbon nanotubes (CNT) such as SWCNTs $/ \mathrm{SnO}_{2}{ }^{373}$ and $\mathrm{CNT} / \mathrm{SnO}_{2}{ }^{374-377}$ can also improve the sensing performance. ${ }^{378}$ The $\mathrm{p}-\mathrm{n}$ junctions formed between the SMONs and p-type MWCNTs are responsible for their enhanced gas sensing responses. For example, Srivastava et al. ${ }^{124}$ reported an $\mathrm{RT} \mathrm{NO}_{2}$ gas sensor based on multi-walled carbon nanotubes/ $\mathrm{SnO}_{2}$. The sensor exhibits a much higher response to $\mathrm{NO}_{2}$ than the pure $\mathrm{SnO}_{2}$ based sensor operated at RT. Due to the good conductivity of the CNTs and the high porosity of the $\mathrm{ZnO}$ networks, ${ }^{354}$ the response value of $2 \%$ CNTs/ZnO networks has been increased from 37 to 330 when the sensor was exposed to $100 \mathrm{ppm} \mathrm{NH}_{3}$ at RT (see Fig. 24c). The response/recovery times are decreased from $58 / 61 \mathrm{~s}$ to $18 / 35 \mathrm{~s}$, respectively. The sensor 


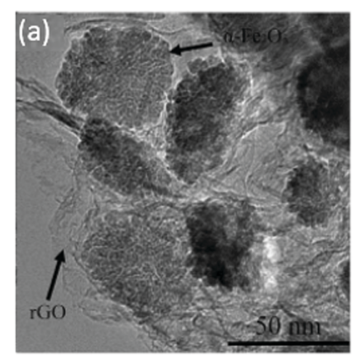

(d)

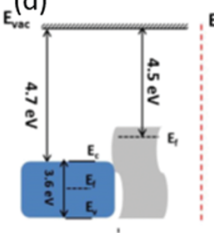

\begin{tabular}{ll|l}
$\mathrm{SnO}_{2}$ nanorod & $\mathrm{rGO}$
\end{tabular}

electron $\mathrm{SnO}_{2}$

rGo

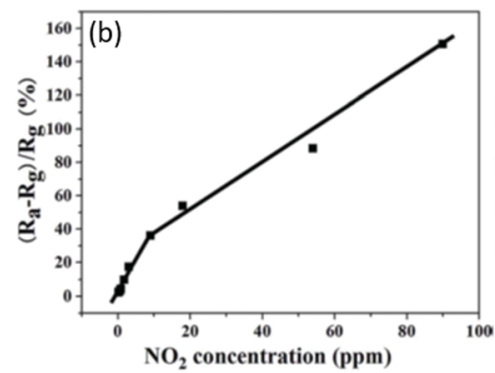

(e)

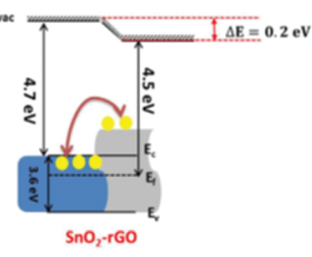

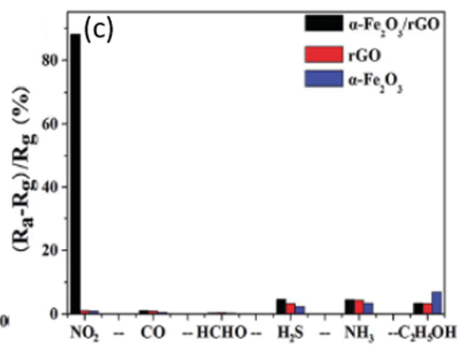

Fig. 23 (a) TEM image of the $\alpha-\mathrm{Fe}_{2} \mathrm{O}_{3} / \mathrm{rGO}$ composite; (b) response values of the sensor based on $\alpha-\mathrm{Fe}_{2} \mathrm{O}_{3} / \mathrm{rGO}$ at different $\mathrm{NO}_{2}$ concentrations; (c) response histogram of the sensor to different gases. ${ }^{342}$ Copyright 2014, Royal Society of Chemistry. (d) Band gap diagrams of $\mathrm{SnO}_{2}$-nanorods/ reduced graphene oxide nanostructures before and after combination. ${ }^{347}$ Copyright 2017, Elsevier. (e) TEM image of the $\mathrm{ZnO} / \mathrm{rGO}$ composite; (f) response/recovery curves to $50 \mathrm{ppm} \mathrm{NO}$ of the sensor based on a-ZnO/rGO or $\mathrm{ZnO} .{ }^{135}$ Copyright 2017, Elsevier.
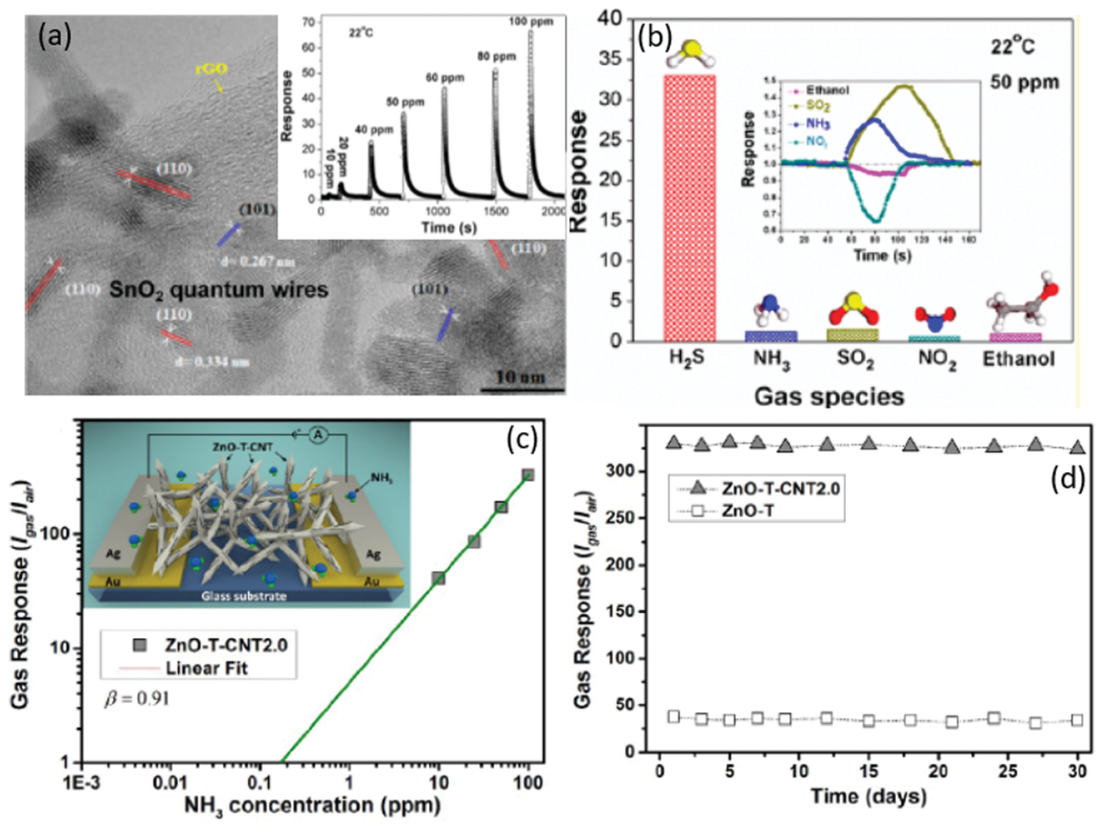

Fig. 24 (a) TEM image of the $\mathrm{SnO}_{2}$ quantum wires/rGO nanosheets, the inset shows the response/recovery of the sensor based on $\mathrm{SnO} \mathrm{O}_{2}$ quantum wires/rGO nanosheets for different $\mathrm{H}_{2} \mathrm{~S}$ concentrations; (b) response histogram of the $\mathrm{SnO}_{2}$ quantum wires/rGO nanosheet based sensor to different gases. ${ }^{4}$ Copyright 2016, American Chemical Society. (c) Response values at different concentrations of $\mathrm{NH}_{3}$ gas for $2 \% \mathrm{CNTs} / \mathrm{ZnO}$ networks (the inset presents the sensor structure); (d) long-time stability of the RT gas sensors to 100 ppm of $\mathrm{NH}_{3}$ at $30 \% \mathrm{RH}^{354}$ Copyright 2017, American Chemical Society.

also displays good stability at RT over a duration of one month (see Fig. 24d). In addition, the CNTs can serve as acceptors for the released electrons, which are injected into the SMONs from the target gases. $\mathrm{A}_{2} \mathrm{~S}$ gas sensor made of nanocomposites of $\mathrm{SnO}_{2}$ quantum dots/MWCNTs reported by Liu et al. ${ }^{379}$

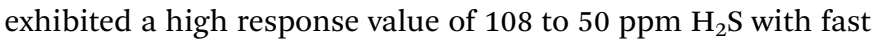
response/recovery times of 23/44 s.
Adding noble metal nanoparticles into the composite is another method to further improve the gas sensing performance of SMONs/rGO composites. Being good catalysts, these noble metal nanoparticles can enhance the catalytic efficiency by creating extra new sites to promote fast adsorption of gas molecules and decrease the reaction temperatures by lowering the activation energy of the gas sensing reactions. For example, 
Shojaee et al $^{357}$ reported that the nanocomposites of Pd loaded $\mathrm{SnO}_{2}$ and partially reduced graphene oxide showed good performance to detect $\mathrm{CO}$ from 50 to $1600 \mathrm{ppm}$ with fast response and recovery times at $26{ }^{\circ} \mathrm{C}$. The $\mathrm{Pd} / \mathrm{SnO}_{2} / \mathrm{rGO}$ based $\mathrm{H}_{2}$ sensor ${ }^{362}$ and $\mathrm{Pd} / \mathrm{TiO}_{2} / \mathrm{rGO}_{\text {based }} \mathrm{NH}_{3}$ sensor ${ }^{351}$ prepared using a chemical solution method exhibited higher sensitivity and faster response time than those of the $\mathrm{SnO}_{2} / \mathrm{rGO}$ and $\mathrm{TiO}_{2} / \mathrm{rGO}$ sensors. In addition to Pd nanoparticles, Ag nanoparticles were also used to improve the RT sensing performance of $\mathrm{SnO}_{2}-\mathrm{rGO}$ hybrids for detection of $\mathrm{NO}_{2}$. The $\mathrm{Ag} / \mathrm{SnO}_{2} / \mathrm{rGO}$ hybrid composites exhibit much shorter response time and recovery time (49 s and $339 \mathrm{~s}$ ) to $5 \mathrm{ppm}$ $\mathrm{NO}_{2}$ at RT than the $\mathrm{SnO}_{2}-\mathrm{rGO}$ hybrids (415 s and $\left.740 \mathrm{~s}\right)^{329}$.

Similar to those cases for the rGO/SMON composites, modifications of the CNT/SMON composites using noble metal nanoparticles can also improve their gas sensing properties. For example, CNT/Au/ $\mathrm{SnO}_{2}$ composites were synthesized by homogeneously coating $\mathrm{SnO}_{2}$ and $\mathrm{Au}$ nanocrystals onto the CNTs, and then applied to detect $\mathrm{CO}$ gas at RT. ${ }^{358}$ The sensor made of the $\mathrm{CNT} / \mathrm{Au} / \mathrm{SnO}_{2}$ composites shows better selectivity to $\mathrm{CO}$ than that made of the $\mathrm{CNT} / \mathrm{SnO}_{2}$ composite. It has a high sensitivity of 70 when exposed to $2500 \mathrm{ppm}$ of $\mathrm{CO}$, and shows higher sensitivity values to $\mathrm{CO}$ gases with different concentrations varying from 500 to $2500 \mathrm{ppm}$ when compared with those of the $\mathrm{Au} / \mathrm{SnO}_{2}$ composites.

In brief, due to the high conductivity of carbon nanomaterials and the formation of heterojunctions, the response/recovery times of the composites of SMONs with carbon nanomaterials are much shorter than those from the pure SMONs, although it seems that the increase of response values achieved using these composites might be less significant.

\subsection{Room temperature photoactivated gas sensors based on semiconducting metal oxide nanostructures}

Generally, many of the SMON-based gas sensors are needed to heat up for the best gas sensing performance, which is inconvenient in many situations. Instead, UV light can be used to activate and enhance the gas sensing performance of SMONS operated at RT. ${ }^{380}$ The reported SMONs whose sensing properties can be improved by UV light are mainly $\mathrm{ZnO},{ }^{381-385} \mathrm{In}_{2} \mathrm{O}_{3},{ }^{386,387}$ $\mathrm{TiO}_{2}{ }^{388,389}$ and $\mathrm{SnO}_{2},{ }^{390,391}$ which have been summarized in Table 7. The SMONs can absorb UV light to produce photo-generated electrons and holes. The photo-generated electrons on the surface can enhance the chemisorption of oxygen molecules to form more $\mathrm{O}_{2}{ }^{-}$as listed in eqn (20) and (21), ${ }^{392}$ thus can enhance the sensitivity and response/recovery times of the SMONs under UV light.

$$
\begin{gathered}
h \nu \rightarrow \mathrm{h}^{+}+\mathrm{e}^{-} \\
\mathrm{O}_{2}+\mathrm{e}^{-}{ }_{(h \nu)} \rightarrow \mathrm{O}_{2}^{-}(h \nu)
\end{gathered}
$$

With the assistance of a UV LED (photon energy of $2.5 \mathrm{~mW}$ ), the RT gas sensor made of mesoporous hollow $\mathrm{TiO}_{2}$ microspheres $^{388}$ exhibited a high response to formaldehyde with faster response/recovery (40/50 s) and good selectivity. Higher response has also been reported using the sensor made of $\mathrm{ZnO} /$ $\mathrm{SnO}_{2}$ composite materials ${ }^{395}$ to detect $\mathrm{NO}_{2}$ under UV light illumination at RT. After the sensing materials are exposed to $\mathrm{NO}_{2}$ gas, the $\mathrm{NO}_{2}$ molecules will collect the photo-generated electrons to form $\mathrm{NO}$ and $\mathrm{O}_{2}{ }^{-}$as shown in eqn $(22),{ }^{393}$ which results in an increase in the resistance of the sensor.

$$
2 \mathrm{NO}_{2(\mathrm{~g})}+\mathrm{e}^{-}(h \nu) \rightarrow 2 \mathrm{NO}_{(h \nu)}+\mathrm{O}_{2}^{-}{ }_{(h \nu)}
$$

Simultaneously, a heterojunction is formed at the interfaces between $\mathrm{ZnO}$ and $\mathrm{SnO}_{2}$. The photogenerated electrons are transferred from $\mathrm{ZnO}$ to $\mathrm{SnO}_{2}$ due to the higher Fermi energy level of $\mathrm{ZnO}$ than that of $\mathrm{SnO}_{2}$ (see Fig. 25a). The efficient charge separation increases charge concentrations on the surface of $\mathrm{SnO}_{2}$, which remarkably improves the sensitivity under UV light stimulation at RT as shown in Fig. 25b.

Apart from the UV light, visible light (including blue light and white light) assisted RT gas sensors with enhanced performance have also been reported. ${ }^{387,398-400}$ Klaus et al. ${ }^{387}$ reported a blue light (460 nm) activated ozone gas sensor based on nanoporous $\operatorname{In}_{2} \mathrm{O}_{3}$ particles, which showed a high response value of 200 and a low LOD of $50 \mathrm{ppb}$ at RT. Geng et al. ${ }^{399}$ reported that a sensor made

\begin{tabular}{|c|c|c|c|c|c|c|c|c|}
\hline Material & Structure & Synthesis method & Target gas & $C(\mathrm{ppm})$ & Response & $t_{\text {res }} / t_{\text {rec }}$ & LOD & Ref. \\
\hline $\mathrm{ZnO}$ & Nanorods & Hydrothermal & $\mathrm{HCHO}$ & 110 & $11.5^{a}$ & $14 / 0.5 \mathrm{~min}$ & $1.8 \mathrm{ppm}$ & 383 \\
\hline $\mathrm{ZnO}$ & Nanofibers & Electrospinning & $\mathrm{HCHO}$ & 100 & 12.3 & $32 / 17 \mathrm{~s}$ & $\sim 5 \mathrm{ppm}$ & 384 \\
\hline $\mathrm{ZnO}$ & Nanoparticles & Hydrothermal & $\mathrm{NO}_{2}$ & 20 & $85^{a}$ & $26 / 16 \mathrm{~s}$ & $\sim 1 \mathrm{ppm}$ & 393 \\
\hline $\mathrm{ZnO}$ & Microwires & Surface etching & $\mathrm{NO}_{2}$ & 20 & $411^{b}$ & $221 / 118 \mathrm{~s}$ & $\sim 10 \mathrm{ppm}$ & 381 \\
\hline $\mathrm{ZnO}$ & Nanowires & Wet-chemical & $\mathrm{C}_{2} \mathrm{H}_{5} \mathrm{OH}$ & 700 & $85^{b}$ & - & $\sim 100 \mathrm{ppm}$ & 382 \\
\hline $\mathrm{In}_{2} \mathrm{O}_{3}$ & Nanostructures & Arc-discharge & NO & 50 & 41.7 & $\sim 10 /-\min$ & $\sim 2 \mathrm{ppm}$ & 386 \\
\hline $\mathrm{In}_{2} \mathrm{O}_{3}$ & Nanoporous particles & Nanocasting & Ozone & 0.22 & 200 & $2.5 /-\min$ & $50 \mathrm{ppb}$ & 387 \\
\hline $\mathrm{TiO}_{2}$ & Thin films & Rf-sputter & $\mathrm{NO}_{2}$ & 250 & $\sim 1.8^{b}$ & $100 / 210 \mathrm{~s}$ & $100 \mathrm{ppm}$ & 389 \\
\hline $\mathrm{TiO}_{2}$ & Hollow microspheres & Hydrothermal & $\mathrm{HCHO}$ & 5 & $\sim 40$ & $40 / 55 \mathrm{~s}$ & $124 \mathrm{ppb}$ & 388 \\
\hline $\mathrm{SnO}_{2}$ & Nanowires & - & $\mathrm{NO}_{2}$ & 10 & $\sim 85^{b}$ & $10 / 15 \mathrm{~min}$ & $\sim 0.1 \mathrm{ppm}$ & 390 \\
\hline $\mathrm{SnO}_{2} / \mathrm{TiO}_{2}$ & Hollow spheres & Thermal evaporation & Ethanol & 100 & 160 & $50 / 150 \mathrm{~s}$ & - & 394 \\
\hline $\mathrm{ZnO} / \mathrm{SnO}_{2}$ & Nanorods & Wet chemical & $\mathrm{NO}_{2}$ & 0.5 & $1266^{a}$ & $7 / 8 \mathrm{~min}$ & $\sim 200 \mathrm{ppb}$ & 395 \\
\hline $\mathrm{Ag} / \mathrm{ZnO}$ & Nanorods & Hydrothermal & $\mathrm{HCHO}$ & 40 & $119.8^{b}$ & - & 5 ppm & 396 \\
\hline $\mathrm{NiO} / \mathrm{TiO}_{2}$ & Microspheres & Hydrothermal & $\mathrm{NH}_{3}$ & 100 & $140^{b}$ & $\sim 400 / \sim 400 \mathrm{~s}$ & $\sim 10 \mathrm{ppm}$ & 397 \\
\hline
\end{tabular}
of $\mathrm{Cu}_{x} \mathrm{O}_{1-y} / \mathrm{ZnO}_{1-\alpha}$ nanocomposites showed enhanced $\mathrm{NO}_{2}$

Table 7 Room temperature sensing properties of semiconducting metal oxide nanostructures enhanced by UV light

$C=$ concentration; $t_{\mathrm{res}} / t_{\mathrm{rec}}=$ response time/recovery time; LOD $=$ limit of detection; response is defined as $R_{\mathrm{a}} / R_{\mathrm{g}}$ (for reducing gases) or $R_{\mathrm{g}} / R_{\mathrm{a}}$ (for oxidizing gases), $R_{\mathrm{a}}$ : resistance of the sensor exposed to the reference, $R_{\mathrm{g}}$ : resistance of the sensor exposed to the target. ${ }^{a}$ Here the response is defined as $\Delta R / R_{\mathrm{g}}$ (for reducing gases) or $\Delta R / R_{\mathrm{a}}$ (for oxidizing gases), $\Delta R$ : the change in resistance. ${ }^{b}$ Here the response is defined as $\left(\Delta R / R_{\mathrm{g}}\right) \times 100 \%$ (for reducing gases) or $\left(\Delta R / R_{\mathrm{a}}\right) \times 100 \%$ (for oxidizing gases). 

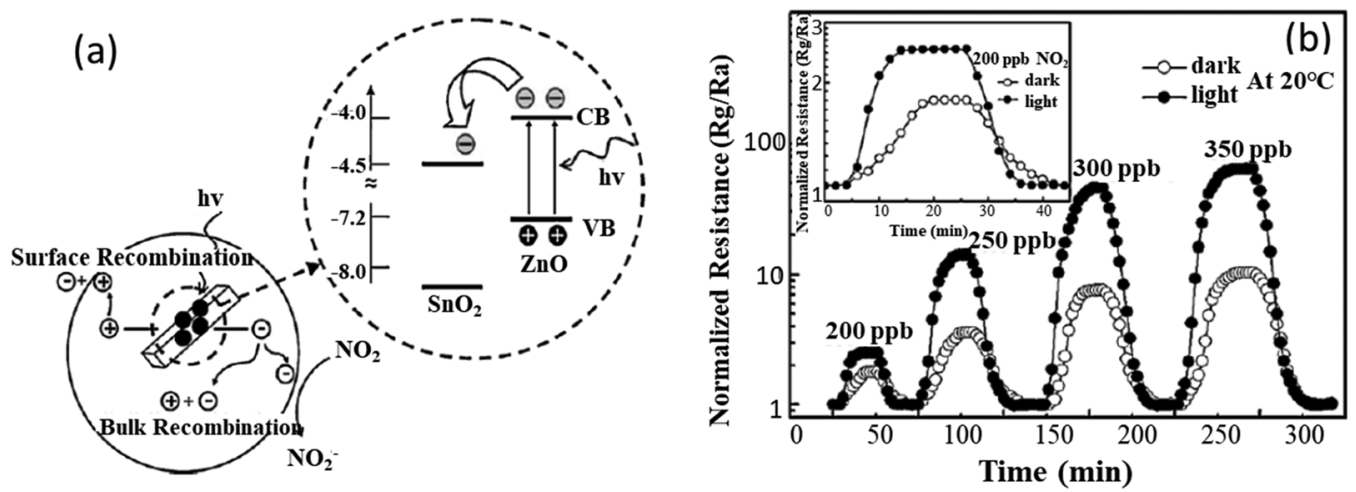

Fig. 25 (a) Schematic diagram of the carrier transport under UV light and the electron-hole pair separation on heterostructure of $\mathrm{ZnO} \mathrm{SnO}_{2}$ composite; (b) response/recovery of $\mathrm{ZnO} / \mathrm{SnO}_{2}$ composites at different concentrations of $\mathrm{NO}_{2}$ with and without UV light stimulation at room temperature. ${ }^{395}$ Copyright 2011, Elsevier.

sensing properties at RT with high response and good selectivity after being illuminated with white light. Similarly, infrared (IR) light should also be beneficial for the improvement in the sensing performance.

Although the photoactivated SMON gas sensors could achieve the improved gas sensing performance operated at RT, the lightemitting diodes, UV source, or infrared light, as well as optical power detection devices are necessary to be used, which will increase the size and production cost of the sensor device. The integration and shrinkage of the devices along with mass production capabilities are challenges. In addition, for the application of the gas sensors in a real environment, the gas sensor will be exposed to air for real-time monitoring. Sunlight will severely influence the gas sensing response.

\section{Mechanically flexible gas sensors based on semiconducting metal oxide nanostructures}

Mechanically flexible gas sensors are in great demand due to their promising applications in wearable electronic devices. SMONs with a potentially higher carrier mobility and mechanical robustness are good candidates for the realization of stretchable and flexible sensors. ${ }^{223}$ The mechanically flexible and wearable RT gas sensors based on SMONs have been an active research area recently as listed in Table 8. Compared with those on the rigid substrates, the wearable devices need substrates which are flexible, light weight, transparent, transportable, with a small volume, and low cost. ${ }^{401}$ Due to their excellent dielectric

Table 8 Sensing performance of room temperature flexible gas sensors based on semiconducting metal oxide nanostructures

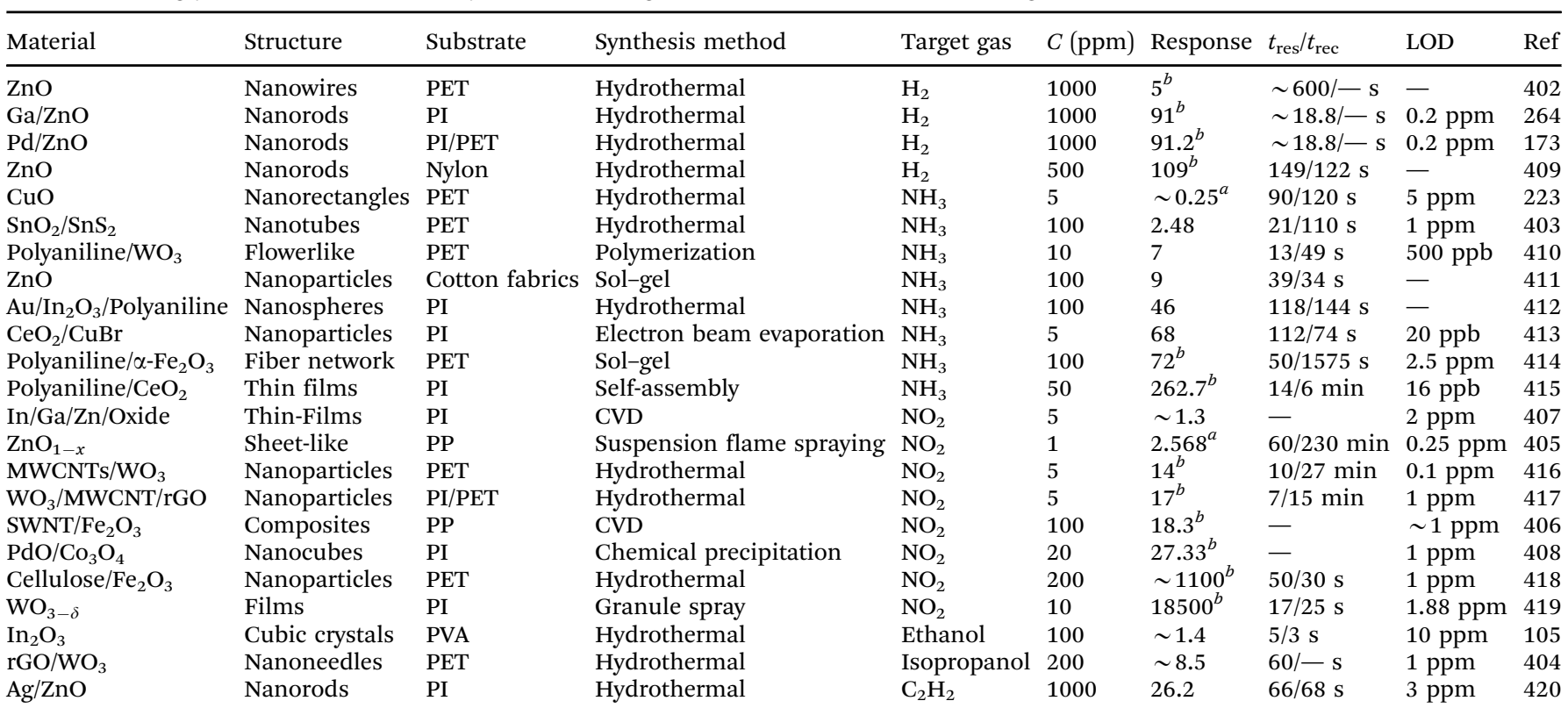

$C=$ concentration; $t_{\text {res }} / t_{\text {rec }}=$ response time/recovery time; LOD $=$ limit of detection; response is defined as $R_{\mathrm{a}} / R_{\mathrm{g}}$ (for reducing gases) or $R_{\mathrm{g}} / R_{\mathrm{a}}$ (for oxidizing gases), $R_{\mathrm{a}}$ : resistance of the sensor exposed to the reference, $R_{\mathrm{g}}$ : resistance of the sensor exposed to the target. ${ }^{a}$ Here the response is defined as $\Delta R / R_{\mathrm{g}}$ (for reducing gases) or $\Delta R / R_{\mathrm{a}}$ (for oxidizing gases), $\Delta R$ : the change in resistance. ${ }^{b}$ Here the response is defined as $\left(\Delta R / R_{\mathrm{g}}\right) \times 100 \%$ (for reducing gases) or $\left(\Delta R / R_{\mathrm{a}}\right) \times 100 \%$ (for oxidizing gases). 
properties, and thermal and chemical stability, many plastic substrates have been used as flexible substrates for the RT gas sensors including polyethylene terephthalate (PET), ${ }^{223,402-404}$ polypropylene (PP), ${ }^{405,406}$ polyimide (PI), ${ }^{264,407,408}$ polyvinyl acetate (PVA) $^{105}$ and nylon. ${ }^{409}$

For many of these flexible RT gas sensors, a sensitive layer such as $\mathrm{ZnO}$ nanorods is often used to deposit onto the device, for example, $\mathrm{ZnO}$ nanorods/nylon, ${ }^{409} \mathrm{Ga}-\mathrm{ZnO}$ nanorods/PI, ${ }^{264}$ Pd-ZnO nanorods/PI/PET. ${ }^{173}$ The aqueous solution method to prepare these $\mathrm{ZnO}$ nanorod layers on the polymer substrate is facile with advantages of low growth temperature and easy modifications. For example, Mohammad et al. ${ }^{409}$ prepared well-aligned $\mathrm{ZnO}$ nanorods on a thin nylon substrate with a thickness of $15 \mu \mathrm{m}$ using a hydrothermal process, and then made $\mathrm{a}_{2}$ gas sensor. There are many contact points among ZnO nanorods which form paths of electric carriers and result in the improvement of electron transport. The mechanically flexible hydrogen gas sensor exhibited a good response value of $109 \%$ (defined as $\left(\Delta R / R_{\mathrm{g}}\right) \times 100 \%$ ) with fast response/recovery.

Rashid et al. ${ }^{173}$ prepared vertically aligned $\mathrm{ZnO}$ nanorods on the PI substrate using a hydrothermal method, and then made the sensors for hydrogen detection at RT. Pd nanoparticles with $10 \mathrm{~nm}$ size were further sputtered on the surface of $\mathrm{ZnO}$ nanorods using RF magnetron sputtering. After being bent for $10^{3}$ cycles, there were no cracks or breaks on the $\mathrm{ZnO}$ nanorod film (see Fig. 26a). Such flexible hydrogen sensors had a response value of $\sim 91 \%$ (defined as $\left(\Delta R / R_{\mathrm{g}}\right) \times 100 \%$ ) for $1000 \mathrm{ppm}$ hydrogen with good repeatability and stability, and a low LOD of $0.2 \mathrm{ppm}$ at RT. The gas sensing performance at different bent angles from $0^{\circ}$, to $90^{\circ}$ did not exhibit apparent changes (see Fig. 26b). Even after the sensor was bent to a curvature angle of $90^{\circ}$ for $10^{5}$ cycles, the sensing performance of this flexible $\mathrm{H}_{2}$ sensor did not show any degradation (see Fig. 26c). The vertically well-aligned $\mathrm{ZnO}$ nanorods with the Pd catalyst on Ga-modified ZnO seed layer on flexible PI substrates also showed good $\mathrm{H}_{2}$ sensing properties and good mechanical flexibility at RT with good repeatability, stability and a low LOD of $0.2 \mathrm{ppm}$, even after being bent at a curvature angle of $90^{\circ} .^{264}$

In addition to being directly grown onto the plastic substrates, the $\mathrm{ZnO}$ nanowires were also transferred onto plastic substrates of PET to fabricate a flexible gas sensor using various methods, including slide transfer, roll transfer and heat transfer. ${ }^{402}$ A 2D sheet-like $\mathrm{ZnO}$ layer was deposited onto the flexible polypropylene papers using a suspension flame spraying method, and the prepared $\mathrm{ZnO}$ flexible sensor exhibited good responses and stability to sub-ppm level of $\mathrm{NO}_{2}$ at RT under white LED light illumination. ${ }^{405}$

Other types of SMONs have also been applied for making flexible RT gas sensors, and these include $\mathrm{WO}_{3}, \mathrm{SnO}_{2}, \mathrm{CeO}_{2}$, $\mathrm{Co}_{3} \mathrm{O}_{4}, \mathrm{In}_{2} \mathrm{O}_{3}$, etc. For example, Ryu et al. ${ }^{419}$ fabracted flexible RT $\mathrm{NO}_{2}$ gas sensors based on a $\mathrm{WO}_{3}-\delta$ film on a plastic substrate of polyimide (PI) using the granule spray method with a vacuum process. The sensor has a repsonse of up to $18500 \%$ to $10 \mathrm{ppm}$ $\mathrm{NO}_{2}$ with fast response/recovery times of 17/25 $\mathrm{s}$ and reliable flexibility after 4000 bending/extending cycles. As another example, a nanocompsite of polyaniline and nanoflower-like $\mathrm{WO}_{3}$ synthesized using a facile chemicaloxidation polymerization process was prepared on a PET substrate to fabricate a $\mathrm{NH}_{3}$ flexible sensor, which shows a high response and fast response/recovery times (13/49 s) to $10 \mathrm{ppm} \mathrm{NH}_{3}$ at RT. ${ }^{410}$

Modifying the SMONs using polyaniline (PANI) can effectivly enhance the sensing performance and stability of the flexible gas sensors, such as PANI- $\mathrm{CeO}_{2}, \mathrm{PANI} / \alpha-\mathrm{Fe}_{2} \mathrm{O}_{3}$ and PANI $/ \mathrm{WO}_{3}$. The morphology and sensing performance of flexible RT $\mathrm{NH}_{3}$ gas sensors based on PANI-CeO ${ }_{2}$ nanocomposite thin films are stable after being bent/cycled for 500 times. ${ }^{415}$ Furthermore, adding noble metals into the SMON/PANI composites can further improve their RT sensing performance. For example, after adding $\mathrm{Au}$ nanoparticles, the response of the $\mathrm{RT} \mathrm{NH}_{3}$ gas sensor made of the composite of mesoporous $\operatorname{In}_{2} \mathrm{O}_{3}$ nanospheres/polyaniline has been increased up to 4 times higher. ${ }^{412}$

Graphene and carbon nanotubes have excellent performance during severe plastic deformation, thus the composite integrating these carbon nanomaterials with the SMONs can achieve excellent sensing performance and mechanical flexibility. For example, a flexible isopropanol sensor was fabricated using a mixture of $\mathrm{WO}_{3} \cdot 0.33 \mathrm{H}_{2} \mathrm{O}$ nano-needles and rGO on PET substrates (see Fig. 27a). ${ }^{404}$ Compared with the sensor made of pure $\mathrm{WO}_{3} \cdot 0.33 \mathrm{H}_{2} \mathrm{O}$ nano-needles, the $5 \% \mathrm{rGO} / \mathrm{WO}_{3} \cdot 0.33 \mathrm{H}_{2} \mathrm{O}$ based sensor showed better selectivity and a superior response (4.96 to $100 \mathrm{ppm}$ to isopropanol) (see Fig. 27b), with good performance after repeated bending for many cycles. Similarly, SWNT- $\mathrm{Fe}_{2} \mathrm{O}_{3}$ composite films were prepared using the CVD method and then transferred onto the flexible PP polymer substrate. ${ }^{406}$ Compared with that fabricated using the single SWNTs, the flexible gas sensor of the SWNT- $\mathrm{Fe}_{2} \mathrm{O}_{3}$ composite film exhibited
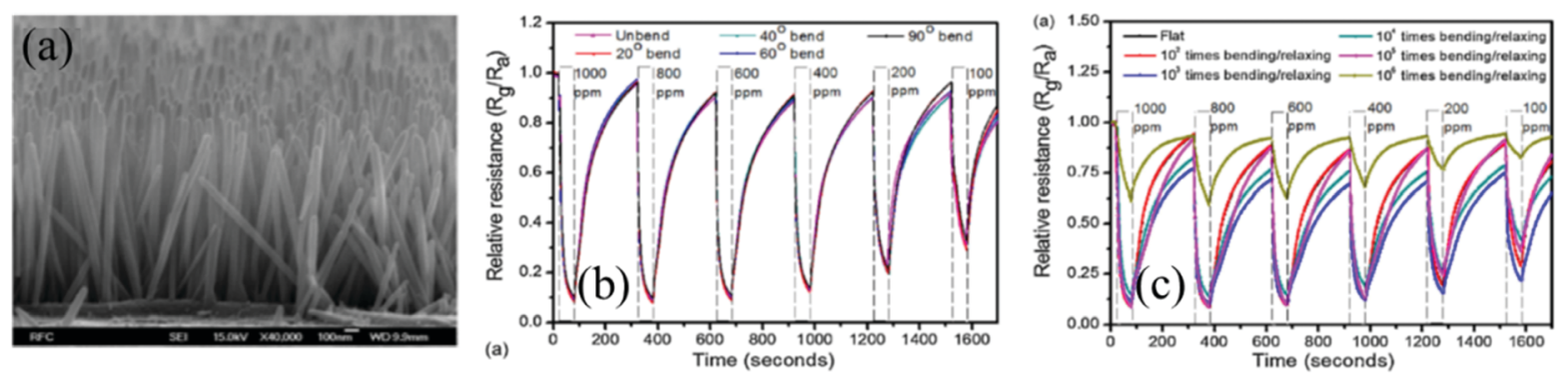

Fig. 26 (a) SEM images of $\mathrm{Pd} / \mathrm{ZnO}$ nanorods after $10^{3}$ times bending/relaxing. (b) Response/recovery curves of the flexible sensor to $\mathrm{H}_{2}$ at different bending angles, (c) the reliability test of the flexible sensor. ${ }^{173}$ Copyright 2013, Elsevier. 

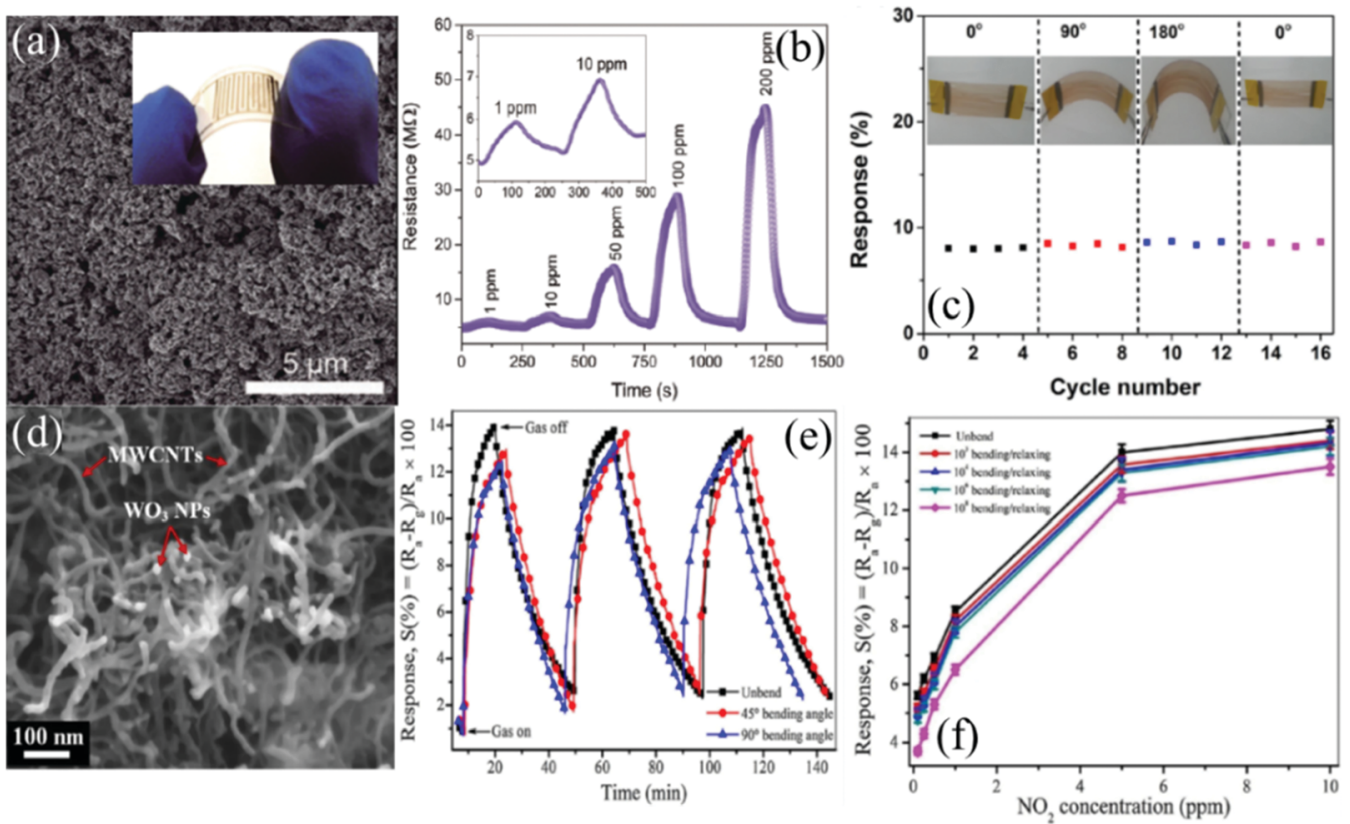

Fig. 27 (a) SEM images of $5 \% \mathrm{rGO} / \mathrm{WO}_{3} \cdot 0.33 \mathrm{H}_{2} \mathrm{O}$ deposited on polyethylene terephthalate; the inset is the photograph of the flexible gas sensor, (b) response/recovery curves to isopropanol with different concentrations. ${ }^{404}$ Copyright 2018, Royal Society of Chemistry. (c) Responses of the SWNT/ $\mathrm{Fe}_{2} \mathrm{O}_{3}$ gas sensor to $20 \mathrm{ppm} \mathrm{H} \mathrm{H}_{2} \mathrm{~S}$ under different bending angles from $0^{\circ}$ to $180^{\circ}$ and back to $0^{\circ}{ }^{406}$ Copyright 2017, Elsevier. (d) SEM images of the MWCNTs $/ \mathrm{WO}_{3}$ composite, (e) response curves to $5 \mathrm{ppm} \mathrm{NO}$ at RT under different bending angles, (f) responses to different $\mathrm{NO}_{2}$ concentrations at RT after bending/relaxing several times $\left(90^{\circ}\right.$ angle) ${ }^{416}$ Copyright 2015 , Elsevier.

an improved response to $\mathrm{H}_{2} \mathrm{~S}$ at RT. Under repeated bending to large angles (such as $90^{\circ}$ and $180^{\circ}$ ) for 16 times as shown in Fig. 27c, the flexible sensor exhibited stable sensing response values to $\mathrm{H}_{2} \mathrm{~S}$. As another example, hydrothermally synthesized $\mathrm{WO}_{3}$ nanoparticles were mixed with MWCNTs (see Fig. 27d), and then cast onto a PET substrate to fabricate a flexible $\mathrm{NO}_{2}$ gas sensor. ${ }^{416}$ This sensor not only shows good sensing performance, but also has excellent mechanical flexibility (see Fig. 27e). There was no significant degradation of response values after bending/relaxing for $10^{6}$ cycles, demonstrating the excellent mechanical robustness of the MWCNTs $/ \mathrm{WO}_{3}$ composite layers on the flexible gas sensors (see Fig. 27f).

Cotton fabrics are also reported to be used as a good substrate for flexible RT gas sensors, for example, a flexible $\mathrm{NH}_{3}$ gas sensor was made by growing nanostructured $\mathrm{ZnO}$ onto cotton fabrics. ${ }^{411}$ Flexible nanowires of the SMONs can also be isostatically pressed into a thin paper, and then the nanowire paper is cut into small pieces to directly fabricate a flexible gas sensor. Based on this idea, a- $\mathrm{MoO}_{3}$ nanowire paper ${ }^{421}$ has been fabricated and a flexible gas sensor was made to detect hydrogen gas. The sensor shows fast response and recovery speeds (3.0 and $2.7 \mathrm{~s}$ toward $1.5 \% \mathrm{H}_{2}$ ), good selectivity, and high sensitivity at RT. Wei et al. ${ }^{422}$ also reported a flexible gas sensor based on cellulose/ $\mathrm{TiO}_{2} /$ PANI composite nanofibers, which showed excellent ammonia gas sensing performance at RT. Similarly, a stretchable $\mathrm{ZnO}$ nano-accordion structure has also shown good applications in flexible RT gas sensors. ${ }^{423}$

In summary, flexible RT gas sensors can be fabricated using SMONs as the sensing materials on a mechanically flexible platform, and the sensors have demonstrated excellent mechanical robustness and can maintain good sensing performance at RT after bending/ recovering many times. Furthermore, the composite of SMONs with graphene or CNT can achieve better mechanical robustness for the flexible gas sensor. However, so far, excellent sensing performance and reliability and stability have not been achieved in the case of flexible RT gas sensors compared with their rigid counterparts.

\section{Conclusions and outlook}

In this paper, we have summarized the recent progress in designs and mechanisms of RT gas sensors based on different SMONs. Our emphasis has been on the critical review of different structures of SMON-based gas sensors that may help the design of new devices. The key topics covered in this paper include single phase n-type SMONs, single phase p-type SMONs, noble metal nanoparticle modified SMONs, metal ion modified SMONs, SMON composites with multiple metal oxides, and SMON composites with carbon nanomaterials. The different nanostructures of these SMONs include nanoparticles, nanowires, nanofibers, nanorods, nanosheets, nanotubes etc. The sensing performance of these SMON based RT sensors has been reviewed for detecting various toxic or flammable gases, such as hydrogen disulfide, nitrogen dioxide, ammonia, carbon monoxide and hydrogen, as well as organic gases of formaldehyde, acetone, methanol and ethanol, etc. In addition, photoactivated RT gas sensors and flexible RT gas sensors based on SMONs are also summarized. 
Availability of numerous surface chemisorbed oxygen species of $\mathrm{O}_{2}{ }^{-}$at $\mathrm{RT}$ was identified to be the key reason for the high sensitivity of these RT gas sensors. These oxygen species react with the target molecules to change the electronic resistance of the sensor. However, many $\mathrm{RT}_{2} \mathrm{~S}$ sensors are exceptional as the sensing mechanism is dominated by the formation of metallic conducting metal sulfide.

Noble metal nanoparticles on the surface of SMONs can stimulate the adsorption of oxygen molecules to form oxygen ions by reduction processes. These oxygen ions spill onto the surface of SMONs to improve the concentration of oxygen ions on the surface of SMONs for sensing reactions. In addition, noble metal nanoparticles can accelerate the transfer of electrons to SMONs. Therefore, both the chemical sensitization and electronic sensitization enhance the sensitivity and speed of the SMON-based sensors. Doping of metal ions in the SMONs can increase the number of active sites and defects on the surface of SMON nanocrystals, and thus enhance the amount of oxygen species and increase the adsorbed gas molecules on the sensor surface. Heterojunctions can form at the interfaces of different metal oxides or at the interfaces between the SMONs and carbon nanomaterials. These can effectively accelerate the transformation of electrons and enhance oxygen adsorption, and are beneficial to improve the sensitivity and response rates in application of RT gas sensors. The sensing performance also depends significantly on the nanostructures of the SMONs. Large specific surfaces are beneficial to the formation of more oxygen species, and porous nanostructures facilitate the adsorption and desorption of target gases, thus achieving fast response and recovery.

Generally, the RT SMON based gas sensors show high response values and low LODs; however, their response and recovery times could be too long. Modifications of the SMON sensors using various methods can improve their sensing performance, which include using noble metal modified SMONs; metal ion doped SMONs, composite SMONs, and composites with carbon nanomaterials. The key conclusions are summarized below:

(1) Surface modifications of the SMONs using noble metal nanoparticles can effectively enhance their sensitivity, response/ recovery speeds, selectivity and LODs through both chemical sensitization and electronic sensitization.

(2) Metal ion doped SMONs have increased number of active sites and more defects on their surfaces, which can enhance the oxygen species for sensing reactions and improve the adsorption of gas molecules.

(3) SMON composites can form abundant oxygen vacancies on their surfaces, thus providing many active sites. Heterojunctions can be formed at the interfaces of different metal oxides, which can effectively accelerate the transformation of electrons between different particles, thus improving the response rates. The composite SMONs often contain numerous mesopores which are beneficial to the adsorption and desorption of gas molecules. Hence, sensors based on the majority of reported composite oxides exhibit a high response value and very fast response.

(4) Because of the high conductivity of carbon nanomaterials, the composites of SMONs combined with carbon nanomaterials can achieve fast response/recovery.
(5) The photo-generated electrons on the surfaces of SMON sensing materials can enhance the chemisorption of oxygen molecules to form more $\mathrm{O}_{2}{ }^{-}$, which can enhance the sensitivity and response/recovery speed of the SMONs.

(6) RT flexible gas sensors based on the sensing layer of the SMON sensing materials have excellent mechanical robustness and can maintain good sensing performance after repeated bending/recovering.

Although there has been significant progress in developing novel SMONs for gas sensing at RT, there are still many challenges and problems towards achieving high response, fast response/recovery speed, good selectivity and long-term stability:

(1) One of the key challenges is the durability and long-term stability of the sensors for application under varying environmental conditions, such as different humidity levels and different temperatures, which could have significant influences on the sensing properties of many RT gas sensors. This is especially important for $\mathrm{RT} \mathrm{NH}_{3}$ sensing, as high humidity seriously affects the sensitivity and the response time. Light exposure, especially ultraviolet and infrared light, and even visible light, all influence the response of the RT SMON sensors. In the literature, the performance of sensors has been normally characterized based on experiments conducted in a well-controlled laboratory environment. However, in a practical setting with variable environmental conditions, the sensing performance may be altered with light exposure. Therefore, the sensing properties under different environmental conditions should be systematically investigated in order to establish the relationship between environmental conditions and sensing properties, which are then used to correct the sensing results.

(2) Interfering gases often affect the sensing performance, resulting in a drastically reduced response. Lack of good selectivity is still the most serious problem hindering the wide applications of these RT gas sensors. There are few reports on specific gas sensors which only respond to a target gas but not all the other gases. Because the resistive gas sensors rely on their changes in resistance upon adsorption of gas molecules, it can distinguish between the reducing gases and oxidizing gases based on the increase or decrease of resistance; however, it is difficult to discriminate a group of gases which can produce similar changing trends of resistance values.

Therefore, selectivity is particularly important for multipleagent gas sensors. To solve this problem, arrays of different sensing materials can be fabricated such that forming an array of gas sensors, which could obtain good selectivity by analyzing and comparing data from the different single sensors. ${ }^{424}$ For example, Zhang et al. $^{425}$ reported a method to detect multiple VOCs using an array of gas sensors based on $\mathrm{Ag}$ doped $\mathrm{LaFeO}_{3}$ (ALFO). The device was optimized for the detection of acetone, benzene, methanol and formaldehyde to monitor air quality. The selectivity of ALFO can be altered using a molecular imprinting technique towards specific targets. Responsivity values of individual sensing elements vary between 14 and 21 while the values to other VOCs are lower than 4 . The response and recovery times are on the order of $10 \mathrm{~s}$ and $100 \mathrm{~s}$ levels. Flitti et al. ${ }^{426}$ reported a micromachined $4 \times 4$ array of sensors 
for multiple target detection. The sensing film for individual elements is based on $\mathrm{SnO}_{2}$ and the elements are post-treated using metal catalysts of Pt, Pd, and Au and ions implanted using B, P, and $\mathrm{H}$. The basic post-treatment methods are effective in selectively detecting gases of $\mathrm{CO}, \mathrm{CH}_{4}$, ethanol, $\mathrm{CH}_{4}-\mathrm{CO}$, ethanol-CO, and ethanol- $\mathrm{CH}_{4}$ using an algorithm based on vector angle similarity. Recognition accuracy higher than $95 \%$ is reported in this study. ${ }^{427}$ This method has been demonstrated being capable of forming 12000 virtual sensors using dedicated temperature modulations. Sensing networks will be the future trends.

(3) The sensing mechanism of the SMONs is mainly based on the interaction between the target gas molecules and chemisorbed oxygen species, such as $\mathrm{O}_{2}{ }^{-}, \mathrm{O}^{-}$and $\mathrm{O}^{2-}$ ions. However, other oxygen groups such as $\mathrm{OH}^{-}$can also react with the target gas molecules. More effective analysis and theory development of the surface groups is urgently needed to assess their effect on the sensing properties, and the surface modification methods should be developed to minimize this influence.

(4) Many gas sensing mechanisms of SMON based materials with various sizes and morphologies have been presented to explain their sensing properties. However, it is not clearly elucidated why the same SMON based materials with similar sizes and morphologies show markedly different sensing properties. Therefore, in situ characterization techniques and theory development for the sensing mechanisms are necessary.

(5) Response times of many RT gas sensors are very long, which cannot meet the need for timely triggering of the alarm. Exploring novel SMON based sensing materials for rapid response at RT is still necessary. 3-D nano-arrays of SMONs facilitate gas diffusion, which might be promising to shorten the response time.

(6) Flexible wearable RT gas sensors are in great demand due to their promising applications. SMONs with the potential of higher carrier mobility and mechanical robustness are among the good candidates for making stretchable and flexible gas sensors. For RT gas sensors, there are still challenges regarding their manufacturing technologies, and cracking and spalling problems of SMON layers on the flexible substrates usually happen, which need to be solved to achieve reliable RT flexible gas sensors. Therefore, finding new low-cost SMON based sensing materials with excellent sensing performance and mechanical robustness is still the major challenge.

\section{Conflicts of interest}

There are no conflicts to declare.

\section{Acknowledgements}

This work was supported by the National Key Research and Development Program of China (Grant no. 2016YFB0402705), the National Natural Science Foundation of China (NSFC, 21711530211, 61390502, 21673091), the Foundation for Innovative Research Groups of the National Natural Science Foundation of China (Grant No. 51521003) and by Self-Planned Task (No. SKLRS201607B) of State Key Laboratory of Robotics and System
(HIT), Shenzhen Science \& Technology Project (Grant no. JCYJ20170817100658231), the Natural Science Foundation of Hubei Province (No. 2015CFA125), UK Engineering Physics and Science Research Council (EPSRC EP/P018998/1 and EP/ P026435/1) and Newton Mobility Grant (IE161019) through Royal Society and NFSC, as well as Royal Academy of Engineering UK-Research Exchange with China and India.

\section{References}

1 M. Jerrett, D. Donaire-Gonzalez, O. Popoola, R. Jones, R. C. Cohen, E. Almanza, A. de Nazelle, I. Mead, G. CarrascoTurigas, T. Cole-Hunter, M. Triguero-Mas, E. Seto and M. Nieuwenhuijsen, Environ. Res., 2017, 158, 286-294.

2 Z. A. Barakeh, P. Breuil, N. Redon, C. Pijolat, N. Locoge and J.-P. Viricelle, Sens. Actuators, B, 2017, 241, 1235-1243.

3 D. Sett and D. Basak, Sens. Actuators, B, 2017, 243, 475-483. 4 Z. Song, Z. Wei, B. Wang, Z. Luo, S. Xu, W. Zhang, H. Yu, M. Li, Z. Huang, J. Zang, F. Yi and H. Liu, Chem. Mater., 2016, 28, 1205-1212.

5 H. Ren, C. Gu, S. W. Joo, J. Zhao, Y. Sun and J. Huang, Sens. Actuators, B, 2018, 266, 506-513.

6 G. Tuerdi, P. Nizamidin, N. Kari, A. Yimit and F. Wang, RSC Adv., 2018, 8, 5614-5621.

7 A. Paliwal, A. Sharma, M. Tomar and V. Gupta, Sens. Actuators, B, 2017, 250, 679-685.

8 B. Gong, T. Shi, W. Zhu, G. Liao, X. Li, J. Huang, T. Zhou and Z. Tang, Sens. Actuators, B, 2017, 245, 821-827.

9 R. Kitture, D. Pawar, C. N. Rao, R. K. Choubey and S. N. Kale, J. Alloys Compd., 2017, 695, 2091-2096.

10 M. Asad and M. H. Sheikhi, Sens. Actuators, B, 2014, 198, 134-141.

11 S.-H. Wang, C.-Y. Shen, H.-M. Huang and Y.-C. Shih, Sens. Actuators, A, 2014, 216, 237-242.

12 L. Rana, R. Gupta, M. Tomar and V. Gupta, Sens. Actuators, $B, 2017,252,840-845$.

13 T. Goto, T. Itoh, T. Akamatsu, N. Izu and W. Shin, Sens. Actuators, B, 2016, 223, 774-783.

14 L. Sun, W. L. Luan, T. C. Wang, W. X. Su and L. X. Zhang, Nanotechnology, 2017, 28, 075501.

15 H. Liang, X. Zhang, H. Sun, H. Jin, X. Zhang, Q. Jin, J. Zou, H. Haick and J. Jian, ACS Sens., 2017, 2, 1467-1473.

16 G. Jiang, M. Goledzinowski, F. J. E. Comeau, H. Zarrin, G. Lui, J. Lenos, A. Veileux, G. Liu, J. Zhang, S. Hemmati, J. Qiao and Z. Chen, Adv. Funct. Mater., 2016, 26, 1729-1736.

17 E. Menart, V. Jovanovski and S. B. Hočevar, Sens. Actuators, B, 2017, 238, 71-75.

18 S. S. Shendage, V. L. Patil, S. A. Vanalakar, S. P. Patil, N. S. Harale, J. L. Bhosale, J. H. Kim and P. S. Patil, Sens. Actuators, B, 2017, 240, 426-433.

19 Y. Li, N. Chen, D. Deng, X. Xing, X. Xiao and Y. Wang, Sens. Actuators, B, 2017, 238, 264-273.

20 R. Kumar, O. Al-Dossary, G. Kumar and A. Umar, NanoMicro Lett., 2014, 7, 97-120.

21 A. Dey, Mater. Sci. Eng., B, 2018, 229, 206-217. 
22 S. W. Lee, W. Lee, Y. Hong, G. Lee and D. S. Yoon, Sens. Actuators, B, 2018, 255, 1788-1804.

$23 \mathrm{H}$. Wu, Z. Chen, J. Zhang, F. Wu, C. He, Y. Wu and Z. Ren, J. Mater. Chem. A, 2017, 5, 24493-24501.

24 S. Park, M. Park, S. Kim, S.-G. Yi, M. Kim, J. Son, J. Cha, J. Hong and K.-H. Yoo, Appl. Phys. Lett., 2017, 111, 213102.

25 S. W. Lee, W. Lee, D. Lee, Y. Choi, W. Kim, J. Park, J. H. Lee, G. Lee and D. S. Yoon, Sens. Actuators, B, 2018, 266, 485-492.

26 N. Joshi, T. Hayasaka, Y. Liu, H. Liu, O. N. Oliveira, Jr. and L. Lin, Mikrochim. Acta, 2018, 185, 213.

27 Y. Li, M. Jiao, H. Zhao and M. Yang, Sens. Actuators, B, 2018, 264, 285-295.

28 J. Cai, C. Zhang, A. Khan, C. Liang and W.-D. Li, RSC Adv., 2018, 8, 5312-5320.

29 H. J. Park, W.-J. Kim, H.-K. Lee, D.-S. Lee, J.-H. Shin, Y. Jun and Y. J. Yun, Sens. Actuators, B, 2018, 257, 846-852.

30 H. T. Hien, H. T. Giang, N. V. Hieu, T. Trung and C. V. Tuan, Sens. Actuators, B, 2017, 249, 348-356.

31 V. L. Patil, S. A. Vanalakar, P. S. Patil and J. H. Kim, Sens. Actuators, B, 2017, 239, 1185-1193.

32 M. Jiao, N. V. Chien, N. V. Duy, N. D. Hoa, N. V. Hieu, K. Hjort and H. Nguyen, Mater. Lett., 2016, 169, 231-235.

33 D. N. Oosthuizen, D. E. Motaung and H. C. Swart, Sens. Actuators, B, 2018, 266, 761-772.

34 X. Liu, M. Hu, Y. Wang, J. Liu and Y. Qin, J. Alloys Compd., 2016, 685, 364-369.

35 A. Umar, J.-H. Lee, R. Kumar, O. Al-Dossary, A. A. Ibrahim and S. Baskoutas, Mater. Des., 2016, 105, 16-24.

36 O. Lupan, V. Postica, V. Cretu, N. Wolff, V. Duppel, L. Kienle and R. Adelung, Phys. Status Solidi RRL, 2016, 10, 260-266.

37 S. Xu, H. Zhao, Y. Xu, R. Xu and Y. Lei, ACS Appl. Mater. Interfaces, 2018, 10, 13895-13902.

38 I. Cho, K. Kang, D. Yang, J. Yun and I. Park, ACS Appl. Mater. Interfaces, 2017, 9, 27111-27119.

39 Y. Zhao, W. Zhang, B. Yang, J. Liu, X. Chen, X. Wang and C. Yang, Nanotechnology, 2017, 28, 452002.

40 X. Tong, W. Shen, X. Chen and J.-P. Corriou, Ceram. Int., 2017, 43, 14200-14209.

41 W. Guo, Q. Feng, Y. Tao, L. Zheng, Z. Han and J. Ma, Mater. Res. Bull., 2016, 73, 302-307.

42 Z. Li, Y. Huang, S. Zhang, W. Chen, Z. Kuang, D. Ao, W. Liu and Y. Fu, J. Hazard. Mater., 2015, 300, 167-174.

43 Z. Li, Z. Lin, N. Wang, Y. Huang, J. Wang, W. Liu, Y. Fu and Z. Wang, Mater. Des., 2016, 110, 532-539.

44 D. Han, L. Zhai, F. Gu and Z. Wang, Sens. Actuators, B, 2018, 262, 655-663.

45 J. Hu, Y. Sun, Y. Xue, M. Zhang, P. Li, K. Lian, S. Zhuiykov, W. Zhang and Y. Chen, Sens. Actuators, B, 2018, 257, 124-135.

46 S. C. Zhang, Y. W. Huang, Z. Kuang, S. Y. Wang, W. L. Song, D. Y. Ao, W. Liu and Z. J. Li, Nanosci. Nanotechnol. Lett., 2015, 7, 455-461.

47 Z. Li, S. Yan, Z. Wu, H. Li, J. Wang, W. Shen, Z. Wang and Y. Fu, Int. J. Hydrogen Energy, 2018, 43, 22746-22755.

48 T. Zhou, T. Zhang, J. Deng, R. Zhang, Z. Lou and L. Wang, Sens. Actuators, B, 2017, 242, 369-377.
49 S. F. Shen, M. L. Xu, D. B. Lin and H. B. Pan, Appl. Surf. Sci., 2017, 396, 327-332.

50 Z. Zhang, L. Zhu, Z. Wen and Z. Ye, Sens. Actuators, B, 2017, 238, 1052-1059.

51 S. Poongodi, P. S. Kumar, D. Mangalaraj, N. Ponpandian, P. Meena, Y. Masuda and C. Lee, J. Alloys Compd., 2017, 719, 71-81.

52 H. Kim, Y. Pak, Y. Jeong, W. Kim, J. Kim and G. Y. Jung, Sens. Actuators, B, 2018, 262, 460-468.

53 R. Sankar Ganesh, M. Navaneethan, V. L. Patil, S. Ponnusamy, C. Muthamizhchelvan, S. Kawasaki, P. S. Patil and Y. Hayakawa, Sens. Actuators, B, 2018, 255, 672-683.

54 X. Hu, Z. Zhu, C. Chen, T. Wen, X. Zhao and L. Xie, Sens. Actuators, B, 2017, 253, 809-817.

55 L. Xiao, S. Xu, G. Yu and S. Liu, Sens. Actuators, B, 2018, 255, 2002-2010.

56 V. S. Bhati, S. Ranwa, S. Rajamani, K. Kumari, R. Raliya, P. Biswas and M. Kumar, ACS Appl. Mater. Interfaces, 2018, 10, 11116-11124.

57 V. S. Bhati, S. Ranwa, M. Fanetti, M. Valant and M. Kumar, Sens. Actuators, B, 2018, 255, 588-597.

58 V. V. Ganbavle, S. I. Inamdar, G. L. Agawane, J. H. Kim and K. Y. Rajpure, Chem. Eng. J., 2016, 286, 36-47.

59 X. Kou, N. Xie, F. Chen, T. Wang, L. Guo, C. Wang, Q. Wang, J. Ma, Y. Sun, H. Zhang and G. Lu, Sens. Actuators, B, 2018, 256, 861-869.

60 Q. Zhou, W. Chen, L. Xu, R. Kumar, Y. Gui, Z. Zhao, C. Tang and S. Zhu, Ceram. Int., 2018, 44, 4392-4399.

61 C. Zhao, H. Gong, W. Lan, R. Ramachandran, H. Xu, S. Liu and F. Wang, Sens. Actuators, B, 2018, 258, 492-500.

62 H. W. Kim, H. G. Na, Y. J. Kwon, S. Y. Kang, M. S. Choi, J. H. Bang, P. Wu and S. S. Kim, ACS Appl. Mater. Interfaces, 2017, 9, 31667-31682.

63 P. Tyagi, A. Sharma, M. Tomar and V. Gupta, Sens. Actuators, B, 2017, 248, 980-986.

64 B. Zhang, M. Cheng, G. Liu, Y. Gao, L. Zhao, S. Li, Y. Wang, F. Liu, X. Liang, T. Zhang and G. Lu, Sens. Actuators, B, 2018, 263, 387-399.

65 S. Park, S. Kim, H. Kheel, S. K. Hyun, C. Jin and C. Lee, Mater. Res. Bull., 2016, 82, 130-135.

66 D. Li, L. Qin, P. Zhao, Y. Zhang, D. Liu, F. Liu, B. Kang, Y. Wang, H. Song, T. Zhang and G. Lu, Sens. Actuators, B, 2018, 254, 834-841.

67 H. Gao, L. Zhao, L. Wang, P. Sun, H. Lu, F. Liu, X. Chuai and G. Lu, Sens. Actuators, B, 2018, 255, 3505-3515.

68 I. Eisele, T. Doll and M. Burgmair, Sens. Actuators, B, 2001, 78, 19-25.

69 S. Stegmeier, M. Fleischer, A. Tawil, P. Hauptmann, K. Egly and K. Rose, Sens. Actuators, B, 2011, 154, 270-276.

70 A. I. Ayesh, J. Nanomater., 2016, 2016, 1-17.

71 Z. S. Hosseini, A. I. Zad and A. Mortezaali, Sens. Actuators, $B, 2015,207,865-871$.

72 T. Sin Tee, T. Chun Hui, C. Wu Yi, Y. Chi Chin, A. A. Umar, G. Riski Titian, L. Hock Beng, L. Kok Sing, M. Yahaya and M. M. Salleh, Sens. Actuators, B, 2016, 227, 304-312. 
73 A. Azam, S. S. Habib, N. A. Salah and F. Ahmed, Int. J. Nanomed., 2013, 8, 3875-3881.

74 H. Wang, Q. Sun, Y. Yao, Y. Li, J. Wang and L. Chen, Ceram. Int., 2016, 42, 8565-8571.

75 W. Li, J. Liang, J. Liu, L. Zhou, R. Yang and M. Hu, Mater. Lett., 2016, 173, 199-202.

76 Y. Wei, C. Chen, G. Yuan and S. Gao, J. Alloys Compd., 2016, 681, 43-49.

77 Y. Li, Q. Zhang, X. Li, H. Bai, W. Li, T. Zeng and G. Xi, RSC Adv., 2016, 6, 95747-95752.

78 S. Mohamed Sali, S. Joy, N. Meenakshisundaram, R. K. Karn, C. Gopalakrishnan, P. Karthick, K. Jeyadheepan and K. Sankaranarayanan, RSC Adv., 2017, 7, 37720-37728.

79 Z. P. Tshabalala, D. E. Motaung, G. H. Mhlongo and O. M. Ntwaeaborwa, Sens. Actuators, B, 2016, 224, 841-856.

80 Y. Huang, W. Chen, S. Zhang, Z. Kuang, D. Ao, N. R. Alkurd, W. Zhou, W. Liu, W. Shen and Z. Li, Appl. Surf. Sci., 2015, 351, 1025-1033.

81 R. K. Bedi and I. Singh, ACS Appl. Mater. Interfaces, 2010, 2, 1361-1368.

82 P. Shankar and J. B. B. Rayappan, ACS Appl. Mater. Interfaces, 2017, 9, 38135-38145.

83 N. Kumar, A. K. Srivastava, R. Nath, B. K. Gupta and G. D. Varma, Dalton Trans., 2014, 43, 5713-5720.

84 Z. Zeng, K. Wang, Z. Zhang, J. Chen and W. Zhou, Nanotechnology, 2009, 20, 045503.

85 Y. Shen, S. Zhao, J. Ma, X. Chen, W. Wang, D. Wei, S. Gao, W. Liu, C. Han and B. Cui, J. Alloys Compd., 2016, 664, 229-234.

86 Z. Li, X. Niu, Z. Lin, N. Wang, H. Shen, W. Liu, K. Sun, Y. Q. Fu and Z. Wang, J. Alloys Compd., 2016, 682, 647-653.

87 O. Lupan, V. Postica, R. Adelung, F. Labat, I. Ciofini, U. Schürmann, L. Kienle, L. Chow, B. Viana and T. Pauporté, Phys. Status Solidi RRL, 2018, 12, 1700321.

88 Y. L. Wang, X. C. Jiang and Y. N. Xia, J. Am. Chem. Soc., 2003, 125, 16176-16177.

89 O. Lupan, L. Chow, T. Pauporté, L. K. Ono, B. Roldan Cuenya and G. Chai, Sens. Actuators, B, 2012, 173, 772-780.

90 W. Song, H. Wu, J. Wang, Y. Lin, J. Song, Y. Xie, L. Li and K. Shi, Aust. J. Chem., 2015, 68, 1569.

91 L. Yu, F. Guo, S. Liu, B. Yang, Y. Jiang, L. Qi and X. Fan, J. Alloys Compd., 2016, 682, 352-356.

92 Z. Li, Z. Lin, N. Wang, J. Wang, W. Liu, K. Sun, Y. Q. Fu and Z. Wang, Sens. Actuators, B, 2016, 235, 222-231.

93 Z. Li, N. Wang, Z. Lin, J. Wang, W. Liu, K. Sun, Y. Q. Fu and Z. Wang, ACS Appl. Mater. Interfaces, 2016, 8, 20962-20968.

94 J. Zhang, D. Zeng, Q. Zhu, J. Wu, Q. Huang and C. Xie, J. Phys. Chem. C, 2016, 120, 3936-3945.

95 C. Jiang, G. Zhang, Y. Wu, L. Li and K. Shi, CrystEngComm, 2012, 14, 2739.

96 A. Hazra, K. Dutta, B. Bhowmik, P. P. Chattopadhyay and P. Bhattacharyya, Appl. Phys. Lett., 2014, 105, 081604.

97 B. Bhowmik, A. Hazra, K. Dutta and P. Bhattacharyya, IEEE Trans. Device Mater. Reliab., 2014, 14, 961-967.

98 J. Z. Zhang and Y. Yan, J. Mater. Sci., 2017, 52, 13711-13718. 99 S. Shao, H. Wu, S. Wang, Q. Hong, R. Koehn, T. Wu and W.-F. Rao, J. Mater. Chem. C, 2015, 3, 10819-10829.
100 H. Duan, L. Yan, Y. He, H. Li, L. Liu, Y. Cheng and L. Du, Mater. Res. Express, 2017, 4, 095022.

101 Y. Wang, G. Duan, Y. Zhu, H. Zhang, Z. Xu, Z. Dai and W. Cai, Sens. Actuators, B, 2016, 228, 74-84.

102 J. Gao, H. Wu, J. Zhou, L. Yao, G. Zhang, S. Xu, Y. Xie, L. Li and K. Shi, New J. Chem., 2016, 40, 1306-1311.

103 B. Wu, L. Wang, H. Wu, K. Kan, G. Zhang, Y. Xie, Y. Tian, L. Li and K. Shi, Microporous Mesoporous Mater., 2016, 225, 154-163.

104 M. Kaur, N. Jain, K. Sharma, S. Bhattacharya, M. Roy, A. K. Tyagi, S. K. Gupta and J. V. Yakhmi, Sens. Actuators, B, 2008, 133, 456-461.

105 M. Seetha, P. Meena, D. Mangalaraj, Y. Masuda and K. Senthil, Mater. Chem. Phys., 2012, 133, 47-54.

106 R. Senthilkumar, G. Ravi, C. Sanjeeviraja, M. Arivanandhan and Y. Hayakawa, Solid State Phys., 2013, 1512, 648-649.

107 D. F. Rodriguez, P. M. Perillo, C. A. Rinaldi, A. Lamagna and P. Gouma, AIP Conf. Proc., 2011, 1362, 199-200.

108 M. N. Cardoza-Contreras, J. M. Romo-Herrera, L. A. Rios, R. Garcia-Gutierrez, T. A. Zepeda and O. E. Contreras, Sensors, 2015, 15, 30539-30544.

109 C. Wang, X. Chu and M. Wu, Sens. Actuators, B, 2006, 113, 320-323.

110 Y. Xia, J. Wang, X. Li, X. Dan, D. Zhou, L. Xiang and S. Komarneni, Ceram. Int., 2016, 42, 15876-15880.

111 N. Du, H. Zhang, B. D. Chen, X. Y. Ma, Z. H. Liu, J. B. Wu and D. R. Yang, Adv. Mater., 2007, 19, 1641-1645.

112 P. Dhivya and M. Sridharan, J. Electron. Mater., 2014, 43, 3211-3216.

113 S. Arunkumar, T. Hou, Y.-B. Kim, B. Choi, S. H. Park, S. Jung and D.-W. Lee, Sens. Actuators, B, 2017, 243, 990-1001.

114 S.-W. Choi and S. S. Kim, Sens. Actuators, B, 2012, 168, 8-13.

115 K. Wang, T. Zhao, G. Lian, Q. Yu, C. Luan, Q. Wang and

D. Cui, Sens. Actuators, B, 2013, 184, 33-39.

116 P. P. Subha, K. Hasna and M. K. Jayaraj, Mater. Res. Express, 2017, 4, 105037.

117 S. Wang, D. Huang, S. Xu, W. Jiang, T. Wang, J. Hu, N. Hu, Y. Su, Y. Zhang and Z. Yang, Phys. Chem. Chem. Phys., 2017, 19, 19043-19049.

118 G. H. Mhlongo, K. Shingange, Z. P. Tshabalala, B. P. Dhonge, F. A. Mahmoud, B. W. Mwakikunga and D. E. Motaung, Appl. Surf. Sci., 2016, 390, 804-815.

119 J. Wang, L. Wei, L. Zhang, J. Zhang, H. Wei, C. Jiang and Y. Zhang, J. Mater. Chem., 2012, 22, 20038.

120 J. Wang, P. Yang and X. Wei, ACS Appl. Mater. Interfaces, 2015, 7, 3816-3824.

121 P. Chaudhari and S. Mishra, Measurement, 2016, 90, 468-474.

122 J. Zhou, M. Ikram, A. U. Rehman, J. Wang, Y. Zhao, K. Kan, W. Zhang, F. Raziq, L. Li and K. Shi, Sens. Actuators, B, 2018, 255, 1819-1830.

123 M. Kaur, B. K. Dadhich, R. Singh, K. Ganapathi, T. Bagwaiya, S. Bhattacharya, A. K. Debnath, K. P. Muthe and S. C. Gadkari, Sens. Actuators, B, 2017, 242, 389-403.

124 V. Srivastava and K. Jain, Mater. Lett., 2016, 169, 28-32.

125 P.-G. Su and T.-T. Pan, Mater. Chem. Phys., 2011, 125, 351-357. 
126 H. Zhang, L. Yu, Q. Li, Y. Du and S. Ruan, Sens. Actuators, $B, 2017,241,109-115$.

127 Z. Li, J. Wang, S. Zhang, S. Yan, B. Cao, W. Shen, Z. Wang and Y. Q. Fu, J. Alloys Compd., 2018, 742, 712-720.

128 V. Inderan, M. M. Arafat, S. Kumar, A. Haseeb, Z. T. Jiang, M. Altarawneh and H. L. Lee, Nanotechnology, 2017, 28, 265702.

129 A. U. Rehman, J. Zhang, J. Zhou, K. Kan, L. Li and K. Shi, Microporous Mesoporous Mater., 2017, 240, 50-56.

130 J. Liang, K. Zhu, R. Yang and M. Hu, Ceram. Int., 2018, 44, 2261-2268.

131 H. Xu, J. Zhang, A. U. Rehman, L. Gong, K. Kan, L. Li and K. Shi, Appl. Surf. Sci., 2017, 412, 230-237.

132 D. Liu, L. Lin, Q. Chen, H. Zhou and J. Wu, ACS Sens., 2017, 2, 1491-1497.

133 Y. Wang, Y. Zhou, C. Meng, Z. Gao, X. Cao, X. Li, L. Xu, W. Zhu, X. Peng, B. Zhang, Y. Lin and L. Liu, Nanotechnology, 2016, 27, 425503.

134 S. Xu, J. Gao, L. Wang, K. Kan, Y. Xie, P. Shen, L. Li and K. Shi, Nanoscale, 2015, 7, 14643-14651.

135 Z. Liu, L. Yu, F. Guo, S. Liu, L. Qi, M. Shan and X. Fan, Appl. Surf. Sci., 2017, 423, 721-727.

136 N. Van Hieu, L. T. B. Thuy and N. D. Chien, Sens. Actuators, B, 2008, 129, 888-895.

137 N. Tiwale, Mater. Sci. Technol., 2015, 31, 1681-1697.

138 A. Mirzaei, B. Hashemi and K. Janghorban, J. Mater. Sci.: Mater. Electron., 2015, 27, 3109-3144.

139 G. Korotcenkov and B. K. Cho, Sens. Actuators, B, 2014, 196, 80-98.

140 S. Das and V. Jayaraman, Prog. Mater. Sci., 2014, 66, 112-255.

141 H.-J. Kim and J.-H. Lee, Sens. Actuators, B, 2014, 192, 607-627.

142 D. R. Miller, S. A. Akbar and P. A. Morris, Sens. Actuators, B, 2014, 204, 250-272.

143 G. Korotcenkov, V. Brinzari and B. K. Cho, Microchim. Acta, 2016, 183, 1033-1054.

144 P. Rai, S. M. Majhi, Y.-T. Yu and J.-H. Lee, $R S C A d v .$, 2015, 5, 76229-76248.

145 S. Gupta Chatterjee, S. Chatterjee, A. K. Ray and A. K. Chakraborty, Sens. Actuators, B, 2015, 221, 1170-1181.

146 M. Gardon and J. M. Guilemany, J. Mater. Sci.: Mater. Electron., 2012, 24, 1410-1421.

147 P. T. Moseley, Meas. Sci. Technol., 2017, 28, 082001.

148 Y. F. Sun, S. B. Liu, F. L. Meng, J. Y. Liu, Z. Jin, L. T. Kong and J. H. Liu, Sensors, 2012, 12, 2610-2631.

149 H. Gu, Z. Wang and Y. Hu, Sensors, 2012, 12, 5517-5550.

150 A. Mirzaei, S. G. Leonardi and G. Neri, Ceram. Int., 2016, 42, 15119-15141.

151 L. Zhu and W. Zeng, Sens. Actuators, A, 2017, 267, 242-261.

152 A. D. Faisal, Bull. Mater. Sci., 2017, 40, 1061-1068.

153 N. Zhang, K. Yu, Q. Li, Z. Q. Zhu and Q. Wan, J. Appl. Phys., 2008, 103, 104305.

154 T. Kondo, Y. Sato, M. Kinoshita, P. Shankar, N. N. Mintcheva, M. Honda, S. Iwamori and S. A. Kulinich, Jpn. J. Appl. Phys., 2017, 56, 080304.

155 Y. Li, S. Wang, P. Hao, J. Tian, H. Cui and X. Wang, Sens. Actuators, B, 2018, 273, 751-759.
156 A. Beniwal, P. K. Sahu and S. Sharma, J. Sol-Gel Sci. Technol., 2018, 88, 322-333.

157 M. Kodu, T. Avarmaa, A. Floren and R. Jaaniso, J. Eur. Ceram. Soc., 2013, 33, 2335-2340.

158 K. Khun Khun, A. Mahajan and R. K. Bedi, J. Appl. Phys., 2009, 106, 124509.

159 T. Yang, M. Zhu, K. Gu, C. Zhai, Q. Zhao, X. Yang and M. Zhang, New J. Chem., 2018, 42, 13612-13618.

160 D. Hanft, M. Bektas and R. Moos, Materials, 2018, 11, 1342.

161 L. Xu, B. Dong, Y. Wang, X. Bai, Q. Liu and H. Song, Sens. Actuators, B, 2010, 147, 531-538.

162 T. M. Perfecto, C. A. Zito and D. P. Volanti, CrystEngComm, 2017, 19, 2733-2738.

163 X. W. Huang, X. B. Zou, J. Y. Shi, J. W. Zhao, Y. Li, L. Hao and J. Zhang, Anal. Chim. Acta, 2013, 787, 233-238.

164 H. Liu, W. Shen, X. Chen and J.-P. Corriou, J. Mater. Sci.: Mater. Electron., 2018, 29, 18380-18387.

165 L. Y. Hong and H. N. Lin, Beilstein J. Nanotechnol., 2016, 7, 1044-1051.

166 Z. P. Tshabalala, K. Shingange, B. P. Dhonge, O. M. Ntwaeaborwa, G. H. Mhlongo and D. E. Motaung, Sens. Actuators, B, 2017, 238, 402-419.

167 P. M. Perillo and D. F. Rodríguez, Sens. Actuators, B, 2014, 193, 263-266.

168 B. C. Yadav, S. Singh and A. Yadav, Appl. Surf. Sci., 2011, 257, 1960-1966.

169 X. Song, Q. Xu, T. Zhang, B. Song, C. Li and B. Cao, Sens. Actuators, B, 2018, 268, 170-181.

170 Y. X. Li, Z. X. Song, F. Jiang, Q. Sun, F. Ma, H. R. Wang and K. Chen, Ceram. Int., 2016, 42, 18318-18323.

171 J. Liang, W. Li, J. Liu and M. Hu, J. Alloys Compd., 2016, 687, 845-854.

172 C. A. Zito, T. M. Perfecto and D. P. Volanti, New J. Chem., 2018, 42, 15954-15961.

173 T.-R. Rashid, D.-T. Phan and G.-S. Chung, Sens. Actuators, $B, 2013,185,777-784$.

174 P. Dhivya, A. K. Prasad and M. Sridharan, Ceram. Int., 2014, 40, 409-415.

175 S. A. Hakim, Y. Liu, G. S. Zakharova and W. Chen, RSC Adv., 2015, 5, 23489-23497.

176 S. Lin, D. Li, J. Wu, X. Li and S. A. Akbar, Sens. Actuators, B, 2011, 156, 505-509.

177 B. Zhang, M. Li, Z. Song, H. Kan, H. Yu, Q. Liu, G. Zhang and H. Liu, Sens. Actuators, B, 2017, 249, 558-563.

178 W. Ponhan, S. Phadungdhitidhada and S. Choopun, Mater. Today, 2017, 4, 6342-6348.

179 M. Thepnurat, T. Chairuangsri, N. Hongsith, P. Ruankham and S. Choopun, ACS Appl. Mater. Interfaces, 2015, 7, 24177-24184.

180 P. Shankar and J. B. B. Rayappan, J. Mater. Chem. C, 2017, 5, 10869-10880.

181 N. Van Quy, V. A. Minh, N. Van Luan, V. N. Hung and N. Van Hieu, Sens. Actuators, B, 2011, 153, 188-193.

182 G. K. Mani and J. B. B. Rayappan, Sens. Actuators, B, 2013, 183, 459-466.

183 X. Pan, X. Zhao, J. Chen, A. Bermak and Z. Fan, Sens. Actuators, B, 2015, 206, 764-771. 
184 V. P. Verma, S. Das, S. Hwang, H. Choi, M. Jeon and W. Choi, Mater. Sci. Eng., B, 2010, 171, 45-49.

185 X. Pan and X. Zhao, Sensors, 2015, 15, 8919-8930.

186 O. Lupan, G. Chai and L. Chow, Microelectron. J., 2007, 38, 1211-1216.

187 O. Lupan, G. Chai and L. Chow, Microelectron. Eng., 2008, 85, 2220-2225.

188 B.-R. Huang and J.-C. Lin, Appl. Surf. Sci., 2013, 280, 945-949.

189 K. Vijayalakshmi and D. Gopalakrishna, J. Mater. Sci.: Mater. Electron., 2014, 25, 2253-2260.

190 Y. T. Lim, J. Y. Son and J. S. Rhee, Ceram. Int., 2013, 39, 887-890.

191 J. J. Hassan, M. A. Mahdi, C. W. Chin, H. Abu-Hassan and Z. Hassan, Sens. Actuators, B, 2013, 176, 360-367.

192 S. Yang, Z. Wang, Y. Hu, X. Luo, J. Lei, D. Zhou, L. Fei, Y. Wang and H. Gu, ACS Appl. Mater. Interfaces, 2015, 7, 9247-9253.

193 I. H. Kadhim and H. Abu Hassan, J. Electron. Mater., 2016, 46, 1419-1426.

194 M. Belaqziz, M. b. Amjoud, A. Gaddari, B. Rhouta and D. Mezzane, Superlattice Microstruct., 2014, 71, 185-189.

195 A. Kaur Bal, A. Singh and R. K. Bedi, Phys. B, 2010, 405, 3124-3128.

196 X. Mu, C. Chen, L. Han, B. Shao, Y. Wei, Q. Liu and P. Zhu, J. Alloys Compd., 2015, 637, 55-61.

197 L. Yanxiao, Z. Xiao-bo, H. Xiao-wei, S. Ji-yong, Z. Jie-wen, M. Holmes and L. Hao, Biosens. Bioelectron., 2015, 67, 35-41.

198 J. Wang, Z. Li, S. Zhang, S. Yan, B. Cao, Z. Wang and Y. Fu, Sens. Actuators, B, 2018, 255, 862-870.

199 Z. Li, S. Yan, S. Zhang, J. Wang, W. Shen, Z. Wang and Y. Q. Fu, J. Alloys Compd., 2019, 770, 721-731.

200 C. Zhang, X. Geng, H. Liao, C.-J. Li and M. Debliquy, Sens. Actuators, B, 2017, 242, 102-111.

201 R. Chen, J. Wang and L. Xiang, Sens. Actuators, B, 2018, 270, 207-215.

202 Y. Wu, M. Hu and Y. Tian, Chin. Phys. B, 2017, 26, 020701.

203 V. Annapureddy, Y. Kim, G.-T. Hwang, H. W. Jang, S.-D. Kim, J.-J. Choi, B. Cho and J. Ryu, Adv. Mater. Interfaces, 2018, 5, 1700811.

204 L. Han, C. Chen, Y. Wei, B. Shao, X. Mu, Q. Liu and P. Zhu, J. Alloys Compd., 2016, 656, 326-331.

205 M. Hu, D.-L. Jia, Q.-L. Liu, M.-D. Li and P. Sun, Chin. Phys. B, 2013, 22, 068204.

206 W. Liu, L. Xu, K. Sheng, C. Chen, X. Zhou, B. Dong, X. Bai, S. Zhang, G. Lu and H. Song, J. Mater. Chem. A, 2018, 6, 10976-10989.

207 S. S. Kim, H. G. Na, Y. J. Kwon, H. Y. Cho and H. W. Kim, Met. Mater. Int., 2015, 21, 415-421.

208 X. Gou, R. Li, G. Wang, Z. Chen and D. Wexler, Nanotechnology, 2009, 20, 495501.

209 S. Bai, Y. Ma, X. Shu, J. Sun, Y. Feng, R. Luo, D. Li and A. Chen, Ind. Eng. Chem. Res., 2017, 56, 2616-2623.

210 A. Wei, Z. Wang, L.-H. Pan, W.-W. Li, L. Xiong, X.-C. Dong and W. Huang, Chin. Phys. Lett., 2011, 28, 080702.
211 H. Abdollahi, M. Samkan and M. M. Hashemi, Microsyst. Technol., 2018, 24, 3741-3749.

212 R. S. Ganesh, G. K. Mani, R. Elayaraja, E. Durgadevi, M. Navaneethan, S. Ponnusamy, K. Tsuchiya, C. Muthamizhchelvan and Y. Hayakawa, Appl. Surf. Sci., 2018, 449, 314-321.

213 A. El Bouari, A. Gaddari, M. Amjoud, F. Berger, J. B. Sanchez, M. Lahcini, B. Rhouta, D. Mezzane, C. Mavon, R. El Ouatib, H. Hannache, S. Krimi, M. Lamire, I. Mansouri, R. Moussa and A. Aboulayt, MATEC Web of Conferences, 2013, 5, 04010.

214 Y. Xiong, W. Xu, D. Ding, W. Lu, L. Zhu, Z. Zhu, Y. Wang and Q. Xue, J. Hazard. Mater., 2018, 341, 159-167.

215 S. Yang, Y. Liu, W. Jin, Y. Qi, G. S. Zakharova and W. Chen, Ferroelectrics, 2015, 477, 112-120.

216 Y. Xiong, Z. Zhu, T. Guo, H. Li and Q. Xue, J. Hazard. Mater., 2018, 353, 290-299.

217 E. Zampetti, A. Macagnano and A. Bearzotti, J. Nanopart. Res., 2013, 15, 1566.

218 C. Shao, Y. Chang and Y. Long, Sens. Actuators, B, 2014, 204, 666-672.

219 M. Chitra, K. Uthayarani, N. Rajasekaran, N. Neelakandeswari, E. K. Girija and D. P. Padiyan, Chin. Phys. Lett., 2015, 32, 078101.

220 E. Wongrat, W. Ponhan and S. Choopun, Ceram. Int., 2017, 43, S520-S524.

221 L. Hou, C.-M. Zhang, P. Ma, L. Li, K.-K. Zhu, X.-F. Kang and W. Chen, Chin. J. Anal. Chem., 2018, 46, E1854-E1862.

222 A. P. Sharma, P. Dhakal, D. K. Pradhan, M. K. Behera, B. Xiao and M. Bahoura, AIP Adv., 2018, 8, 095219.

223 B. Sakthivel, L. Manjakkal and G. Nammalvar, IEEE Sens. J., 2017, 17, 6529-6536.

224 N. S. Ramgir, S. K. Ganapathi, M. Kaur, N. Datta, K. P. Muthe, D. K. Aswal, S. K. Gupta and J. V. Yakhmi, Sens. Actuators, B, 2010, 151, 90-96.

225 Z. Li, J. Wang, N. Wang, S. Yan, W. Liu, Y. Q. Fu and Z. Wang, J. Alloys Compd., 2017, 725, 1136-1143.

226 J. Zhang, D. Zeng, Q. Zhu, J. Wu, K. Xu, T. Liao, G. Zhang and C. Xie, J. Phys. Chem. C, 2015, 119, 17930-17939.

227 J. Zhou, M. Ikram, A. U. Rehman, J. Wang, Y. Zhao, K. Kan, W. Zhang, F. Raziq, L. Li and K. Shi, Sens. Actuators, B, 2018, 255, 1819-1830.

228 I. Singh and R. K. Bedi, Solid State Sci., 2011, 13, 2011-2018. 229 S. Li, M. Wang, C. Li, J. Liu, M. Xu, J. Liu and J. Zhang, Sci. China Mater., 2018, 61, 1085-1094.

230 D. N. Oosthuizen, D. E. Motaung and H. C. Swart, Sens. Actuators, B, 2018, 266, 761-772.

231 Z. Wang, F. Li, H. Wang, A. Wang and S. Wu, J. Mater. Sci.: Mater. Electron., 2018, 29, 16654-16659.

232 S. Wang, D. Huang, S. Xu, W. Jiang, T. Wang, J. Hu, N. Hu, Y. Su, Y. Zhang and Z. Yang, Phys. Chem. Chem. Phys., 2017, 19, 19043-19049.

233 J. Wang, L. Wei, L. Zhang, J. Zhang, H. Wei, C. Jiang and Y. Zhang, J. Mater. Chem., 2012, 22, 20038-20047.

234 B. Geng, F. Zhan, C. Fang and N. Yu, J. Mater. Chem., 2008, 18, 4977-4984. 
235 X. Zhang, J. Wang, L. Xuan, Z. Zhu, Q. Pan, K. Shi and G. Zhang, J. Alloys Compd., 2018, 768, 190-197.

236 S. Li, F.-L. Li, S.-M. Zhou, P. Wang, K. Cheng and Z.-L. Du, Chin. Phys. B, 2009, 18, 3985-3989.

237 H. Liu, X. Du, X. Xing, G. Wang and S. Z. Qiao, Chem. Commun., 2012, 48, 865-867.

238 W. Zhang, C. Zeng, M. Kong, Y. Pan and Z. Yang, Sens. Actuators, B, 2012, 162, 292-299.

239 R. Kumar, R. Kumar, N. Kushwaha and J. Mittal, IEEE Sens. J., 2016, 16, 4691-4695.

240 S. Balamurugan, A. Rajalakshmi and D. Balamurugan, J. Alloys Compd., 2015, 650, 863-870.

241 Y. Wang, B. Liu, D. Cai, H. Li, Y. Liu, D. Wang, L. Wang, Q. Li and T. Wang, Sens. Actuators, B, 2014, 201, 351-359.

242 N. S. Ramgir, P. K. Sharma, N. Datta, M. Kaur, A. K. Debnath, D. K. Aswal and S. K. Gupta, Sens. Actuators, B, 2013, 186, 718-726.

243 Q. A. Drmosh, Z. H. Yamani, A. K. Mohamedkhair, A. H. Y. Hendi, M. K. Hossain and A. Ibrahim, Mater. Lett., 2018, 214, 283-286.

244 H. Fu, C. Hou, F. Gu, D. Han and Z. Wang, Sens. Actuators, $B, 2017,243,516-524$.

245 D. Naberezhnyi, M. Rumyantseva, D. Filatova, M. Batuk, J. Hadermann, A. Baranchikov, N. Khmelevsky, A. Aksenenko, E. Konstantinova and A. Gaskov, Nanomaterials, 2018, 8, 801.

246 A. N. A. Anasthasiya, R. K. Kampara, P. K. Rai and B. G. Jeyaprakash, Appl. Surf. Sci., 2018, 449, 244-249.

247 Z. Zhu, C.-T. Kao and R.-J. Wu, Appl. Surf. Sci., 2014, 320, 348-355.

248 S. Yan, Z. Li, H. Li, Z. Wu, J. Wang, W. Shen and Y. Q. Fu, J. Mater. Sci., 2018, 53, 16331-16344.

249 S. C. Wang and M. O. Shaikh, Sensors, 2015, 15, 14286-14297.

250 Q. A. Drmosh, Z. H. Yamani, A. K. Mohamedkhair, A. H. Y. Hendi and A. Ibrahim, Vacuum, 2018, 156, 68-77.

251 L. Chandra, P. K. Sahu, R. Dwivedi and V. N. Mishra, Mater. Res. Express, 2017, 4, 125017.

252 O. Lupan, V. Postica, F. Labat, I. Ciofini, T. Pauporté and R. Adelung, Sens. Actuators, B, 2018, 254, 1259-1270.

253 J. M. Lee, J.-e. Park, S. Kim, S. Kim, E. Lee, S.-J. Kim and W. Lee, Int. J. Hydrogen Energy, 2010, 35, 12568-12573.

254 K. Vijayalakshmi, A. Renitta and A. Monamary, J. Mater. Sci.: Mater. Electron., 2018, 29, 21023-21032.

255 X. Wei, X. Yang, T. Wu, S. Wu, W. Li, X. Wang and Z. Chen, Int. J. Hydrogen Energy, 2017, 42, 24580-24586.

256 W. Lu, D. Ding, Q. Xue, Y. Du, Y. Xiong, J. Zhang, X. Pan and W. Xing, Sens. Actuators, B, 2018, 254, 393-401.

257 Z. S. Hosseini, A. Mortezaali, A. Iraji zad and S. Fardindoost, J. Alloys Compd., 2015, 628, 222-229.

258 F.-C. Chung, Z. Zhu, P.-Y. Luo, R.-J. Wu and W. Li, Sens. Actuators, B, 2014, 199, 314-319.

259 Z. Zhu, J.-L. Chang and R.-J. Wu, Sens. Actuators, B, 2015, 214, 56-62.

260 H. Wu, H. Huang, J. Zhou, D. Hong, M. Ikram, A. U. Rehman, L. Li and K. Shi, Sci. Rep., 2017, 7, 14688.

261 J. Liang, J. Liu, W. Li and M. Hu, Mater. Res. Bull., 2016, 84, 332-339.
262 J. Liang, W. Li, J. Liu and M. Hu, Mater. Lett., 2016, 184, 92-95.

263 S. Park, H. Kim, C. Jin and C. Lee, J. Korean Phys. Soc., 2012, 60, 1560-1564.

264 T.-R. Rashid, D.-T. Phan and G.-S. Chung, Sens. Actuators, B, 2014, 193, 869-876.

265 S. Ren, G. Fan, S. Qu and Q. Wang, J. Appl. Phys., 2011, 110, 084312.

266 Z. Wang, Z. Li, T. Jiang, X. Xu and C. Wang, ACS Appl. Mater. Interfaces, 2013, 5, 2013-2021.

267 W. P. Chen, Y. Xiong, Y. S. Li, P. Cui, S. S. Guo, W. Chen, Z. L. Tang, Z. Yan and Z. Zhang, Int. J. Hydrogen Energy, 2016, 41, 3307-3312.

268 B. Liu, D. Cai, Y. Liu, D. Wang, L. Wang, Y. Wang, H. Li, Q. Li and T. Wang, Sens. Actuators, B, 2014, 193, 28-34.

269 P. Li, Z. Xiong, S. Zhu, M. Wang, Y. Hu, H. Gu, Y. Wang and W. Chen, Int. J. Hydrogen Energy, 2017, 42, 30186-30192.

270 B. Huang, Y. Wang, Q. Hu, X. Mu, Y. Zhang, J. Bai, Q. Wang, Y. Sheng, Z. Zhang and E. Xie, J. Mater. Chem. C, 2018, 6, 10935-10943.

271 M. Chitra, K. Uthayarani, N. Rajasekaran, N. Neelakandeswari, E. K. Girija and D. P. Padiyan, Surf. Rev. Lett., 2016, 23, 1550094.

272 L. Yang, L. Li, Y. Yang, G. Zhang, L. Gong, L. Jing, H. Fu and K. Shi, Mater. Res. Bull., 2013, 48, 3657-3665.

273 S. Jain, A. Patrike, S. S. Badadhe, M. Bhardwaj and S. Ogale, ACS Omega, 2018, 3, 1977-1982.

274 N. Singh, C. Yan and P. S. Lee, Sens. Actuators, B, 2010, 150, 19-24.

275 H. Ahn, Y. Wang, S. Hyun Jee, M. Park, Y. S. Yoon and D.-J. Kim, Chem. Phys. Lett., 2011, 511, 331-335.

276 M. R. Modaberi, R. Rooydell, S. Brahma, A. A. Akande, B. W. Mwakikunga and C.-P. Liu, Sens. Actuators, B, 2018, 273, 1278-1290.

277 C. Stella, D. Prabhakar, M. Prabhu, N. Soundararajan and K. Ramachandran, J. Mater. Sci.: Mater. Electron., 2015, 27, 1636-1644.

278 Z. Li, A. A. Haidry, T. Wang and Z. J. Yao, Appl. Phys. Lett., 2017, 111, 032104.

279 A. Renitta and K. Vijayalakshmi, Catal. Commun., 2016, 73, 58-62.

280 K. Karthick, D. Srinivasan and J. B. Christopher, J. Mater. Sci.: Mater. Electron., 2017, 28, 11979-11986.

281 J. Ma, Y. Liu, H. Zhang, P. Ai, N. Gong, Y. Wu and D. Yu, Sens. Actuators, B, 2015, 216, 72-79.

282 X. Zou, H. Fan, Y. Tian, M. Zhang and X. Yan, Dalton Trans., 2015, 44, 7811-7821.

283 A. J. Kulandaisamy, J. R. Reddy, P. Srinivasan, K. J. Babu, G. K. Mani, P. Shankar and J. B. B. Rayappan, J. Alloys Compd., 2016, 688, 422-429.

284 K. Khun Khun, A. Mahajan and R. K. Bedi, Chem. Phys. Lett., 2010, 492, 119-122.

285 J. M. Wu, Nanotechnology, 2010, 21, 235501.

286 T. Pauporte, O. Lupan, V. Postica, M. Hoppe, L. Chow and R. Adelung, Phys. Status Solidi A, 2018, 215, 1700824.

287 R. Jaisutti, M. Lee, J. Kim, S. Choi, T. J. Ha, J. Kim, H. Kim, S. K. Park and Y. H. Kim, ACS Appl. Mater. Interfaces, 2017, 9, 8796-8804. 
288 K. Vijayalakshmi and K. Karthick, Int. J. Hydrogen Energy, 2014, 39, 7165-7172.

289 H. Liu, D. Ding, C. Ning and Z. Li, Nanotechnology, 2012, 23, 015502.

290 M. Kaur, S. Bhattacharya, M. Roy, S. K. Deshpande, P. Sharma, S. K. Gupta and J. V. Yakhmi, Appl. Phys. A: Mater. Sci. Process., 2007, 87, 91-96.

291 A. Chaparadza and S. B. Rananavare, Nanotechnology, 2008, 19, 245501.

292 H. Tang, M. Yan, H. Zhang, S. Li, X. Ma, M. Wang and D. Yang, Sens. Actuators, B, 2006, 114, 910-915.

293 P. M. Calaque, C. J. Vergara, L. I. Ballesteros and A. Somintac, AIP Conf. Proc., 2017, 1808, 020013.

294 T.-t. Li, R.-r. Zheng, H. Yu, L. Xia, Y. Yang and X.-t. Dong, Solid State Ionics, 2018, 325, 17-23.

295 M. Bao, Y. Chen, F. Li, J. Ma, T. Lv, Y. Tang, L. Chen, Z. Xu and T. Wang, Nanoscale, 2014, 6, 4063-4066.

296 G. Cui, P. Zhang, L. Chen, X. Wang, J. Li, C. Shi and D. Wang, Sci. Rep., 2017, 7, 43887.

297 C. Jiang, S. Xu, G. Zhang, L. Li, Y. Yang and K. Shi, CrystEngComm, 2013, 15, 2482.

298 D. R. Patil, L. A. Patil and P. P. Patil, Sens. Actuators, B, 2007, 126, 368-374.

299 S. Bhuvaneshwari, S. Papachan and N. Gopalakrishnan, AIP Conf. Proc., 2017, 1832, 050126.

300 J. Zhang, D. Zeng, Q. Zhu, J. Wu, Q. Huang, W. Zhang and C. Xie, Phys. Chem. Chem. Phys., 2016, 18, 5386-5396.

301 H. Wu, K. Kan, L. Wang, G. Zhang, Y. Yang, H. Li, L. Jing, P. Shen, L. Li and K. Shi, CrystEngComm, 2014, 16, 9116-9124.

302 R. Lu, W. Zhou, K. Shi, Y. Yang, L. Wang, K. Pan, C. Tian, Z. Ren and H. Fu, Nanoscale, 2013, 5, 8569-8576.

303 X. Yue, T. Hong, Z. Yang and S. Huang, Chin. Sci. Bull., 2012, 58, 821-826.

304 X. Liu, B. Du, Y. Sun, M. Yu, Y. Yin, W. Tang, C. Chen, L. Sun, B. Yang, W. Cao and M. N. Ashfold, ACS Appl. Mater. Interfaces, 2016, 8, 16379-16385.

305 W. Zang, Y. Nie, D. Zhu, P. Deng, L. Xing and X. Xue, J. Phys. Chem. C, 2014, 118, 9209-9216.

306 L. A. Patil and D. R. Patil, Sens. Actuators, B, 2006, 120, 316-323.

307 A. Mirzaei, G.-J. Sun, J. K. Lee, C. Lee, S. Choi and H. W. Kim, Ceram. Int., 2017, 43, 5247-5254.

308 S. Park, H. Kheel, G.-J. Sun, H. W. Kim, T. Ko and C. Lee, Met. Mater. Int., 2016, 22, 730-736.

309 M.-R. Yu, G. Suyambrakasam, R.-J. Wu and M. Chavali, Mater. Res. Bull., 2012, 47, 1713-1718.

310 J. Liang, R. Yang, K. Zhu and M. Hu, J. Mater. Sci.: Mater. Electron., 2017, 29, 3780-3789.

311 L. F. da Silva, J. C. M'Peko, A. C. Catto, S. Bernardini, V. R. Mastelaro, K. Aguir, C. Ribeiro and E. Longo, Sens. Actuators, B, 2017, 240, 573-579.

312 D. R. Patil and L. A. Patil, Sens. Actuators, B, 2007, 123, 546-553.

313 D. Zhu, Y. Fu, W. Zang, Y. Zhao, L. Xing and X. Xue, Mater. Lett., 2016, 166, 288-291.

314 G. Lu, L. E. Ocola and J. Chen, Nanotechnology, 2009, 20, 445502 .
315 Y. Wang and S. Gong, J. Mater. Sci.: Mater. Electron., 2015, 26, 5024-5029.

316 W. Yang, P. Wan, X. Zhou, J. Hu, Y. Guan and L. Feng, ACS Appl. Mater. Interfaces, 2014, 6, 21093-21100.

317 S. Liu, B. Yu, H. Zhang, T. Fei and T. Zhang, Sens. Actuators, $B, 2014,202,272-278$.

318 H. Tai, Z. Yuan, W. Zheng, Z. Ye, C. Liu and X. Du, Nanoscale Res. Lett., 2016, 11, 130.

319 Y. Yang, L. Sun, X. Dong, H. Yu, T. Wang, J. Wang, R. Wang, W. Yu and G. Liu, RSC Adv., 2016, 6, 37085-37092.

320 R. Ghosh, A. K. Nayak, S. Santra, D. Pradhan and P. K. Guha, RSC Adv., 2015, 5, 50165-50173.

321 S. Liu, Z. Wang, Y. Zhang, J. Li and T. Zhang, Sens. Actuators, B, 2016, 228, 134-143.

322 Z. Wang, Y. Zhang, S. Liu and T. Zhang, Sens. Actuators, B, 2016, 222, 893-903.

323 Z. Wang, T. Zhang, C. Zhao, T. Han, T. Fei, S. Liu and G. Lu, J. Colloid Interface Sci., 2018, 514, 599-608.

324 M. Shojaee, S. Nasresfahani and M. H. Sheikhi, Sens. Actuators, B, 2018, 254, 457-467.

325 T. Wang, J. Hao, S. Zheng, Q. Sun, D. Zhang and Y. Wang, Nano Res., 2017, 11, 791-803.

326 J. Zhang, J. Wu, X. Wang, D. Zeng and C. Xie, Sens. Actuators, B, 2017, 243, 1010-1019.

327 P.-G. Su, F.-Y. Chen and C.-H. Wei, Sens. Actuators, B, 2018, 254, 1125-1132.

328 J. Zhang, D. Zeng, S. Zhao, J. Wu, K. Xu, Q. Zhu, G. Zhang and C. Xie, Phys. Chem. Chem. Phys., 2015, 17, 14903-14911.

329 Z. Wang, Y. Zhang, S. Liu and T. Zhang, Sens. Actuators, B, 2016, 222, 893-903.

330 Z. Wang, T. Zhang, T. Han, T. Fei, S. Liu and G. Lu, Sens. Actuators, B, 2018, 266, 812-822.

331 J. Pan, W. Li, L. Quan, N. Han, S. Bai, R. Luo, Y. Feng, D. Li and A. Chen, Ind. Eng. Chem. Res., 2018, 57, 10086-10094.

332 X. Liu, J. Sun and X. Zhang, Sens. Actuators, B, 2015, 211, 220-226.

333 N. Chen, X. Li, X. Wang, J. Yu, J. Wang, Z. Tang and S. A. Akbar, Sens. Actuators, B, 2013, 188, 902-908.

334 F. Gu, R. Nie, D. Han and Z. Wang, Sens. Actuators, B, 2015, 219, 94-99.

335 Z. Li, Y. Liu, D. Guo, J. Guo and Y. Su, Sens. Actuators, B, 2018, 271, 306-310.

336 S. Liu, Z. Wang, Y. Zhang, J. Li and T. Zhang, Sens. Actuators, B, 2016, 228, 134-143.

337 X. Jiang, H. Tai, Z. Ye, Z. Yuan, C. Liu, Y. Su and Y. Jiang, Mater. Lett., 2017, 186, 49-52.

338 D. Zhang, J. Liu and B. Xia, J. Electron. Mater., 2016, 45, 4324-4330.

339 X. Liu, J. Li, J. Sun and X. Zhang, RSC Adv., 2015, 5, 73699-73704.

340 Y. Xia, J. Wang, J. L. Xu, X. Li, D. Xie, L. Xiang and S. Komarneni, ACS Appl. Mater. Interfaces, 2016, 8, 35454-35463.

341 T. Wang, J. Hao, S. Zheng, Q. Sun, D. Zhang and Y. Wang, Nano Res., 2018, 11, 791-803.

342 Y.-l. Dong, X.-f. Zhang, X.-l. Cheng, Y.-m. Xu, S. Gao, H. Zhao and L.-h. Huo, RSC Adv., 2014, 4, 57493-57500. 
343 W. Fang, Y. Yang, H. Yu, X. Dong, R. Wang, T. Wang, J. Wang, Z. Liu, B. Zhao and X. Wang, New J. Chem., 2017, 41, 7517-7523.

344 Y. Yang, C. Tian, L. Sun, R. Lü, W. Zhou, K. Shi, K. Kan, J. Wang and H. Fu, J. Mater. Chem. A, 2013, 1, 12742.

345 Y. Yang, C. Tian, J. Wang, L. Sun, K. Shi, W. Zhou and H. Fu, Nanoscale, 2014, 6, 7369-7378.

346 G. P. Evans, M. J. Powell, I. D. Johnson, D. P. Howard, D. Bauer, J. A. Darr and I. P. Parkin, Sens. Actuators, B, 2018, 255, 1119-1129.

347 Y. Chen, W. Zhang and Q. Wu, Sens. Actuators, B, 2017, 242, 1216-1226.

348 H. Meng, W. Yang, K. Ding, L. Feng and Y. Guan, J. Mater. Chem. A, 2015, 3, 1174-1181.

349 X. Li, Y. Zhao, X. Wang, J. Wang, A. M. Gaskov and S. A. Akbar, Sens. Actuators, B, 2016, 230, 330-336.

350 P.-G. Su and L.-Y. Yang, Sens. Actuators, B, 2016, 223, 202-208.

351 P.-G. Su, F.-Y. Chen and C.-H. Wei, Sens. Actuators, B, 2018, 254, 1125-1132.

352 G. Singh, A. Choudhary, D. Haranath, A. G. Joshi, N. Singh, S. Singh and R. Pasricha, Carbon, 2012, 50, 385-394.

353 R. Kumar, N. Kushwaha and J. Mittal, Sens. Actuators, B, 2017, 244, 243-251.

354 F. Schutt, V. Postica, R. Adelung and O. Lupan, ACS Appl. Mater. Interfaces, 2017, 9, 23107-23118.

355 A. Yang, X. Tao, R. Wang, S. Lee and C. Surya, Appl. Phys. Lett., 2007, 91, 133110.

356 D. Zhang, C. Jiang, J. Liu and Y. Cao, Sens. Actuators, B, 2017, 247, 875-882.

357 M. Shojaee, S. Nasresfahani and M. H. Sheikhi, Sens. Actuators, B, 2018, 254, 457-467.

358 N. Du, H. Zhang, X. Ma and D. Yang, Chem. Commun., 2008, 6182-6184.

359 S. Dhall and N. Jaggi, Sens. Actuators, B, 2015, 210, 742-747.

360 D. Zhang, N. Yin, C. Jiang and B. Xia, J. Mater. Sci.: Mater. Electron., 2016, 28, 2763-2768.

361 D. Kathiravan, B. R. Huang and A. Saravanan, ACS Appl. Mater. Interfaces, 2017, 9, 12064-12072.

362 Y. Peng, L. Zheng, K. Zou and C. Li, Nanotechnology, 2017, 28, 215501.

363 Z. Ye, H. Tai, T. Xie, Z. Yuan, C. Liu and Y. Jiang, Sens. Actuators, B, 2016, 223, 149-156.

364 Z. Bo, M. Yuan, S. Mao, X. Chen, J. Yan and K. Cen, Sens. Actuators, B, 2018, 256, 1011-1020.

365 S. Ghosal and P. Bhattacharyya, Microelectron. Reliab., 2017, 78, 299-306.

366 D. Acharyya and P. Bhattacharyya, IEEE Electron Device Lett., 2016, 37, 656-659.

367 S. Nasresfahani, M. H. Sheikhi, M. Tohidi and A. Zarifkar, IEEE Iranian Conference on Electrical Engineering, 2016, 1014-1018.

368 D. Zhang, A. Liu, H. Chang and B. Xia, RSC Adv., 2015, 5, 3016-3022.

369 D. Zhang, Y. e. Sun and Y. Zhang, J. Mater. Sci.: Mater. Electron., 2015, 26, 7445-7451.
370 S. G. Chatterjee, S. Dey, D. Samanta, S. Santra, S. Chatterjee, P. K. Guha and A. K. Chakraborty, J. Mater. Sci.: Mater. Electron., 2018, 29, 20162-20171.

371 J. Hu, C. Zou, Y. Su, M. Li, X. Ye, B. Cai, E. S.-W. Kong, Z. Yang and Y. Zhang, Sens. Actuators, B, 2018, 270, 119-129.

372 D. Ding, Q. Xue, W. Lu, Y. Xiong, J. Zhang, X. Pan and B. Tao, Sens. Actuators, B, 2018, 259, 289-298.

373 B.-Y. Wei, M.-C. Hsu, P.-G. Su, H.-M. Lin, R.-J. Wu and H.-J. Lai, Sens. Actuators, B, 2004, 101, 81-89.

374 G. Lu, L. E. Ocola and J. Chen, Adv. Mater., 2009, 21, 2487-2491.

375 R. Leghrib, A. Felten, J. J. Pireaux and E. Llobet, Thin Solid Films, 2011, 520, 966-970.

376 X. Luo, H. Giessen, Y. Zhou, G. Xie, T. Xie, T. Kang and Y. Jiang, Proc. SPIE, 2014, 9285, 928509.

377 A. Sharma, M. Tomar and V. Gupta, J. Mater. Chem., 2012, 22, 23608.

378 M. Asad and M. H. Sheikhi, Sens. Actuators, B, 2016, 231, 474-483.

379 H. Liu, W. Zhang, H. Yu, L. Gao, Z. Song, S. Xu, M. Li, Y. Wang, H. Song and J. Tang, ACS Appl. Mater. Interfaces, 2016, 8, 840-846.

380 K. Anothainart, M. Burgmair, A. Karthigeyan, M. Zimmer and I. Eisele, Sens. Actuators, B, 2003, 93, 580-584.

381 L. Meng, Q. Xu, Z. Sun, G. Li, S. Bai, Z. Wang and Y. Qin, Mater. Lett., 2018, 212, 296-298.

382 P. Wang, Y. Fu, B. Yu, Y. Zhao, L. Xing and X. Xue, J. Mater. Chem. A, 2015, 3, 3529-3535.

383 L. Peng, Q. Zhao, D. Wang, J. Zhai, P. Wang, S. Pang and T. Xie, Sens. Actuators, B, 2009, 136, 80-85.

384 J. Cui, L. Shi, T. Xie, D. Wang and Y. Lin, Sens. Actuators, B, 2016, 227, 220-226.

385 L. Vogel, R. Wagner, R. Moos and D. Schoenauer-Kamin, Funct. Mater. Lett., 2018, 11, 1850087.

386 N. D. Chinh, N. D. Quang, H. Lee, T. Thi Hien, N. M. Hieu, D. Kim, C. Kim and D. Kim, Sci. Rep., 2016, 6, 35066.

387 D. Klaus, D. Klawinski, S. Amrehn, M. Tiemann and T. Wagner, Sens. Actuators, B, 2015, 217, 181-185.

388 X. Li, X. Li, J. Wang and S. Lin, Sens. Actuators, B, 2015, 219, 158-163.

389 T. Xie, N. Sullivan, K. Steffens, B. Wen, G. Liu, R. Debnath, A. Davydov, R. Gomez and A. Motayed, J. Alloys Compd., 2015, 653, 255-259.

390 J. D. Prades, R. Jimenez-Diaz, F. Hernandez-Ramirez, S. Barth, A. Cirera, A. Romano-Rodriguez, S. Mathur and J. R. Morante, Sens. Actuators, B, 2009, 140, 337-341.

391 Y. Xiong, W. Lu, D. Ding, L. Zhu, X. Li, C. Ling and Q. Xue, ACS Sens., 2017, 2, 679-686.

392 H. Chen, Y. Liu, C. Xie, J. Wu, D. Zeng and Y. Liao, Ceram. Int., 2012, 38, 503-509.

393 R. Gao, Z. Ying, W. Sheng and P. Zheng, Mater. Lett., 2018, 229, 210-212.

394 J. Sun, J. Xu, Y. Yu, P. Sun, F. Liu and G. Lu, Sens. Actuators, $B, 2012,169,291-296$.

395 G. Lu, J. Xu, J. Sun, Y. Yu, Y. Zhang and F. Liu, Sens. Actuators, B, 2012, 162, 82-88. 
396 J. Cui, D. Wang, T. Xie and Y. Lin, Sens. Actuators, B, 2013, 186, 165-171.

397 X. Li, N. Chen, S. Lin, J. Wang and J. Zhang, Sens. Actuators, $B, 2015,209,729-734$.

398 X. Geng, C. Zhang, Y. Luo, H. Liao and M. Debliquy, Ceram. Int., 2017, 43, 5990-5998.

399 X. Geng, C. Zhang, Y. Luo and M. Debliquy, Appl. Surf. Sci., 2017, 401, 248-255.

400 T. Wang, Q. Yu, S. Zhang, X. Kou, P. Sun and G. Lu, Nanoscale, 2018, 10, 4841-4851.

401 K. Zhang, M. Peng, W. Wu, J. Guo, G. Gao, Y. Liu, J. Kou, R. Wen, Y. Lei, A. Yu, Y. Zhang, J. Zhai and Z. L. Wang, Mater. Horiz., 2017, 4, 274-280.

402 W. L. Ong, C. Zhang and G. W. Ho, Nanoscale, 2011, 3, 4206-4214.

403 R. Li, K. Jiang, S. Chen, Z. Lou, T. Huang, D. Chen and G. Shen, RSC Adv., 2017, 7, 52503-52509.

404 T. M. Perfecto, C. A. Zito, T. Mazon and D. P. Volanti, J. Mater. Chem. C, 2018, 6, 2822-2829.

405 X. Geng, C. Zhang, Y. Luo and M. Debliquy, J. Taiwan Inst. Chem. Eng., 2017, 75, 280-286.

406 C. Hua, Y. Shang, Y. Wang, J. Xu, Y. Zhang, X. Li and A. Cao, Appl. Surf. Sci., 2017, 405, 405-411.

407 S. Knobelspies, B. Bierer, A. Daus, A. Takabayashi, G. A. Salvatore, G. Cantarella, A. Ortiz Perez, J. Wollenstein, S. Palzer and G. Troster, Sensors, 2018, 18, 358.

408 S. J. Choi, H. J. Choi, W. T. Koo, D. Huh, H. Lee and I. D. Kim, ACS Appl. Mater. Interfaces, 2017, 9, 40593-40603.

409 S. M. Mohammad, Z. Hassan, R. A. Talib, N. M. Ahmed, M. A. Al-Azawi, N. M. Abd-Alghafour, C. W. Chin and N. H. Al-Hardan, J. Mater. Sci.: Mater. Electron., 2016, 27, 9461-9469.

410 S. Li, P. Lin, L. Zhao, C. Wang, D. Liu, F. Liu, P. Sun, X. Liang, F. Liu, X. Yan, Y. Gao and G. Lu, Sens. Actuators, B, 2018, 259, 505-513.

411 D. K. Subbiah, G. K. Mani, K. J. Babu, A. Das and J. B. B. Rayappan, J. Clean. Prod., 2018, 194, 372-382.
412 S. Li, Y. Diao, Z. Yang, J. He, J. Wang, C. Liu, F. Liu, H. Lu, X. Yan, P. Sun and G. Lu, Sens. Actuators, B, 2018, 276, 526-533.

413 H.-Y. Li, C.-S. Lee, D. H. Kim and J.-H. Lee, ACS Appl. Mater. Interfaces, 2018, 10, 27858-27867.

414 D. K. Bandgar, S. T. Navale, Y. H. Navale, S. M. Ingole, F. J. Stadler, N. Ramgir, D. K. Aswal, S. K. Gupta, R. S. Mane and V. B. Patil, Mater. Chem. Phys., 2017, 189, 191-197.

415 C. Liu, H. Tai, P. Zhang, Z. Yuan, X. Du, G. Xie and Y. Jiang, Sens. Actuators, B, 2018, 261, 587-597.

416 U. Yaqoob, D.-T. Phan, A. S. M. I. Uddin and G.-S. Chung, Sens. Actuators, B, 2015, 221, 760-768.

417 U. Yaqoob, A. S. M. I. Uddin and G.-S. Chung, Sens. Actuators, B, 2016, 224, 738-746.

418 K. K. Sadasivuni, D. Ponnamma, H.-U. Ko, H. C. Kim, L. Zhai and J. Kim, Sens. Actuators, B, 2016, 233, 633-638.

419 V. Annapureddy, Y. Kim, G.-T. Hwang, H. W. Jang, S.-D. Kim, J.-J. Choi, B. Cho and J. Ryu, Adv. Mater. Interfaces, 2018, 5, 1700811.

420 A. S. M. I. Uddin and G.-S. Chung, J. Electroceram., 2018, 40, 42-49.

421 X. Luo, K. You, Y. Hu, S. Yang, X. Pan, Z. Wang, W. Chen and H. Gu, Int. J. Hydrogen Energy, 2017, 42, 8399-8405.

422 Z. Pang, Z. Yang, Y. Chen, J. Zhang, Q. Wang, F. Huang and Q. Wei, Colloid. Surface. A, 2016, 494, 248-255.

423 A. Bagal, E. C. Dandley, J. Zhao, X. A. Zhang, C. J. Oldham, G. N. Parsons and C.-H. Chang, Mater. Horiz., 2015, 2, 486-494.

424 A. Sanaeifar, H. ZakiDizaji, A. Jafari and M. d. 1. Guardia, Trac-Trend. Anal. Chem., 2017, 97, 257-271.

425 Y. Zhang, J. Zhao, T. Du, Z. Zhu, J. Zhang and Q. Liu, Sci. Rep., 2017, 7, 1960.

426 A. B. Far, F. Flitti, B. Guo and A. Bermak, IEEE Sens. J., 2009, 9, 713-722.

427 F. Flitti, A. Far, B. Guo and A. Bermak, J. Sensors, 2008, 2008, 1-6. 